\title{
Evaluation of indirect tensile strength to identify asphalt concrete rutting potential
}

\author{
Geetha Srinivasan \\ West Virginia University
}

Follow this and additional works at: https://researchrepository.wvu.edu/etd

\section{Recommended Citation}

Srinivasan, Geetha, "Evaluation of indirect tensile strength to identify asphalt concrete rutting potential" (2004). Graduate Theses, Dissertations, and Problem Reports. 1465.

https://researchrepository.wvu.edu/etd/1465

This Thesis is protected by copyright and/or related rights. It has been brought to you by the The Research Repository @ WVU with permission from the rights-holder(s). You are free to use this Thesis in any way that is permitted by the copyright and related rights legislation that applies to your use. For other uses you must obtain permission from the rights-holder(s) directly, unless additional rights are indicated by a Creative Commons license in the record and/ or on the work itself. This Thesis has been accepted for inclusion in WVU Graduate Theses, Dissertations, and Problem Reports collection by an authorized administrator of The Research Repository @ WVU. For more information, please contact researchrepository@mail.wvu.edu. 


\title{
Evaluation of Indirect Tensile Strength to Identify Asphalt Concrete Rutting Potential
}

\author{
By

\section{Geetha Srinivasan} \\ Thesis submitted to the College of Engineering and Mineral Resources \\ at West Virginia University \\ in partial fulfillment of the requirements for the degree of \\ Master of Science \\ in \\ Civil Engineering \\ John P. Zaniewski, Ph.D., Chair \\ Ronald W. Eck, Ph.D. \\ Jim French III, Ph.D.
}

Department of Civil and Environmental Engineering

Morgantown, West Virginia

2004

Key Words

Asphalt mix design, rutting potential, Marshall Stabilometer, indirect tensile strength, compaction slope, voids in mineral aggregates 


\section{ABSTRACT \\ Evaluation of Indirect Tensile Strength to Identify Asphalt Concrete Rutting Potential}

Geetha Srinivasan

The Superpave mix design procedure, as implemented at the end of the Strategic Highway Research Program (SHRP) does not include any testing to evaluate asphalt mixture for resistance to permanent deformation. This prompted the National Cooperative Highway Research Program (NCHRP) to sponsor projects for the development of a simple performance test for rutting potential of asphalt mixtures. Anderson et al [2003] found that rutting potential can be evaluated by considering indirect tensile strength (IDT), compaction slope measured with the Superpave Gyratory compactor and voids in mineral aggregate (VMA). Anderson evaluated IDT strength at a deformation rate of $3.75 \mathrm{~mm} / \mathrm{min}$ and $34^{\text {}} \mathrm{C}$, and used repeated shear constant head, $\mathrm{RSCH}$, tester to estimate the rutting potential of asphalt mixtures. $\mathrm{RSCH}$ is a sophisticated and expensive piece of equipment that is available only at a few research agencies and universities. Likewise, few agencies have the ability to duplicate the IDT strength tests methodology used by Anderson.

The objective of this research was to study if rutting potential can be evaluated with equipment readily available to state highway agencies. Rutting potential was evaluated with the Asphalt Pavement Analyzer (APA). The parameters that were evaluated as independent variables include the IDT strength, volumetric parameters, compaction slope, and the compacted aggregate resistance. IDT was measured using the Marshall Stabilometer with a split tensile head and with the samples at $60^{\circ} \mathrm{C}$. The main factors included in the experiment were binder type, asphalt content, sand content, nominal maximum aggregate size, NMAS, and gradation. The analysis of variance demonstrated significant effects of all the main factors and their interactions on rutting potential. Further there is a strong correlation between rutting potential and indirect tensile strength as measured with the stabilometer. 


\section{ACKNOWLEDGEMENTS}

I would like to express my gratitude to my advisor, Dr. John Zaniewski, who provided a motivating and enthusiastic atmosphere. It was a great pleasure for me to work under his supervision. Thank you for your friendship and encouragement throughout this research endeavor.

I would like to extend my thanks to Dr. Ronald Eck and Dr. Jim French III for their review of my work and willingness to serve on my committee. Mr. Andrew Kincell, Manager of the WVU Asphalt Technology Laboratory provided continuing assistance with training, supplying materials and support throughout the laboratory work. I would also like to acknowledge the contributions of my graduate student colleagues, Thomas Adams and Andrew Corkrean, who greatly assisted with the performance of the tests in support of this research.

This research was supported by the West Virginia Division of Highways. The materials division staff, including Larry Barker, Dave Mattics and Stu Groves provided information and guidance relative to practices of the Division.

The support of the asphalt paving industry in West Virginia also contributed to the success of this research, in particular, the materials supplied by JF Allen, Martin Maretta, and Marathon Ashland Petroleum, LLC.

I would also like to give my special thanks to my husband whose patient love and emotional support enabled me to complete this work. 


\section{TABLE OF CONTENTS}

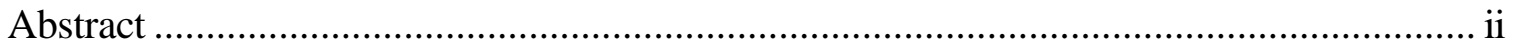

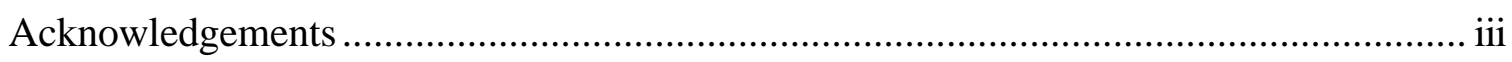

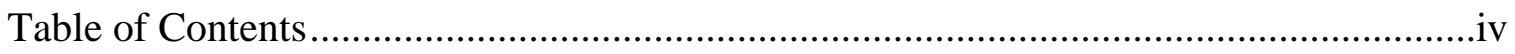

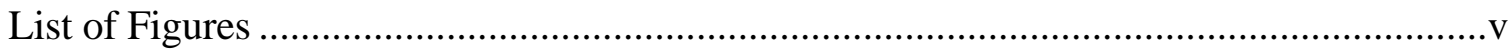

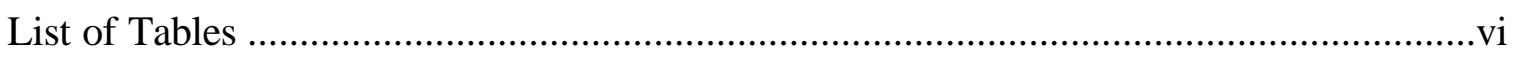

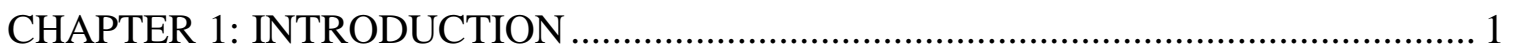

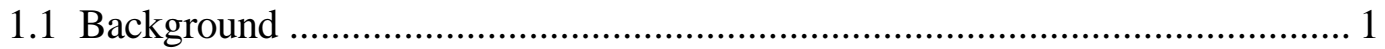

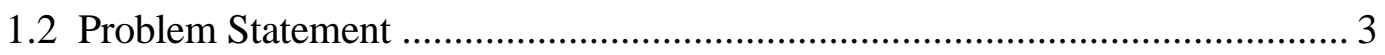

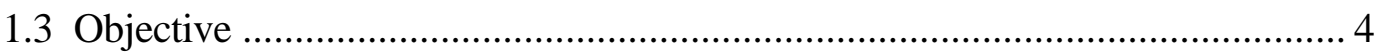

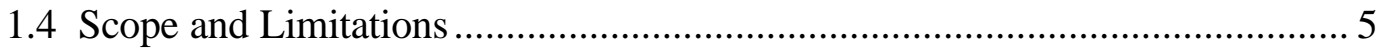

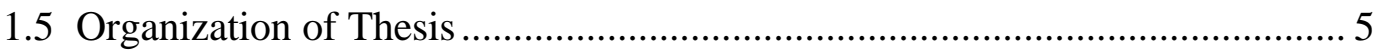

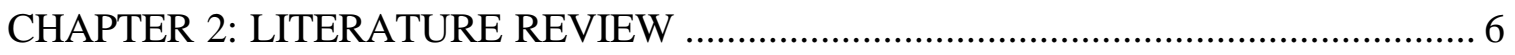

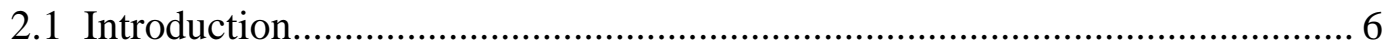

2.2 Principles of Rutting in Asphalt Mixtures ................................................ 6

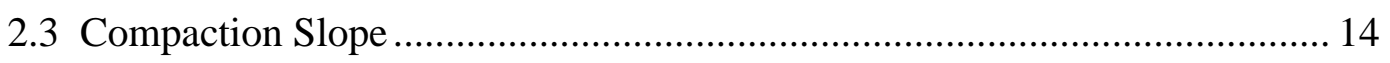

2.4 IDT as an Indicator of Rutting Potential of Asphalt Mixtures...................... 20

2.5 Rutting Potential as Estimated using SGC Properties and IDT Strength ...... 21

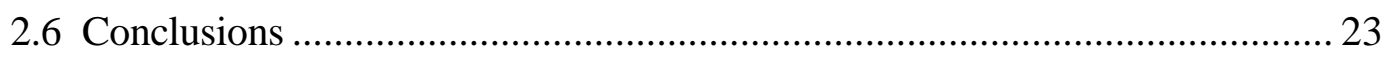

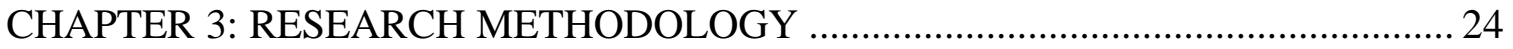

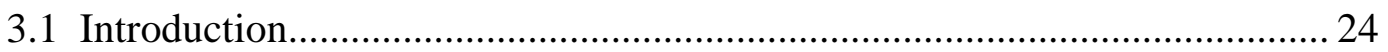

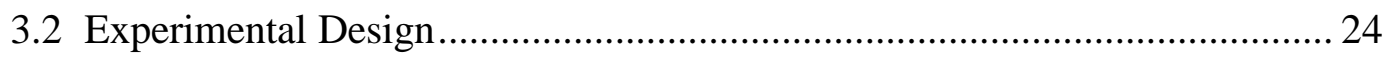

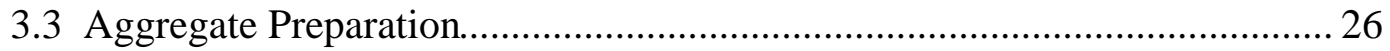

3.3.1 Aggregate Gradation............................................................... 26

3.3.2 Aggregate Specific Gravity....................................................... 28

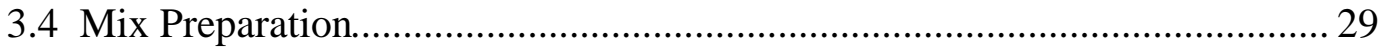

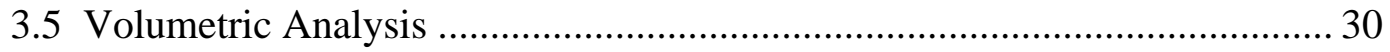

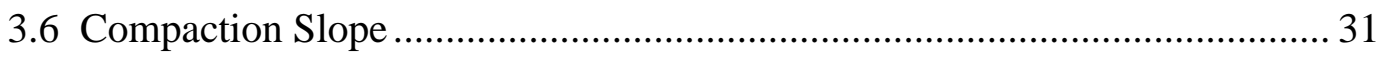

3.7 Evaluation of Rutting Potential Using APA ............................................. 31 


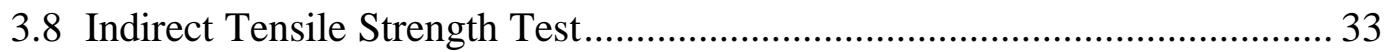

3.9 Compacted Aggregate Resistance Test............................................................ 35

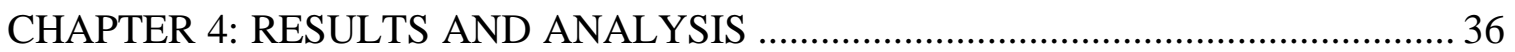

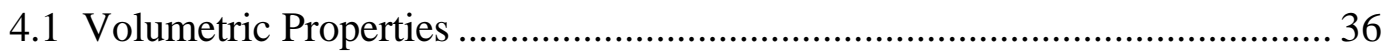

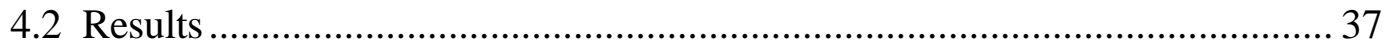

4.2.1 APA Rut Results ......................................................................... 37

4.2.2 IDT Strength Test Results............................................................. 37

4.2.3 Compaction Slope Computations ……………………………….... 37

4.2.4 CAR Test Results................................................................... 38

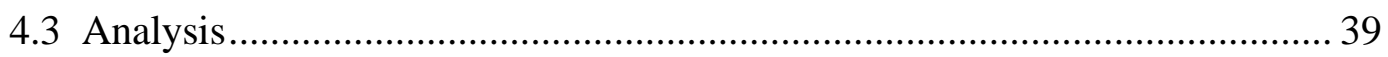

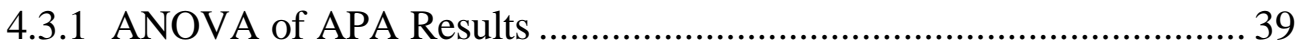

4.3.2 ANOVA of IDT Strength Test Results ............................................. 41

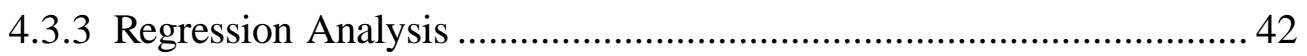

4.4 Evaluation of Covariant Terms ..................................................................... 46

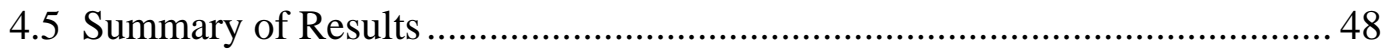

CHAPTER 5:CONCLUSIONS AND RECOMMENDATIONS ....................................... 49

5.1 Conclusions .................................................................................................. 49

5.2 Recommendations for Future Study ...................................................... 50

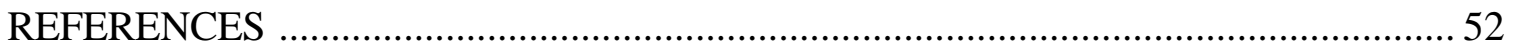

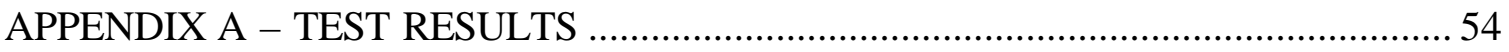

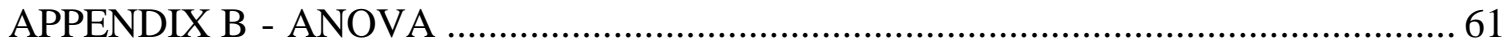

\section{LIST OF FIGURES}

Figure 1.1 Effect of VMA and Compaction Slope on Rut Depth..................................... 3

Figure 2.1 Mohr-Coulomb Failure Theory ………………......................................... 8

Figure 2.2 Maximum Permanent Shear Strain from RSCH Test as a Function of IDT

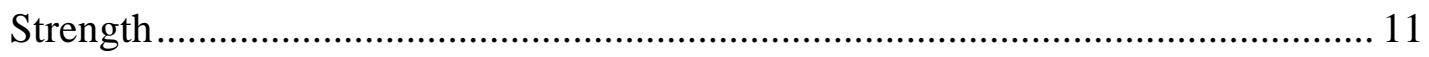

Figure 2.3 Cohesion and Internal Friction as a Function of Binder Content ................... 11

Figure 2.4 Relationship between Mixture Cohesion and Binder High- Temperature PG-

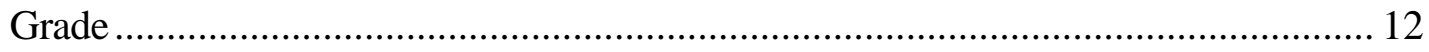

Figure 2.5 Plot of Rut Depth to 1 Million ESALs as a Function of Cohesion ................. 13 
Figure 2.6 Relationship between Mixture Cohesion and IDT Strength......................... 13

Figure 2.7 Mohr's Circle for IDT Strength Test ................................................... 14

Figure 2.8 Effect of Compaction Temperature on VMA............................................. 16

Figure 2.9 Effect of Asphalt Binder Content on SGC Compaction Properties ............... 17

Figure 2.10 Effect of Aggregate Gradation on SGC Compaction Slope ........................ 17

Figure 2.11 Effect of Aggregate Angularity on SGC Compaction Slope....................... 18

Figure 2.12 Relationship between High Temperatures Mix Properties and Compaction

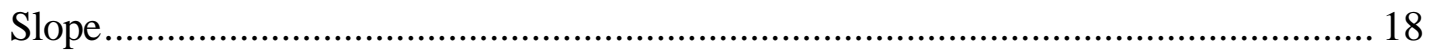

Figure 2.13 N-SR ${ }_{\max }$ Determined Using $2^{\text {nd }}$ Order Polynomial Curve Fit...................... 19

Figure 3.1 Gradation Curve for 9.5 mm NMAS …................................................ 27

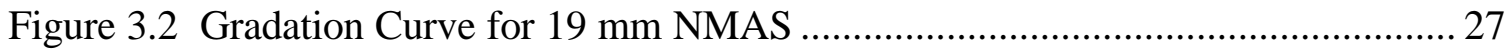

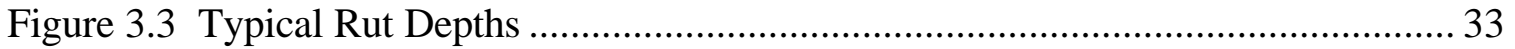

Figure 3.4 Indirect Tensile Strength Test a) loading mode, b) failure plane .................. 34

Figure 3.5 IDT Strength Test Setup and Failure Plane ............................................. 35

Figure 4.1 Relationship between CAR Force and Rutting Potential ............................. 39

Figure 4.2 Relationship between IDT Strength and Rutting Potential ......................... 42

Figure 4.3 Relationship between Rutting Potential and IDT Strength, with Influence of

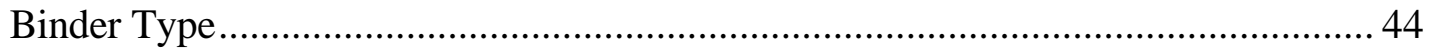

Figure 4.4 Influence of Binder Content on Rutting Potential...................................... 44

Figure 4.5 Influence of Aggregate Characteristics on Rutting Potential ........................ 45

Figure 4.6 Influence of Sand and Gradation on Rutting Potential................................ 46

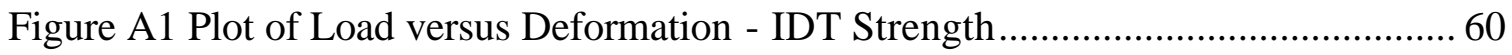

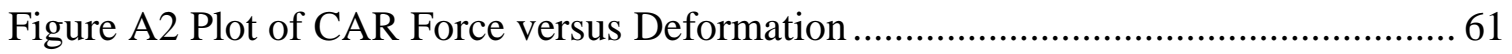

\section{LIST OF TABLES}

Table 2.1 Guidelines for Evaluating Rut Resistance Using IDT Strength ..................... 10

Table 2.2 Description of Variables and Levels ........................................................... 22

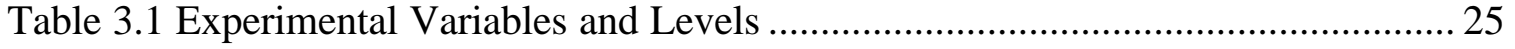

Table 3.2 Experimental Matrix -Half Fractional Factorial .......................................... 25

* Shaded cells are the mixes that were tested............................................................. 25

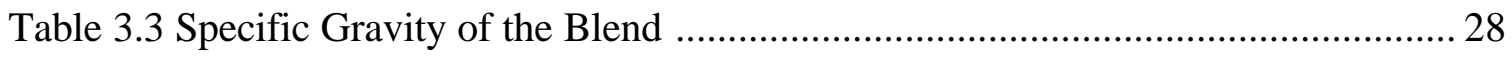

Table 3.4 Mixing and Compaction Temperatures .................................................... 29 
Table 3.5 Randomization for APA Testing ............................................................ 32

Table 4.1 Comparison of Volumetric Properties ....................................................... 36

Table 4.2 Average Rut Depths and Percent Air Voids .............................................. 38

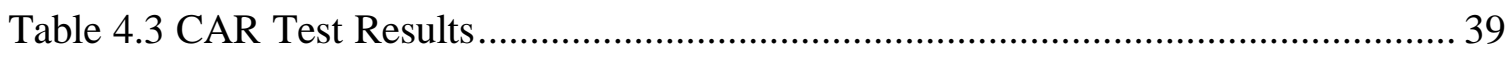

Table 4.4 Effect of Factors on Rut Depth and IDT Strength....................................... 41

Table 4.5 Regression Analysis of Rutting Potential with IDT Strength and Main

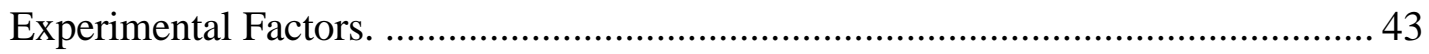

Table 4.6 Regression Analysis of Rutting Potential versus IDT Strength, VMA and k... 47

Table 4.7 Regression Analysis of Rutting Potential versus IDT Strength, and k ............ 47

Table A1 Blend Gradation - 9.5mm NMAS - Coarse ................................................ 54

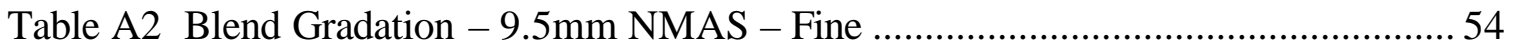

Table A3 Blend Gradation - 19mm NMAS - Coarse ................................................ 55

Table A4 Blend Gradation - 19mm NMAS - Fine ..................................................... 55

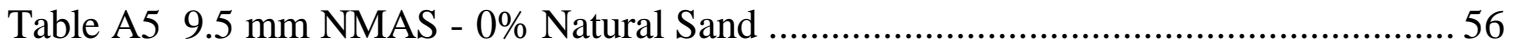

Table A6 9.5 mm NMAS - 40\% Natural Sand .............................................................. 56

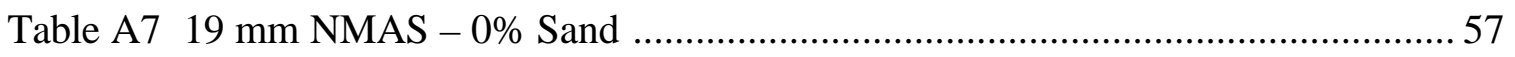

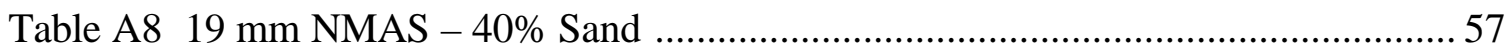

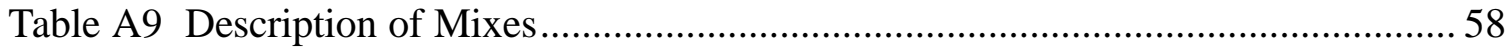

Table A10 Computations for Compaction Slope ....................................................59

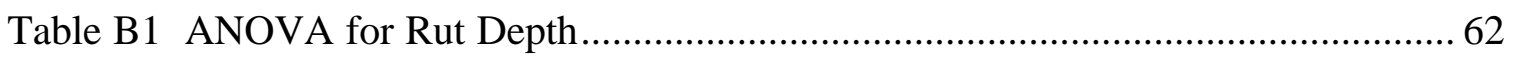

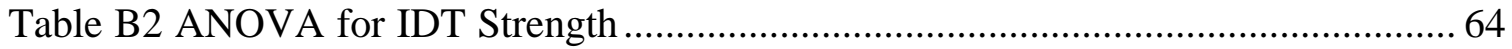




\section{CHAPTER 1: INTRODUCTION}

\subsection{BACKGROUND}

In recent years, rutting of hot mix asphalt (HMA) pavements on some roadways with a high truck volume has resulted in premature failure. On the other hand, some roadways constructed of HMA have carried large volumes of truck traffic with very little rutting. Evaluation of the rutting potential of HMA is considered an important mix design problem to further the development and application of HMA.

Rutting is the formation of twin longitudinal depressions in the wheel paths due to a progressive accumulation of permanent deformation in one or more of the pavement layers [Anani, 1990]. The rate and magnitude of rutting depend on external and internal factors. External factors include load and volume of truck traffic, tire pressure, temperature and construction practices. Internal factors include properties of the binder, the aggregate and mix properties, and the thickness of the pavement layers.

In 1988, the Strategic Highway Research Program (SHRP) was started in USA. The major funds of the SHRP research program were allocated to establish new mix design procedure for asphalt pavements. The research program was completed in 1993 producing the Superpave mix design method.

The original Superpave mix design method was envisioned to include three levels of sophistication for the design of mixes, dependent on the traffic level of the pavement. The simplest Superpave level used only volumetric procedures and parameters in the mix design process. The other levels of Superpave called for sophisticated testing and evaluation of the mix to evaluate performance parameters. Due to the cost and sophistication of the analysis required in levels 2 and 3, only the volumetric Superpave procedures have been implemented at this time.

In addition to the volumetric parameters, Superpave requires aggregates meet consensus properties to provide the internal friction needed to ensure good rutting performance. The consensus parameters include the coarse aggregate angularity, fine aggregate angularity, flat and elongated, and sand equivalency requirements. The fine aggregate angularity requirement has created some controversy in the industry and 
Jahn [2002] has proposed the use of a compacted aggregate resistance, CAR, test to replace the fine aggregate angularity requirement.

Although the volumetric Superpave mixture and analysis system has been very successful in developing durable mix designs, many engineers and technicians feel that a simple performance, or "proof" test is needed to ensure adequate performance for asphalt concrete mixtures. Of special concern is resistance to permanent deformation or rutting. The concern over the lack of a test to evaluate mixture performance has prompted the National Cooperative Highway Research Program (NCHRP), the Federal Highway Administration (FHWA) and State Highway Agencies to sponsor projects with the objective of developing test methods and procedures which can be readily implemented to evaluate the rutting potential of mixes.

Several projects were initiated by the NCHRP to study the issue of a simple performance test for permanent deformation evaluation of asphalt mixtures. One such research by Anderson et al [2003] examines the use of indirect tensile, IDT, strength, volumetric parameters and Superpave Gyratory Compaction (SGC) properties to predict rutting potential of an asphalt mixture.

Anderson [2002c] applied the Mohr-Coulomb theory of material behavior to the evaluation of the rutting potential of HMA. Cohesion was identified as an indicator of how strongly the asphalt cement binds together the aggregate particles of a given mixture. The IDT strength test is a measure of tensile strength and a good indicator of mixture cohesion. IDT strength would provide information on cohesion, specifically asphalt binder stiffness, but not angle of internal friction provided by the aggregates.

The NCHRP 9-16 research validated that the SGC compaction slope captured changes in aggregate characteristics, but was insensitive to asphalt binder volume and stiffness. So it could be expected that compaction slope would provide information on the angle of internal friction, $\varnothing$, but not on cohesion, c [Anderson et al, 2003]. Thus the use of compaction slope, $\mathrm{k}$, along with IDT strength can provide an indicator of rutting resistance of an asphalt mixture. For aggregates having a low compaction slope, the rut depth increases at a much greater rate with increasing Voids in the Mineral Aggregate (VMA), as indicated in Figure 1.1 [Andersonet al, 2003]. 


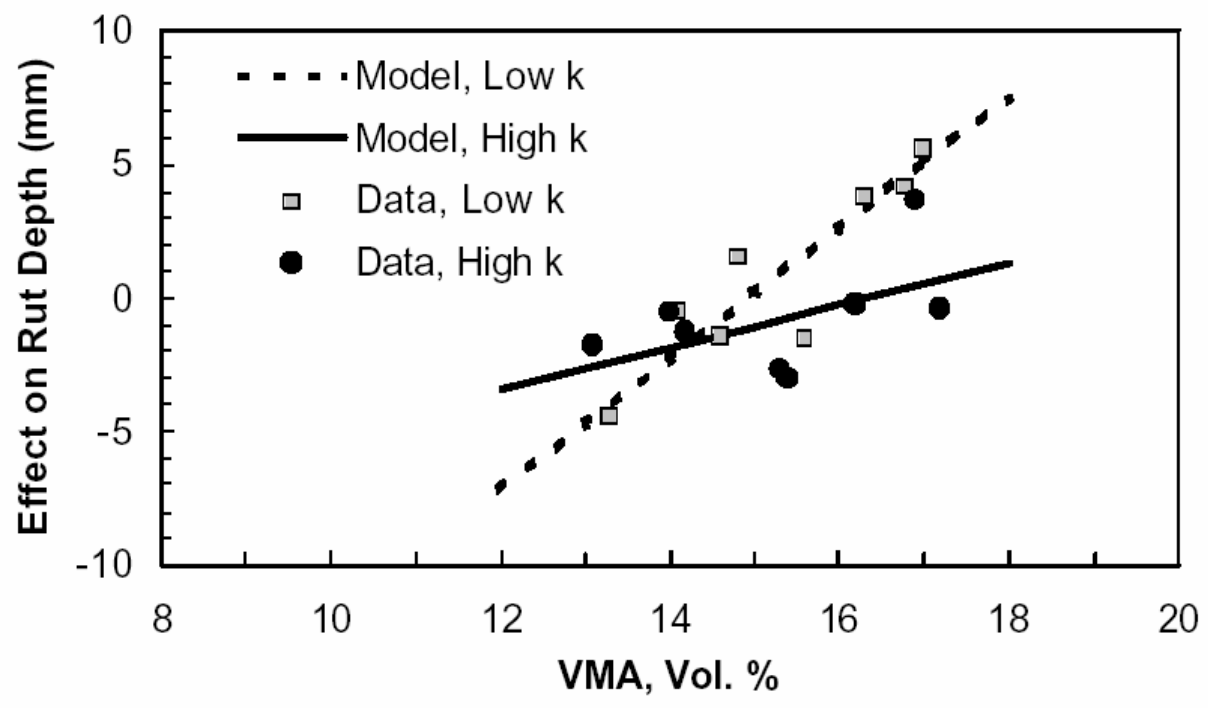

Figure 1.1 Effect of VMA and Compaction Slope on Rut Depth

Anderson's work indicated that mixes with high compaction slope are relatively insensitive to VMA. Compaction slope is an indicator of the internal friction of an aggregate, but if it is to be used in evaluating the rutting resistance of a mixture, then the effect of VMA must also be considered. The rutting resistance of asphalt mixtures made using aggregates with relatively poor internal friction can be substantially improved by lowering VMA [Anderson et al, 2003].

Anderson determined the IDT strength of asphalt mixtures at a deformation rate of $3.75 \mathrm{~mm} / \mathrm{min}$ and a temperature of $34^{\circ} \mathrm{C}$, i.e. $20^{\circ} \mathrm{C}$ below the critical high pavement temperature for Lexington, KY. Rutting resistance of the asphalt mixture was determined at $58^{\circ} \mathrm{C}$ using Repeated Shear Testing at Constant Height (RSCH). Anderson concluded that rutting potential could be predicted using IDT strength, VMA and compaction slope from the SGC.

\subsection{PROBLEM STATEMENT}

Based on Anderson's work, it appears that IDT strength has the potential of providing valuable information about the rutting potential of HMA. However, the equipment used by Anderson is not readily available to highway agencies. Extension of Anderson's work into a procedure that can be readily implemented by state highway agencies is highly desirable. Under the current Superpave procedures, mix designers 
evaluate the moisture susceptibility of mixes using a modified Lottman procedure (AASHTO T283). This procedure uses the Marshall Stabilometer with a modified loading head to measure the IDT strength of samples. Thus, this type of testing is readily available in the industry. If IDT strength measured with the Marshall Stabilometer could be used in lieu of the test used by Anderson, then mix design specifications could be developed that would incorporate a simple proof test using readily available equipment.

Two critical parameters in testing of HMA are the load rate and the test temperature. The Marshall Stabilometer uses a load rate of $50 \mathrm{~mm} / \mathrm{min}$, where as Anderson used a load rate of $3.75 \mathrm{~mm} / \mathrm{min}$. Typically the Lottman procedure uses a test temperature of $25^{\circ} \mathrm{C}$, where as Anderson used a test temperature of $34^{\circ} \mathrm{C}$. The test temperature can be readily modified. However, due to the design of the Marshall Stabilometer, the load rate cannot be readily modified.

The RSCH device used by Anderson for evaluating the rutting potential of the mixes is very sophisticated and has limited availability. Many agencies are using the Asphalt Pavement Analyzer, APA, to evaluate rutting potential of HMA.

Anderson used the SGC compaction slope as an indicator of the angle of internal friction of the aggregates. If a mix design specification was developed from this work, it would require designers to develop mix designs before determining if the aggregate has adequate internal friction for the mixes. Based on the work of Jahn, it may be possible to use the CAR test to evaluate the potential internal friction of an aggregate blend in an asphalt mix as part of the fine aggregate specification.

\subsection{OBJECTIVE}

Taking into consideration all these criteria, for this research, an experimental hypothesis was developed: "The rutting resistance of an asphalt mixture, as determined from the asphalt pavement analyzer, is a function of the compaction parameters as derived from the SGC, volumetric properties and the IDT strength of the mix, as evaluated from Marshall Stabilometer". 


\subsection{SCOPE AND LIMITATIONS}

This research is focused on the potential implementation by the West Virginia Division of Highways, WVDOH. All materials used during the research are typical of those used in the state. Hence, two Nominal Maximum Aggregate Size (NMAS) $9.5 \mathrm{~mm}$ and $19 \mathrm{~mm}$ commonly used by WVDOH were selected for experimentation. Similarly, two binders PG70-22 and PG76-22 were selected. PG70-22 is typically used in conjunction with Superpave mixes, PG76-22 has recently been used by WVDOH for areas with a high rutting potential.

The work was limited to the instruments available in the Asphalt Technology Laboratory of West Virginia University, Morgantown. Marshall Stabilometer available in the lab was used to determine the IDT Strength of asphalt mixtures. The APA was used for evaluating rutting potential of the mixes. All samples were compacted with a Pine AFGC125X SGC. To evaluate the CAR of the aggregates, a Marshall compactor was used to compact the samples.

\subsection{ORGANIZATION OF THESIS}

This report contains five chapters with two appendices. After introducing the objective of this research in the $1^{\text {st }}$ Chapter, Chapter 2 is a summary of the literature. Here, the principles of rutting in asphalt mixtures and the theory of Mohr circle as applied to asphalt mixtures is discussed. Few NCHRP reports that relate rutting potential with indirect tensile strength and SGC compaction properties are discussed in detail. In Chapter 3, the methodology adopted and the test procedures followed during the process of this research is presented. Chapter 4 includes the analysis done using the data in Chapter 3. In this chapter, rut depth was correlated with indirect tensile strength and volumetric and compaction properties. Finally, the conclusions that were arrived at are discussed in Chapter 5. 


\section{CHAPTER 2: LITERATURE REVIEW}

\subsection{INTRODUCTION}

Rutting, or permanent deformation, is one of the main failure mechanisms for asphalt concrete pavements. Excessive permanent deformation can occur in mixtures that lack adequate stiffness and/or strength at high temperatures. Significant rutting normally only occurs during hot weather, when the surface of flexible pavements can reach a temperature of $60^{\circ} \mathrm{C}$ or higher. Furthermore, this mode of distress is also associated with relatively high traffic levels; the greater the number of vehicles and greater the proportion of heavy trucks, the greater the potential for permanent deformation. Rutting is a serious problem for a number of reasons; for example rain or melted snow and ice can pond in the ruts, increasing the chance for vehicle hydroplaning and subsequent accidents. Excessive ruts can also reduce the effective thickness of a pavement, reducing the structural capacity of the pavement and increasing the likelihood of premature failure through fatigue cracking [Christensen et al, 2000].

The severity of rutting of asphalt concrete pavements can be substantially reduced by ensuring that: [Sontowski, 1995]

* significant portion of the coarse aggregates have at least one fractured face

* the aggregate gradation has sufficient mineral filler and dust content

* the asphalt cement has a sufficiently high viscosity

* the asphalt film thickness around the particle is sufficient to provide adequate cohesive strength.

\subsection{PRINCIPLES OF RUTTING IN ASPHALT MIXTURES}

Rutting in hot-mix asphalt concrete (HMAC) can occur from two types of mechanical response: viscous flow and plastic deformation. Plastic deformation occurs as aggregate particles move slightly relative to one another, which is accompanied by viscous flow in the asphalt cement binding these particles together. These processes, though conceptually simple, are very difficult to analyze quantitatively.

The behavior of asphalt concrete can be analyzed by the Mohr-Coulomb failure theory. This theory predicts that the strength of a material such as asphalt concrete depends upon both cohesion and internal friction. For the case of simple shear loading 
with an applied normal stress $\sigma_{N}$, the shear stress at failure $\tau_{\max }$ is given by the following equation [Christensen and Bonaquist, 2002]:

$\tau_{\max }=c+\sigma_{N} \tan \phi$

where

$$
\begin{aligned}
& c=\text { cohesion, } \mathrm{kPa} \text { (or othe } \mathrm{r} \text { consistent units) } \\
& \phi=\text { angle of internal friction, degrees } \\
& \sigma_{N}=\text { normal stress, } \mathrm{Pa}
\end{aligned}
$$

The Mohr-Coulomb theory is often represented graphically by plotting a series of Mohr's circles representing stress states at incipient failure under increasing levels of confining stress and then drawing a tangent to these circles, which represents the MohrCoulomb failure envelope, Figure 2.1 [Christensen et al, 2000]. There are two lines associated with the failure envelope, the $\phi$ line and the $\mathrm{K}_{\mathrm{f}}$ line. The $\phi$-line is tangent to each of the three Mohr's circles as shown in the sketch, while the $\mathrm{K}_{\mathrm{f}}$ line passes through the maximum shear stress for each Mohr's circle.

Normal (confining) stress, $\sigma_{N}$, is the stress normal to the failure plane. Internal friction is proportional to the applied normal stress. At zero normal stress, shear strength is equal to the cohesion. As the confining stress increases, the failure stress increases as a function of the angle of internal friction. The greater the angle of internal friction, the greater the increase in failure stress. The strength of asphalt concrete should be a function of both cohesion and internal friction [Christensen and Bonaquist, 2002].

In analyzing strength tests, this theory is simply a way of mathematically representing the relationship between confining stress and failure stress. The internal friction is an important parameter, indicating the degree of interaction among particles. For most engineering applications, including asphalt concrete, a high value of internal friction is more desirable. An asphalt mixture made of aggregates with relatively poor internal friction is more susceptible to rutting. The cohesion, $\mathrm{c}$, theoretically represents the shear strength at zero confining pressure. Cohesion, in asphalt concrete, is a parameter that indicates how strongly the binder can bind the aggregates together. It is mostly a function of binder content, binder grade and mix temperature. 


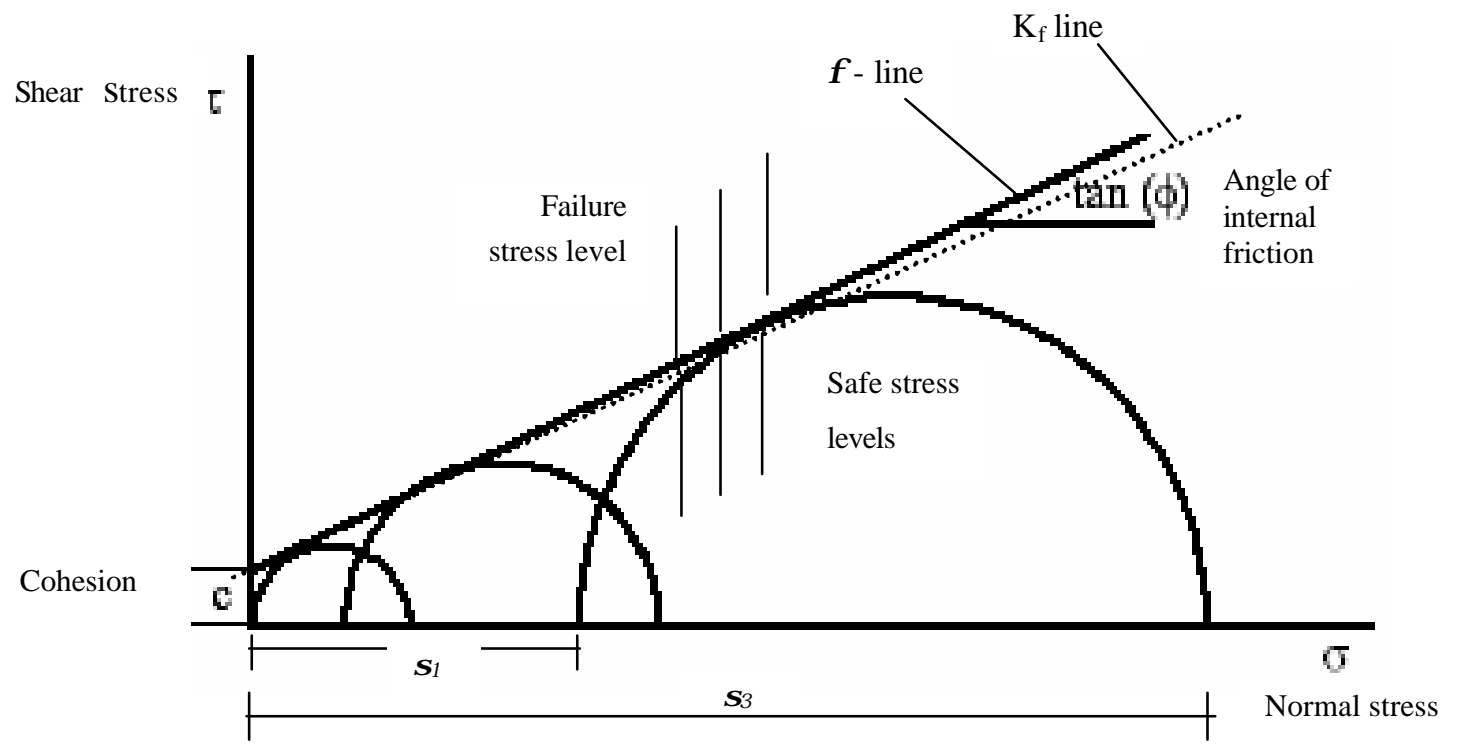

Note: $\sigma_{1}$ and $\sigma_{3}$ major and minor principle stresses

\section{Figure 2.1 Mohr-Coulomb Failure Theory}

Strength is the ability of a material to resist an applied stress without failure, while stiffness represents the ratio of applied stress to resulting strain for a given material. Many methods for analyzing permanent deformation in HMAC have relied upon stiffness characterizations, the reasoning being that low overall stiffness should be correlated to low resistance to rutting. However, since rutting consists of small but permanent changes in the internal arrangement of aggregate particles, which constitutes a type of damage to the asphalt concrete, the strength of a given mixture should be as good or even better a predictor of rut resistance. Stiffness testing is generally carried out at small strains, and is therefore not representative of the relatively large strains, that must occur during significant accumulation of permanent strains. Strength tests, besides being simpler and easier to carry out than stiffness tests, fully mobilize the resistance of both the asphalt binder and the aggregate structure comprising asphalt concrete [Christensen and Bonaquist, 2002].

According to Christensen and Bonaquist [2002], a simplified method for determining mixture cohesion and internal friction involves testing asphalt concrete specimens in indirect tension and unconfined compression. The indirect tension test was run on a $115 \mathrm{~mm}$ high, $150 \mathrm{~mm}$ diameter specimen, at a load rate of $3.75 \mathrm{~mm} / \mathrm{min}$ and at 
$20^{\circ} \mathrm{C}$ below the maximum 7-day pavement temperature, $\mathrm{T}_{\max }$. The unconfined test was run at the same temperature, $\left(\mathrm{T}_{\max }-20^{\circ} \mathrm{C}\right)$ but at $7.5 \mathrm{~mm} / \mathrm{min}$ and used a $150 \mathrm{~mm}$ by 150 $\mathrm{mm}$ specimen. Both tests were performed on specimens produced by the gyratory compactor. By analyzing IDT and compression data, $\mathrm{c}$ and $\phi$ were directly obtained from the following equations:

$a_{1}=\frac{\left|\sigma_{U U C}\right|-4\left|\sigma_{U I D T}\right|}{\left|\sigma_{U U C}\right|-2\left|\sigma_{U I D T}\right|}$

$\phi=\sin ^{-1}\left(a_{1}\right)$

$c=\frac{\left(2-a_{1}\right) * \sigma_{U I D T}}{\cos \phi}$

where,

$\mathrm{a}_{1}=$ slope parameter

$\sigma_{\mathrm{UUC}}=$ unconfined compressive strength, $\mathrm{kPa}$

$\sigma_{\text {UIDT }}=$ indirect tension strength, $\mathrm{kPa}$

The derivation of these equations follows from Mohr-Coulomb theory and the state of stress existing in the IDT test and the unconfined compression test.

Nijboer performed early research involving triaxial testing of asphalt mixtures. The pertinent features of Nijboer's theory on the applications of Mohr-Coulomb [Christensen et al, 2000] are:

* The cohesion of asphalt concrete, which Nijboer calls the initial resistance, is composed of three forces: true cohesion, apparent cohesion and interlocking resistance.

* Internal friction is that portion of the shear resistance proportional to the applied normal stress.

* Asphalt binders in general have a lubricating effect on aggregates, reducing the angle of internal friction.

- The stiffer the binder used in a mixture, the lower the angle of internal friction.

* The cohesion increases with increasing binder stiffness.

* Initial resistance, mass viscosity and internal friction all decrease with increasing air void content. 
- Increasing filler/binder ratio will increase both initial resistance and mass viscosity

Increasing the coarse aggregate content will normally increase all components of the shear resistance: initial resistance, mass viscosity, interlocking resistance and internal friction.

A study conducted jointly by The Pennsylvania Transportation Institute (PTI) of The Pennsylvania State University, and Advanced Asphalt Technologies, LLC (AAT) evaluated $c$ and $\phi$ values determined using tri-axial test, unconfined compression test and IDT strength test [Christensen et al, 2000]. This research included RSCH tests to evaluate how well the data related to rut resistance. Limited field rutting data were also available. Ten mixtures were evaluated. All aggregate gradations passed below the Superpave restricted zone. A range of aggregate types was represented in the mix designs. In analyzing the data, a very good correlation between IDT strength and rut resistance was found, as indicated both by RSCH test results and by observed rutting. Figure 2.2 [Christensen et al, 2000] shows maximum permanent shear strain (MPSS) from the RSCH test as a function of IDT strength with an $\mathrm{R}^{2}$-value of 0.80 . Using this relationship and the Asphalt Institute guidelines for interpreting maximum permanent shear strains from the RSCH test, preliminary guidelines for interpreting IDT strength tests were developed and are given in Table 2.1 [Christensen et al, 2000]. However, these guidelines can only be applied to the test conditions that were observed in their study-a test temperature $20^{\circ} \mathrm{C}$ below the 7-day average maximum pavement temperature and a loading rate of $3.75 \mathrm{~mm} / \mathrm{min}$.

Table 2.1 Guidelines for Evaluating Rut Resistance Using IDT Strength

\begin{tabular}{|l|l|l|}
\hline RSCH MPSS, \% & IDT Strength & Rut Resistance \\
\hline$<1.0$ & $>440$ & Excellent \\
\hline 1.0 to $<2.0$ & $>320$ to 440 & Good \\
\hline 2.0 to $<3.0$ & $>200$ to 320 & Fair \\
\hline$=3.0$ & $=200$ & Poor \\
\hline
\end{tabular}




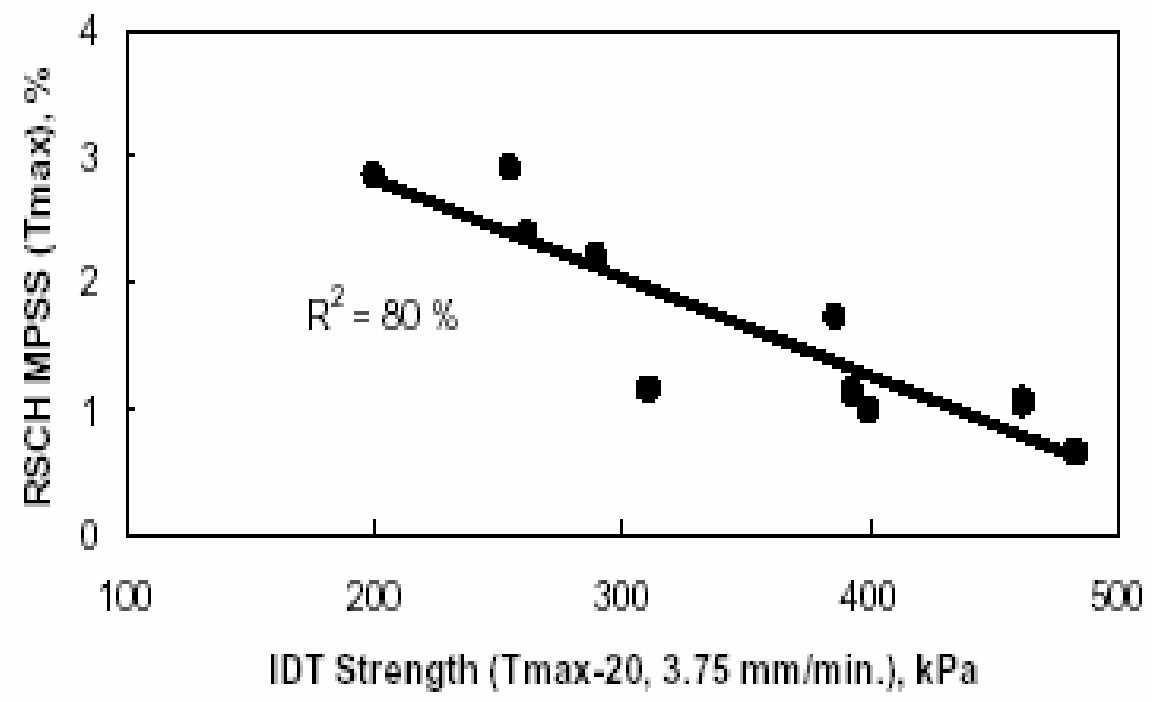

Figure 2.2 Maximum Permanent Shear Strain from RSCH Test as a Function of

\section{IDT Strength}

Significance of Cohesion in obtaining rut resistance: In using the relationship between strength test data and rutting to design asphalt concrete mixtures, it is important to understand the significance of mixture cohesion in obtaining good rut resistance. Increasing binder content, to a point, increases cohesion, but excessive binder content has no effect on cohesion as seen in Figure 2.3 [Christensen and Bonaquist, 2002]. It can be observed that, cohesion is zero when no binder is present. The maximums for both cohesion and internal friction appear to be poorly defined, thus indicating that increasing binder contents does not affect cohesion.

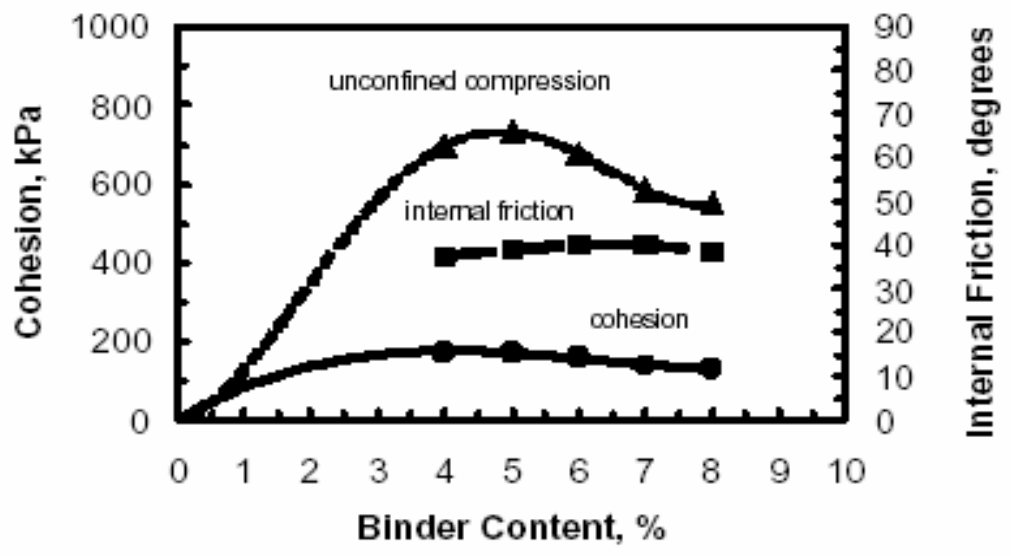

Figure 2.3 Cohesion and Internal Friction as a Function of Binder Content 
Figure 2.4 [Christensen et al, 2000] is a plot of mixture cohesion versus PG-grade. Binder grades used were unmodified PG58-28, PG64-22 and modified PG76-28.

Clearly, mixture cohesion increases with increasing binder high-temperature grade. The scatter in the plot is due to other factors affecting cohesion, which should include mineral filler content, binder content, Voids Filled with Asphalt (VFA) and aggregate-binder interactions

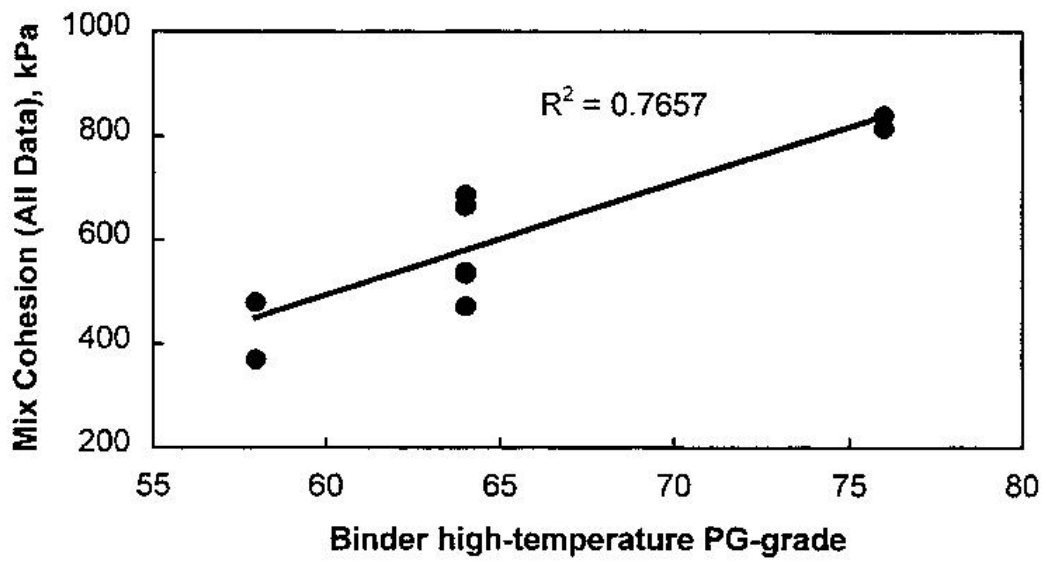

\section{Figure 2.4 Relationship between Mixture Cohesion and Binder High-Temperature PG-Grade}

The obvious substantial increase in rut resistance with decreasing temperature is clear and convincing evidence that mixture cohesion, rather than internal friction (which is largely independent of temperature) is the most important factor in determining mixture rut resistance.

To indicate the relationship between cohesion and field rutting, Figure 2.5 [Christensen et al, 2000] is presented, in which estimated rut depth at 1 million Equivalent Single Axle Loads (ESALs) is plotted, as a function of cohesion. This was done by performing linear regression on log-log transforms of rut depth versus traffic level. The resulting equations were used to estimate the rut depth at a traffic level of 1 million ESALs. 


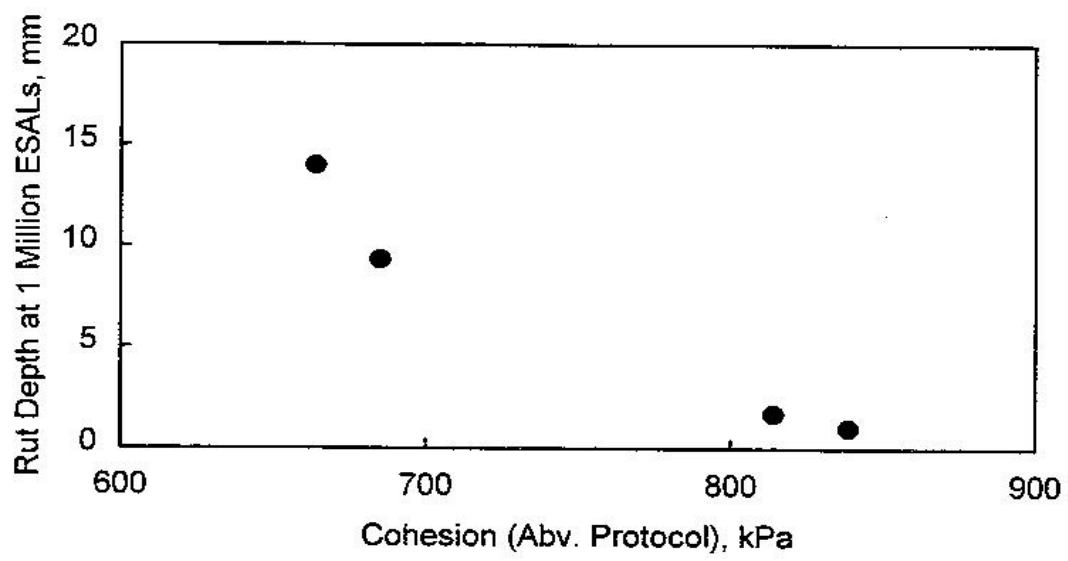

\section{Figure 2.5 Plot of Rut Depth to 1 Million ESALs as a Function of Cohesion}

The IDT test, being a measure of tensile strength, is in fact a good indicator of mixture cohesion. This is illustrated in Figure 2.6 [Christensen et al, 2000], in which mixture cohesion is plotted as a function of IDT strength. The relationship is very strong; assuming the intercept is zero, the mixture cohesion can be accurately estimated as 1.75 times the IDT strength with an $\mathrm{R}^{2}$ value of 98 percent.

This relationship can be explained theoretically using Mohr-Coulomb circles for IDT test. In Figure 2.7 [Christensen et al, 2000], the Mohr's circle farthest to the left represents the state of stress in tension. $\mathrm{S}_{\mathrm{X} \text {-IDT }}$ represents the tensile stress (horizontal) at

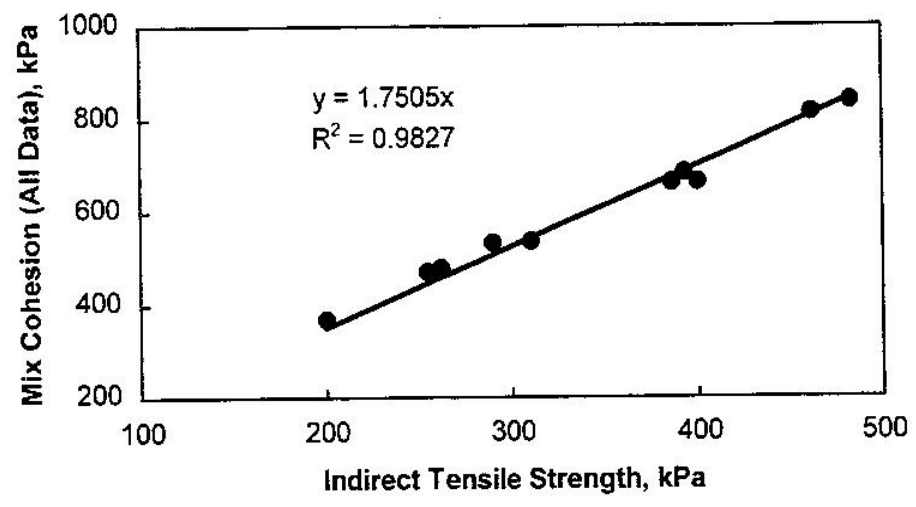

\section{Figure 2.6 Relationship between Mixture Cohesion and IDT Strength}

failure, while $\mathrm{S}_{\mathrm{Y}-\mathrm{IDT}}$ represents the compressive (vertical) stress at failure. The stress state in the IDT test is such that the average normal stress, $\mathrm{p}=\left(\mathrm{s}_{\mathrm{Y}-\mathrm{IDT}}+\mathrm{S}_{\mathrm{X}-\mathrm{IDT}}\right) / 2$, is close to zero. Therefore, at this point, the value of the maximum shear stress, 
$\mathrm{q}=\left(\mathrm{S}_{\mathrm{Y}-\mathrm{IDT}}-\mathrm{S}_{\mathrm{X}-\mathrm{IDT}}\right) / 2$, will be slightly greater than the mixture cohesion, $\mathrm{c}$. For a Poisson's ratio of 0.5 when average normal stress, $\mathrm{p}=-\mathrm{S}_{\mathrm{X}-\mathrm{IDT}}$, maximum shear stress, $\mathrm{q}=$ $-2 \mathrm{~S}_{\mathrm{X}-\mathrm{IDT}}$.

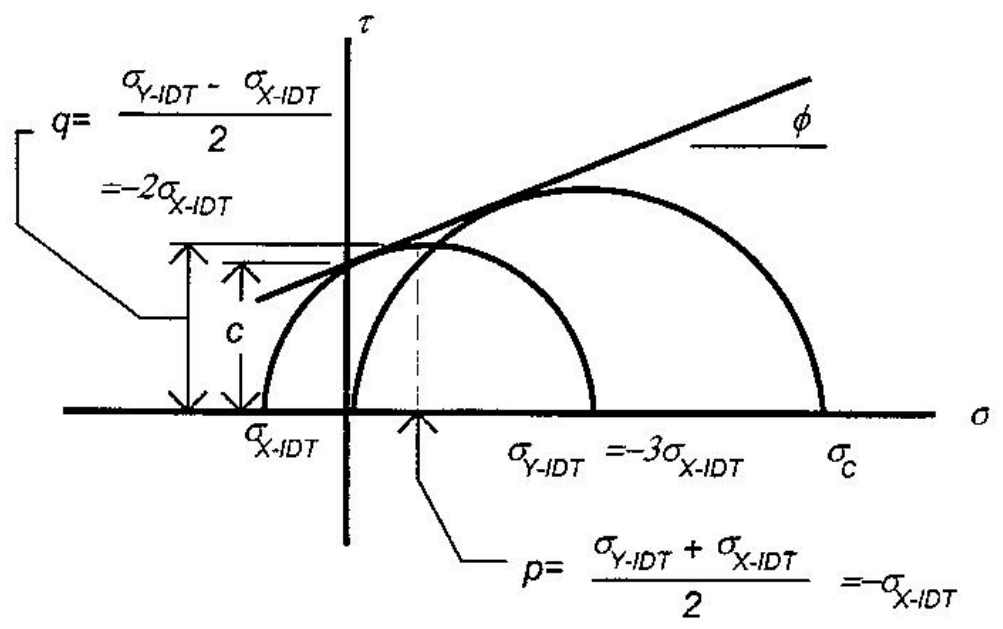

Figure 2.7 Mohr's Circle for IDT Strength Test

Because the average normal stress for the IDT stress state is so close to zero, the differences in angle of internal friction among typical asphalt concrete mixtures has little effect on the relationship between cohesion and maximum shear stress during the IDT strength test; thus, cohesion can be estimated from the IDT strength as $\mathrm{c}=1$.

\subsection{COMPACTION SLOPE}

During compaction with SGC, compaction slope is calculated as the change in percentage of theoretical maximum density, $\% \mathrm{G}_{\mathrm{mm}}$, as a function of the change in the number of gyrations from $\mathrm{N}_{\text {initial }}$ to $\mathrm{N}_{\text {design }}$ i.e.,

Compaction Slope, $k=\frac{\% G_{d e s}-\% G_{\text {ini }}}{\log \left(N_{\text {des }}\right)-\log \left(N_{\text {ini }}\right)} * 100$

where,

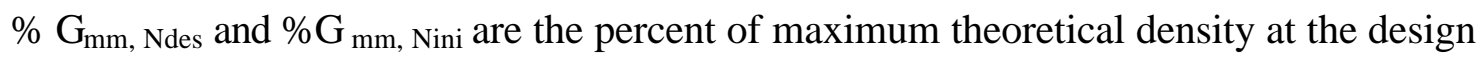
and initial compaction levels respectively and can be estimated as follows

$\% G_{m m},_{N i n i}=\% G_{m m, N d e s} * \frac{h_{d e s}}{h_{i n i}}$ 
$\% G_{m m, \text { Ndes }}=\frac{G_{m b}}{G_{m m}}$

$\mathrm{G}_{\mathrm{mb}}=$ Bulk specific gravity

$\mathrm{G}_{\mathrm{mm}}=$ Maximum specific gravity

$\mathrm{N}_{\mathrm{ini}}=$ Design number of gyrations to compact the sample

$\mathrm{N}_{\text {des }}=$ Initial number of gyrations to compact the sample

$\mathrm{H}_{\mathrm{ini}}=$ Height of the sample at $\mathrm{N}_{\mathrm{ini}}$

$\mathrm{h}_{\text {des }}=$ Height of the sample at $\mathrm{N}_{\text {des }}$

Aggregate characteristics (gradation, particle shape and texture) rather than

asphalt binder characteristics (stiffness and volume) dominate the rate of compaction in the SGC [Anderson et al, 2003].

The SGC operates by applying constant conditions of vertical pressure (600 kPa), angle of gyration $(1.25 \mathrm{deg})$ and rotational speed $(30 \mathrm{rpm})$ to an asphalt mixture during the compaction process. SGC compacts HMA samples to produce specimen sizes of $150 \mathrm{~mm}$ in diameter and $115 \pm 0.5 \mathrm{~mm}$ tall. The energy input to the specimen is not constant, but increases with stiffer asphalt mixtures. Since aggregate characteristics dominate the rate of compaction, the compaction slope is practically insensitive to temperature changes, The SGC indicates no apparent sensitivity of mixture density to changes in compaction temperatures. This was experimentally verified using unmodified PG64-28 and polymer-modified PG76-28 and five compaction temperatures: $120^{\circ} \mathrm{C}$, $135^{\circ} \mathrm{C}, 150^{\circ} \mathrm{C}, 165^{\circ} \mathrm{C}$ and $180^{\circ} \mathrm{C}$. Figure 2.8 [McGinnis et al, 1996] shows that for PG64-28, air voids and VMA are insensitive to compaction temperatures. The results have limited applicability because the experiment involved only one design aggregate structure and two binders. However, the volumetric properties of the mix containing unmodified binder did not appear to be sensitive to compaction temperature as the same mixture with modified binder. An experiment with variety of design aggregate structures and asphalt binders will help understand the effect of compaction temperature better. 


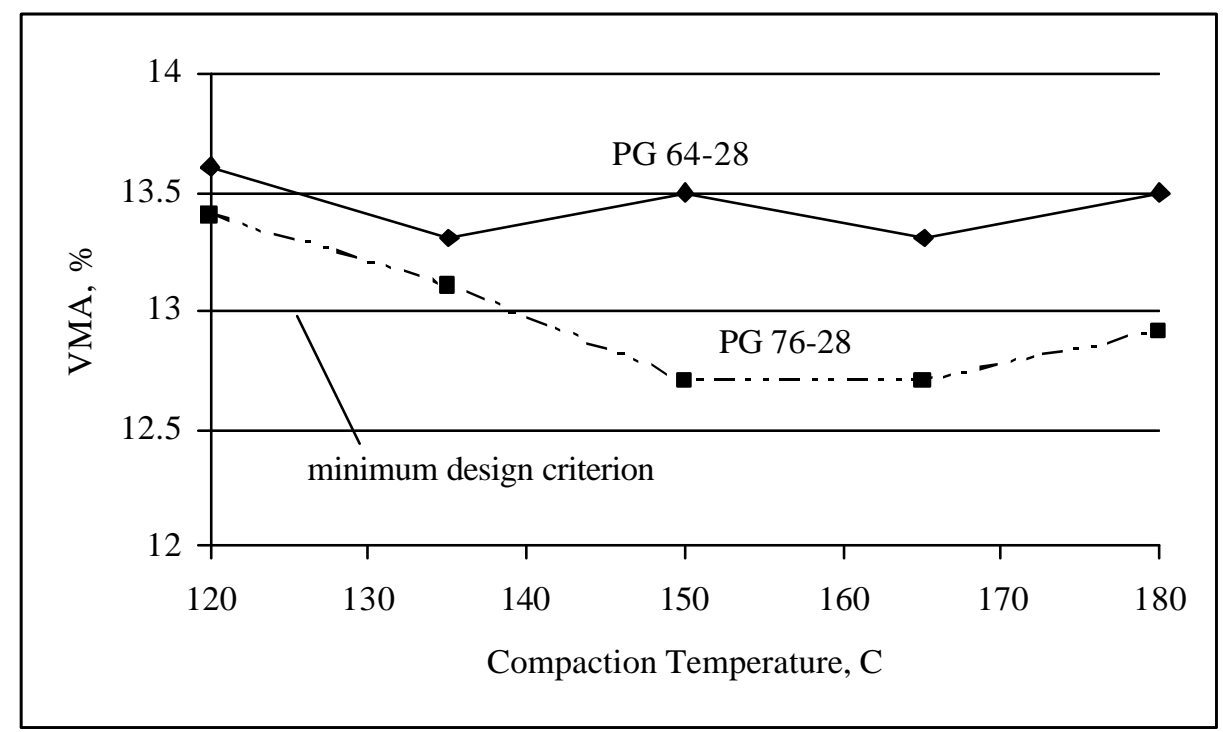

Figure 2.8 Effect of Compaction Temperature on VMA

In the Superpave mix design process, little difference exists in the compaction slope for different asphalt contents with the same aggregate structure. As shown in Figure 2.9 [Anderson et al, 2003], the compaction curves are very close to being parallel lines for blends with the same aggregate structure, but asphalt contents varying by $0.5 \%$. Here, $\mathrm{k}$ is the compaction slope computed using Equation 2.5. By contrast, Figures 2.10 and 2.11 [Anderson et al, 2003] illustrate the effect of aggregate characteristics on compaction slope. Figure 2.10 illustrates the effect of aggregate gradation (same aggregate) on compaction slope; k ranges from 6.66 for fine aggregates to 9.93 for coarse aggregate gradation. Rounded aggregates, with less internal friction, tend to produce lower compaction slopes. This is illustrated in Figure 2.11 where the aggregate gradations are similar for the two mixtures, but the uncrushed river gravel has a compaction slope of 6.14 while the crushed limestone has a compaction slope of 8.84 . 


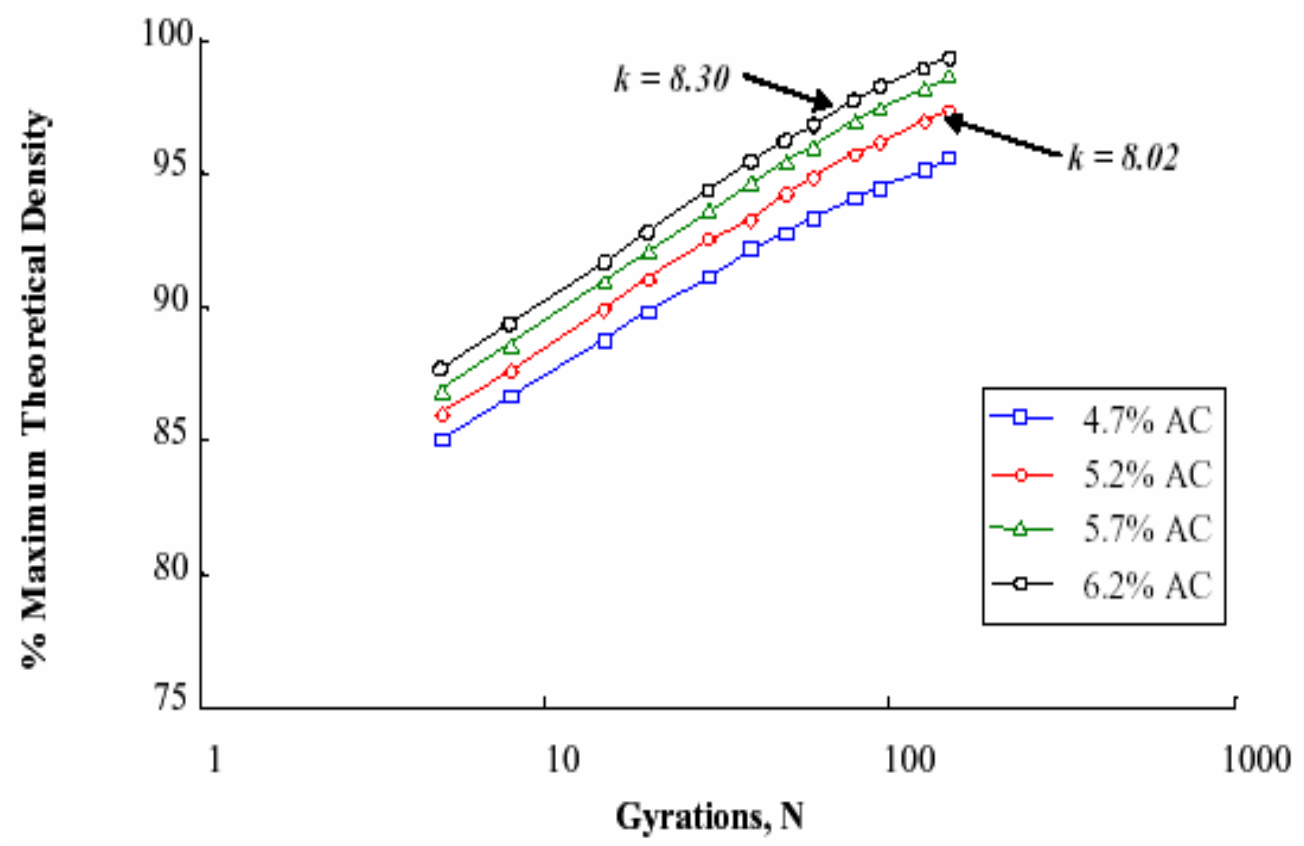

Figure 2.9 Effect of Asphalt Binder Content on SGC Compaction Properties

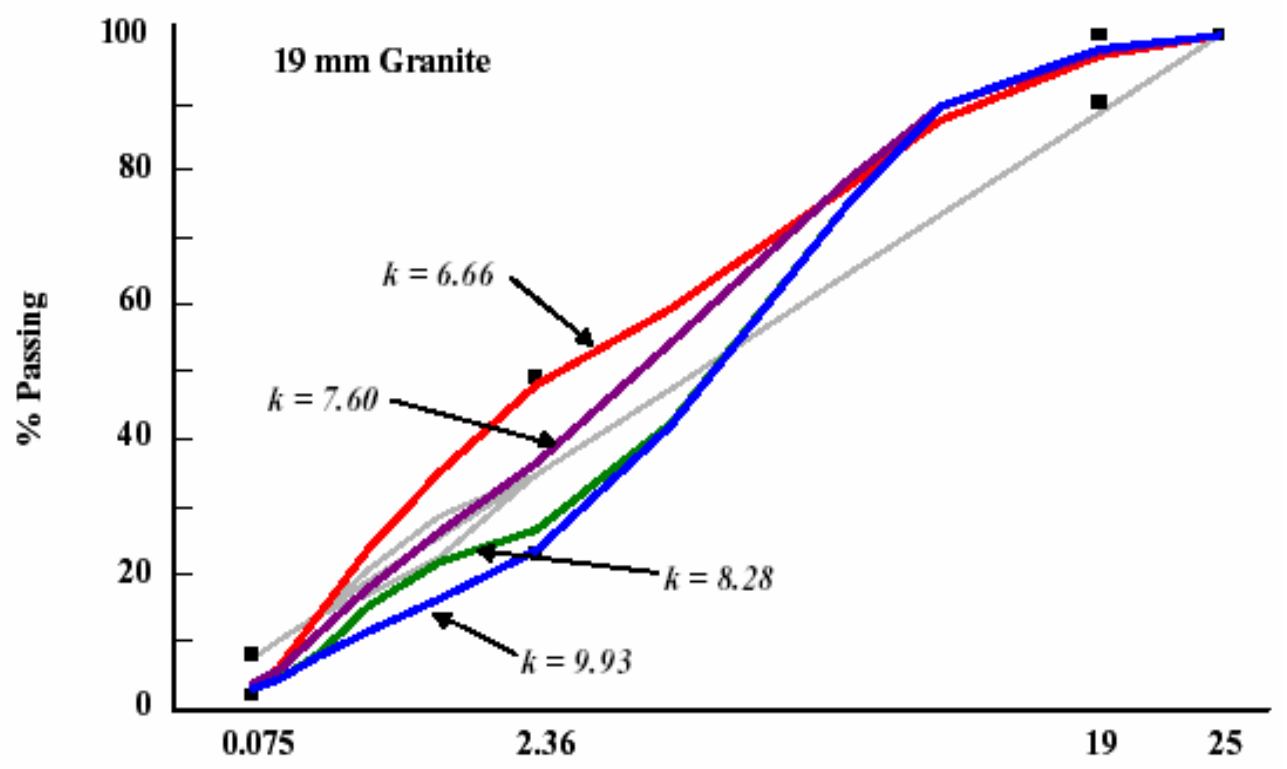

Sieve Size (mm) raised to 0.45 power

Figure 2.10 Effect of Aggregate Gradation on SGC Compaction Slope 


\section{$12.5 \mathrm{~mm}$ Nominal Mixture}

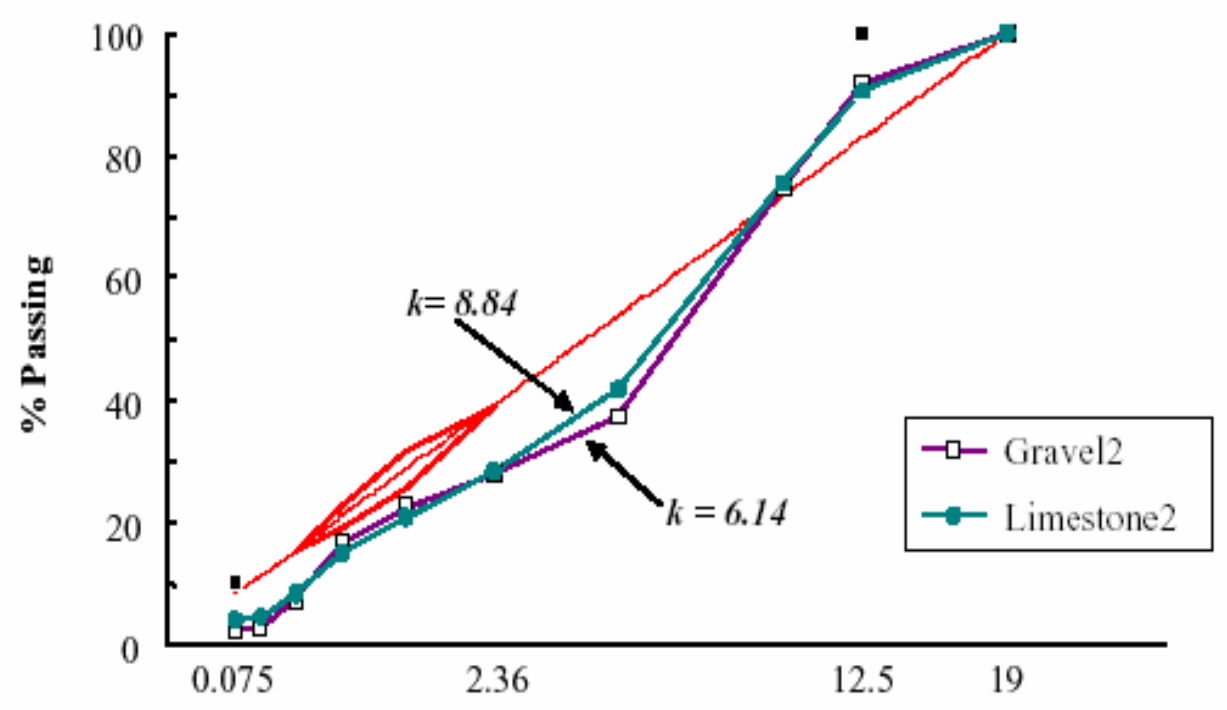

Sieve Size $(\mathrm{mm})$ raised to 0.45 Power

\section{Figure 2.11 Effect of Aggregate Angularity on SGC Compaction Slope}

Attempts to correlate mixture stiffness properties and permanent deformation resistance to compaction slope of the SGC produced mixed results. In most cases, there was a general trend indicating that higher compaction slope mixtures had higher shear stiffness and lower permanent shear strain, i.e., better rutting resistance, as illustrated in Figure 2.12 [Anderson et al, 2002a].

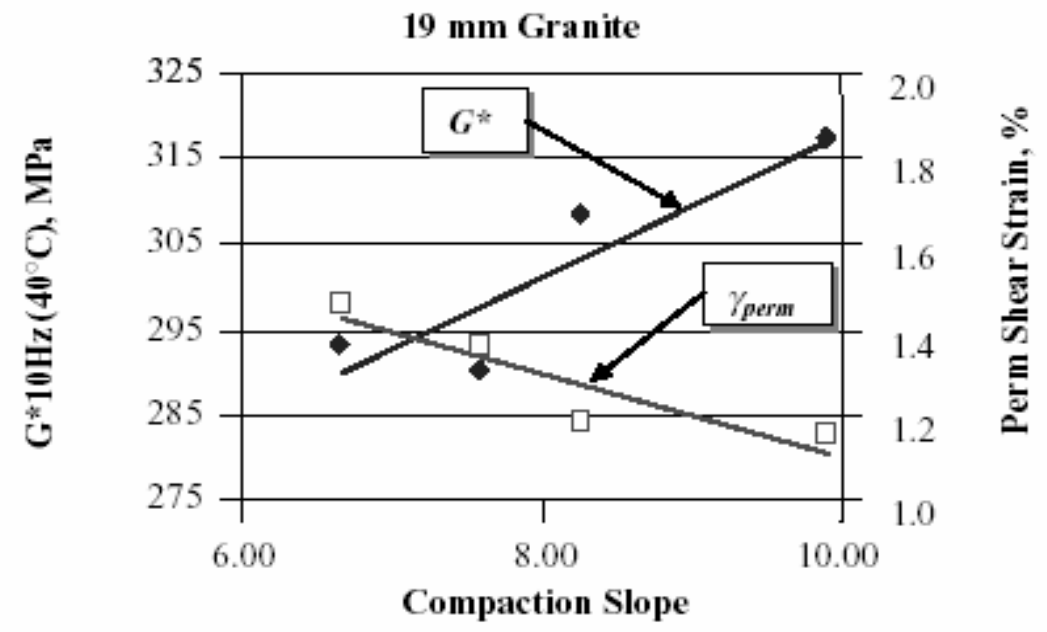

Figure 2.12 Relationship between High Temperatures Mix Properties and Compaction Slope 
Evaluation of the results from the NCHRP 9-16 laboratory experiments indicated $\mathrm{N}-\mathrm{SR}_{\max }$ as another compaction parameter related to asphalt mixture shear stiffness and rutting potential. The $\mathrm{N}-\mathrm{SR}_{\max }$ parameter is the number of gyrations at which the stress ratio (shear stress divided by vertical stress) reaches a maximum value. To determine N$\mathrm{SR}_{\max }$, stress ratio curve was plotted from 10 gyrations to the maximum (160 gyrations) on a normal, arithmetic scale. A second-order polynomial was fit to the data. Identifying the N-SRmax was then a matter of taking the derivative of the equation $(\mathrm{dSR} / \mathrm{dN})$ and setting it equal to zero. This is shown in Figure 2.13 [Anderson, 2002b].
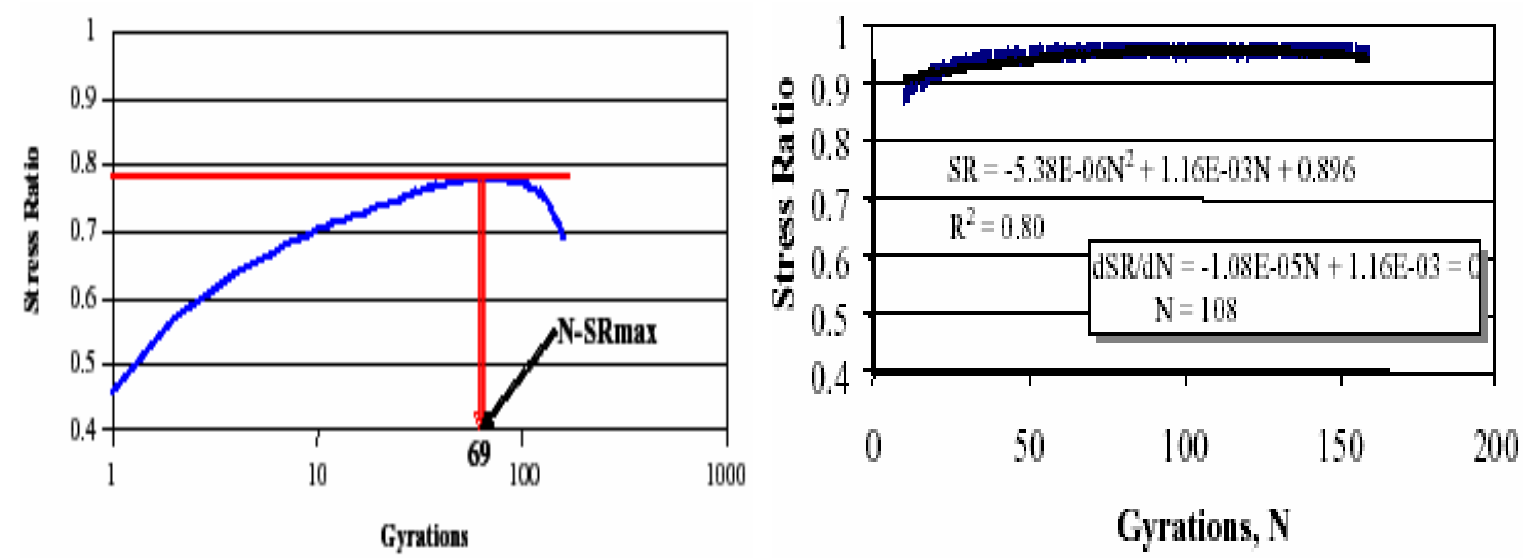

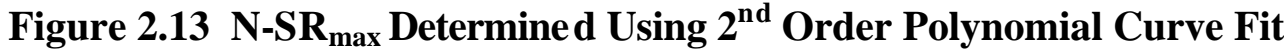

$\mathrm{N}-\mathrm{SR}_{\max }$ appears to be suited for either routine mix design or quality control operations with the following limitations [Anderson, 2002c]:

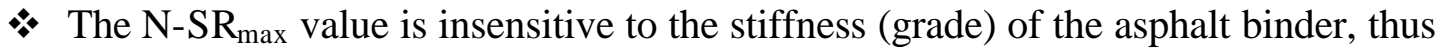
limiting its use to evaluating mixtures with different aggregate structures or different asphalt binder contents.

* The N-SR $R_{\max }$ value can be used as a general indicator of high temperature mixture (rutting) performance, but cannot be used to predict an absolute value of rutting.

* The N-SRmax parameter requires equipment modification. 


\subsection{IDT AS AN INDICATOR OF RUTTING POTENTIAL OF ASPHALT MIXTURES}

Accurate prediction of pavement response and performance requires the use of theoretical models, which closely represent both the pavement structure, and the behavior of the individual materials within the structure.

The Strategic Highway Research Program (SHRP) concluded with the introduction of the Superpave mix design and analysis system. As part of Superpave, a series of mechanical testing procedures were developed by SHRP researchers for advanced mixture analysis. Unfortunately, the cost of the test equipment, the Superpave Shear Tester (SST) and Indirect Tensile Tester, was prohibitive for routine use by hotmix asphalt contractors and state highway agencies. The high cost of the performance testing equipment was only one part of the problem faced by users. Of equal importance, execution of the testing and proper analysis of the results required well-trained, experienced personnel. As a result, most state highway agencies moved towards implementation of the Superpave mix design process relying only on analysis of volumetric and densification properties of the mixture. Unlike the Marshall or Hveem mix design procedures there was no final "strength" test included in the Superpave mix design. Many in the asphalt industry believed that a simple performance test should be included in the Superpave mix design procedure. This would include measurement and determination of properties related to performance [Roque and Buttlar, 1992].

The key to obtaining appropriate asphalt mixture properties for use in theoretical models, which closely represent the pavement structure, is to use testing modes, which induce stress states that are similar to those experienced by the asphalt concrete layer. A few testing modes that have been used to determine properties of asphalt mixtures in the laboratory includes indirect tension, uniaxial and triaxial compression and direct tension.

It can be argued that for low temperatures, where thermal stresses become significant, reasonable estimates of stiffness can be obtained from the indirect tensile mode. As temperature is reduced, asphalt stiffness increases and the asphalt concrete behaves more and more as a linearly elastic material. Thus, the materials behavior becomes much less dependent on stress state, which implies that reasonable estimates of tensile stiffness can be obtained from measurement within the center of the face of the 
indirect tension specimen, even though the stress state involves compression as well as tension. Stiffness measurements have been obtained successfully using the indirect tensile mode.

The stress state in the vicinity of an indirect tension specimen is longitudinal and transverse tension combined with vertical compression. Modulus values determined using strain gauge measurements obtained in this zone of the indirect tension specimen resulted in excellent predictions of strains and deflections measured on full-scale pavements at in-service temperatures less than $30^{\circ} \mathrm{C}$. Measurements obtained from direct tension test can only provide an average failure strain or energy. Indirect tension test has been successfully used to determine failure strain, stress and fracture energy of asphalt mixtures [Roque and Buttlar, 1992].

Christensen and Bonaquist [2002] concluded that, the IDT test is simple, requires low loads, and can be done on thin specimens and pavement cores, which is a significant advantage in QC/QA testing. The IDT strength test appears better suited for routine use in evaluating the rut resistance of asphalt concrete mixtures. The simplicity of this test is such that it should be possible to conduct the necessary research relatively quickly without large expenditures.

\subsection{RUTTING POTENTIAL AS ESTIMATED USING SGC PROPERTIES AND IDT STRENGTH}

Anderson et al [2003] extended his research on the NCHRP 9-16 project and the research conducted by PTI and AAT to examine the possibility of using indirect tensile strength and SGC properties to predict the rutting potential of an asphalt mixture. The experimental variables and the levels are indicated in Table 2.2.

During the NCHRP 9-16 research, mix designs were conducted on the sixteen mixtures to determine the optimum asphalt binder content at $\mathrm{N}_{\text {design }}$ (100 gyrations). SGC specimens were compacted using a modified Pine AFG1 SGC, so that conventional SGC compaction parameters and measured shear stress could be determined. After compaction, the bulk specific gravity of the specimens was determined and the volumetric properties of the mixture were calculated including voids in total mix (VTM), voids in the mineral aggregate (VMA), and voids filled with asphalt (VFA). The 
Table 2.2 Description of Variables and Levels

\begin{tabular}{|l|l|l|}
\hline & \multicolumn{2}{|c|}{ Level } \\
\hline Variable & Low & High \\
\hline Aggregate (Coarse) & River Gravel (Crushed) & Kentucky Limestone \\
\hline Gradation & Coarse & Fine \\
\hline Nominal Maximum Size & $9.5 \mathrm{~mm}$ & $19 \mathrm{~mm}$ \\
\hline Natural Sand Percentage & $0 \%$ & $40 \%$ \\
\hline Asphalt Binder Grade & PG $64-22$ & PG 76-22 \\
\hline Asphalt Binder Content & Optimum & Optimum $+0.8 \%$ \\
\hline
\end{tabular}

compaction slope and $\mathrm{N}-\mathrm{SR}_{\max }$ values were also calculated for each specimen. Repeated shear testing at constant height was conducted at $58^{\circ} \mathrm{C}$ on the mixtures.

Indirect tensile strength testing was conducted on each specimen following the recommended procedure from the PTI/AAT research. For this experiment, the IDT strength test was conducted at $34^{\circ} \mathrm{C}$ (which is $20^{\circ} \mathrm{C}$ below the critical high pavement temperature for Lexington, $\mathrm{KY}$ ) at a deformation rate of $3.75 \mathrm{~mm}$ per minute.

Findings: The average test results reported for the sixteen mixtures included volumetric properties, SGC compaction data, RSCH rut depth and IDT strength.

The compaction slope appeared sensitive to aggregate angularity (\% sand) more than any other variable. The data indicated that $\mathrm{N}-\mathrm{SR}_{\max }$ was significantly affected by asphalt binder volume, where higher asphalt binder content resulted in lower N-SR $\mathrm{R}_{\max }$. IDT strength was affected significantly by asphalt binder grade (stiffness), where the higher PG asphalt binder resulted in higher IDT strength. This finding supports the findings of the PTI/AAT research as well as earlier research. Asphalt binder volume did not have a significant effect on the IDT strength, even when the data were separated by asphalt content (i.e., PG 64-22 Optimum data compared to PG 64-22 Optimum-Plus data).

For the sixteen mixtures, the relationship between estimated rut depth from the $\mathrm{RSCH}$ test and compaction slope was non-existent $\left(\mathrm{R}^{2}=0.03\right)$. This was expected since compaction slope was not affected by asphalt binder grade or volume. The relationship between estimated rut depth from the RSCH test and $\mathrm{N}-\mathrm{SR}_{\max }$ was also very weak 
$\left(\mathrm{R}^{2}=0.28\right)$ when all data were included. When just the PG 64-22 mixtures were analyzed in the NCHRP 9-16 research, the relationship was better $\left(\mathrm{R}^{2}=0.44\right)$, but not nearly good enough to use as a predictive relationship. For this reason $\mathrm{N}-\mathrm{SR}_{\max }$ was suggested as a mixture screening tool rather than as a predictor of rutting potential [Anderson, 2002b].

Using these test data, statistical analysis was performed to develop one or more models relating estimated rut depth to $\mathrm{N}-\mathrm{SR}_{\max }$, compaction slope, IDT strength and volumetric parameters. The best model statistically used IDT strength, VMA, and compaction slope, $\mathrm{k}$, as predictor variables with an adjusted $\mathrm{R}^{2}$ of 0.75 .

RutDepth $=-0.0337 S_{t}-4.37 V M A+5.37 k-0.337 V M A * k$

where,

Rut Depth $=$ Estimated rut depth from RSCH test, mm

$\mathrm{S}_{\mathrm{t}}=$ Indirect tensile strength, $\mathrm{kPa}$

$\mathrm{VMA}=$ Voids in mineral aggregate, percent

$\mathrm{k}=$ Compaction slope

The negative coefficient for IDT strength indicates that as expected, predicted rut depth decreases as IDT strength increases. This research showed that, since the data evaluated included a wide range of aggregates, mixture cohesion alone (as indicated by IDT strength) was an inadequate indicator of rutting resistance. Thus, only by simultaneously considering IDT strength, compaction slope, and VMA can an accurate estimate of rutting resistance be obtained [Anderson et al, 2003].

\subsection{CONCLUSIONS}

Based on the literature reviewed, the following conclusions can be made: $\mathrm{N}-\mathrm{SR}_{\max }$ is insensitive to asphalt grade and it demands equipment modification. Compaction provides information on the angle of internal friction, $\varnothing$, but not on cohesion, c. The IDT strength test, provides information on cohesion, specifically asphalt binder stiffness, but not angle of internal friction. Hence, to estimate the rutting potential of asphalt mixtures, it is necessary to consider its cohesion, internal friction, volumetric properties, and IDT strength. None of these mix properties can by itself make an accurate estimate of rut resistance. 


\section{CHAPTER 3: RESEARCH METHODOLOGY}

\subsection{INTRODUCTION}

The main laboratory experiment consisted of determining the effect of compaction parameters, IDT strength of the asphalt mix, and the volumetric properties on the permanent deformation of the asphalt mixture.

Previous research, relating IDT strength to rutting potential of asphalt mixtures, used equipment to estimate IDT strength, which is highly sophisticated and not readily available by highway agencies. Hence, this research also focused on devising a simple "proof" test, which can be easily implemented to evaluate the rutting potential of asphalt mixes. In this research work, Marshall Stabilometer with a modified loading head was used to determine the IDT strength of mixes.

\subsection{EXPERIMENTAL DESIGN}

Five variables each at two levels were selected, such that they provide mixtures with different rutting resistance. Since this research focuses on being implemented by the WVDOH, all materials used are those typically used in West Virginia. Two nominal maximum aggregate sizes, $9.5 \mathrm{~mm}$ and $19 \mathrm{~mm}$, were used for both a coarse and fine gradation. The sand percentage chosen was 0 percent and 40 percent. These percentages are the percent of limestone aggregate, passing the $4.75 \mathrm{~mm}$ sieve, which were replaced with natural sand. The asphalt cement used in the experiments was unmodified PG70-22 and modified PG76-22, and was supplied by Marathon Ashland Petroleum LLC. Two asphalt contents, optimum and optimum plus 0.5 percent was evaluated. The experimental variables and their levels are as indicated in Table 3.1.

With 5 variables and 2 levels each, there were a total of 32 combinations. With 6 pills for APA machine and 2 for IDT test for each combination, totally 256 pills were required. Due to time constraints, the number of pills made was reduced by applying a half fractional factorial experimental design. The resulting matrix is a $2^{5}$ half factorial consisting of 16 cells. The design matrix is shown in Table 3.2. The shaded cells are the mixes that were tested for rutting and indirect tensile strength of asphalt mixtures. 
Table 3.1 Experimental Variables and Levels

\begin{tabular}{|l|l|l|}
\hline & \multicolumn{2}{|c|}{ Levels } \\
\hline Variables & Low & High \\
\hline Aggregate Gradation & Coarse & Fine \\
\hline NMAS & $19 \mathrm{~mm}$ & $9.5 \mathrm{~mm}$ \\
\hline Sand Content, \% & $0 \%$ & $40 \%$ \\
\hline Binder Content & Optimum & Optimum plus 0.5\% \\
\hline Binder Grade & PG76-22 & PG70-22 \\
\hline
\end{tabular}

Table 3.2 Experimental Matrix -Half Fractional Factorial

\begin{tabular}{|c|c|c|c|c|c|c|c|c|c|}
\hline \multirow{2}{*}{\multicolumn{2}{|c|}{$\begin{array}{c}\text { Gradation } \\
\text { NMAS }\end{array}$}} & \multicolumn{4}{|c|}{ Coarse } & \multicolumn{4}{|c|}{ Fine } \\
\hline & & \multicolumn{2}{|c|}{$9.5 \mathrm{~mm}$} & \multicolumn{2}{|c|}{$19 \mathrm{~mm}$} & \multicolumn{2}{|c|}{$9.5 \mathrm{~mm}$} & \multicolumn{2}{|c|}{$19 \mathrm{~mm}$} \\
\hline \multicolumn{2}{|c|}{ Sand \% } & 0 & 40 & 0 & 40 & 0 & 40 & 0 & 40 \\
\hline $\begin{array}{l}\text { Binder } \\
\text { Grade }\end{array}$ & $\begin{array}{l}\text { Binder } \\
\text { Volume }\end{array}$ & & & & & & & & \\
\hline \multirow{2}{*}{$76-22$} & Opti & $1^{*}$ & 2 & 3 & 4 & 5 & 6 & 7 & 8 \\
\hline & $\mathrm{Opti}^{+}$ & 9 & 10 & 11 & 12 & 13 & 14 & 15 & 16 \\
\hline \multirow{2}{*}{$70-22$} & Opti & 17 & 18 & 19 & 20 & 21 & 22 & 23 & 24 \\
\hline & $\mathrm{Opti}^{+}$ & 25 & 26 & 27 & 28 & 29 & 30 & 31 & 32 \\
\hline
\end{tabular}

${ }^{*}$ Shaded cells are the mixes that were tested 


\subsection{AGGREGATE PREPARATION}

All limestone aggregates used in this research work were supplied by J.F. Allen Company, Buckhannon, WV. The natural sand was obtained from Martin Marietta Apple Grove quarry, Ohio. The aggregates obtained from the supplier were air dried and sieved using the following set of sieves: $37.5 \mathrm{~mm}, 25 \mathrm{~mm}, 19 \mathrm{~mm}, 12.5 \mathrm{~mm}, 9.5 \mathrm{~mm}$, $4.75 \mathrm{~mm}, 2.36 \mathrm{~mm}, 1.18 \mathrm{~mm}, 0.6 \mathrm{~mm}, 0.3 \mathrm{~mm}$ and $0.075 \mathrm{~mm}$. All aggregates larger than $1.18 \mathrm{~mm}$ were washed to take off the fines, oven dried and stored in respective bins.

\subsubsection{Aggregate Gradation}

The aggregate blend used by J. F. Allen Company was used as a starting point and thereafter blends for $9.5 \mathrm{~mm}$ and $19 \mathrm{~mm}$ NMAS was designed for both coarse and fine gradation. The blend was designed such that:

* Gradation curve is within the control points

* Maximum separation is achieved between the coarse and the fine gradation and

* The gradation could be achieved by blending the stockpiles

* Dust is kept minimum, in order to increase the VMA

Gradation curves for $9.5 \mathrm{~mm}$ and $19 \mathrm{~mm}$ NMAS are shown in Figure 3.1 and 3.2 respectively, while gradations are summarized in Table A1 to Table A4 in Appendix A. 


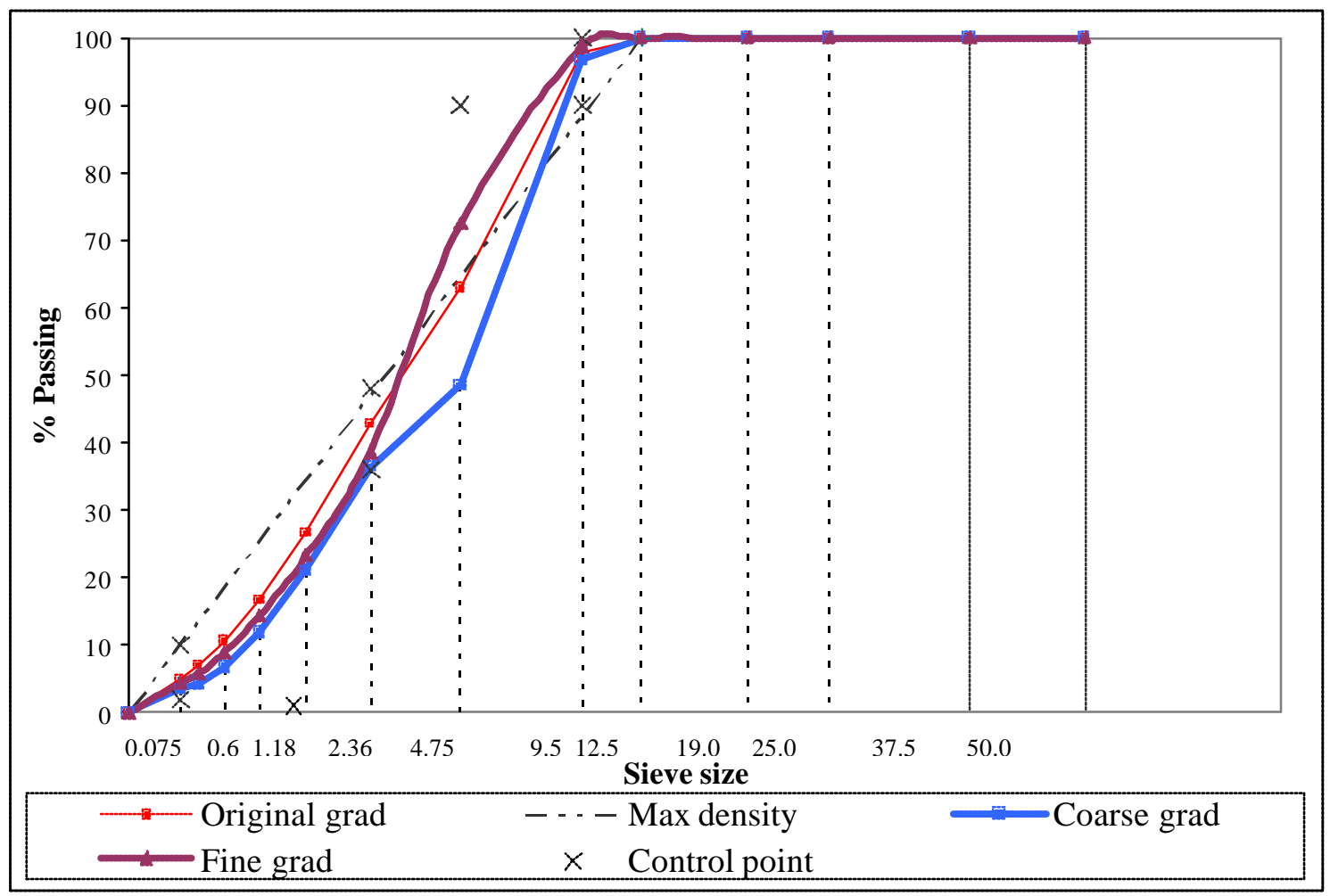

\section{Figure 3.1 Gradation Curve for 9.5 mm NMAS}

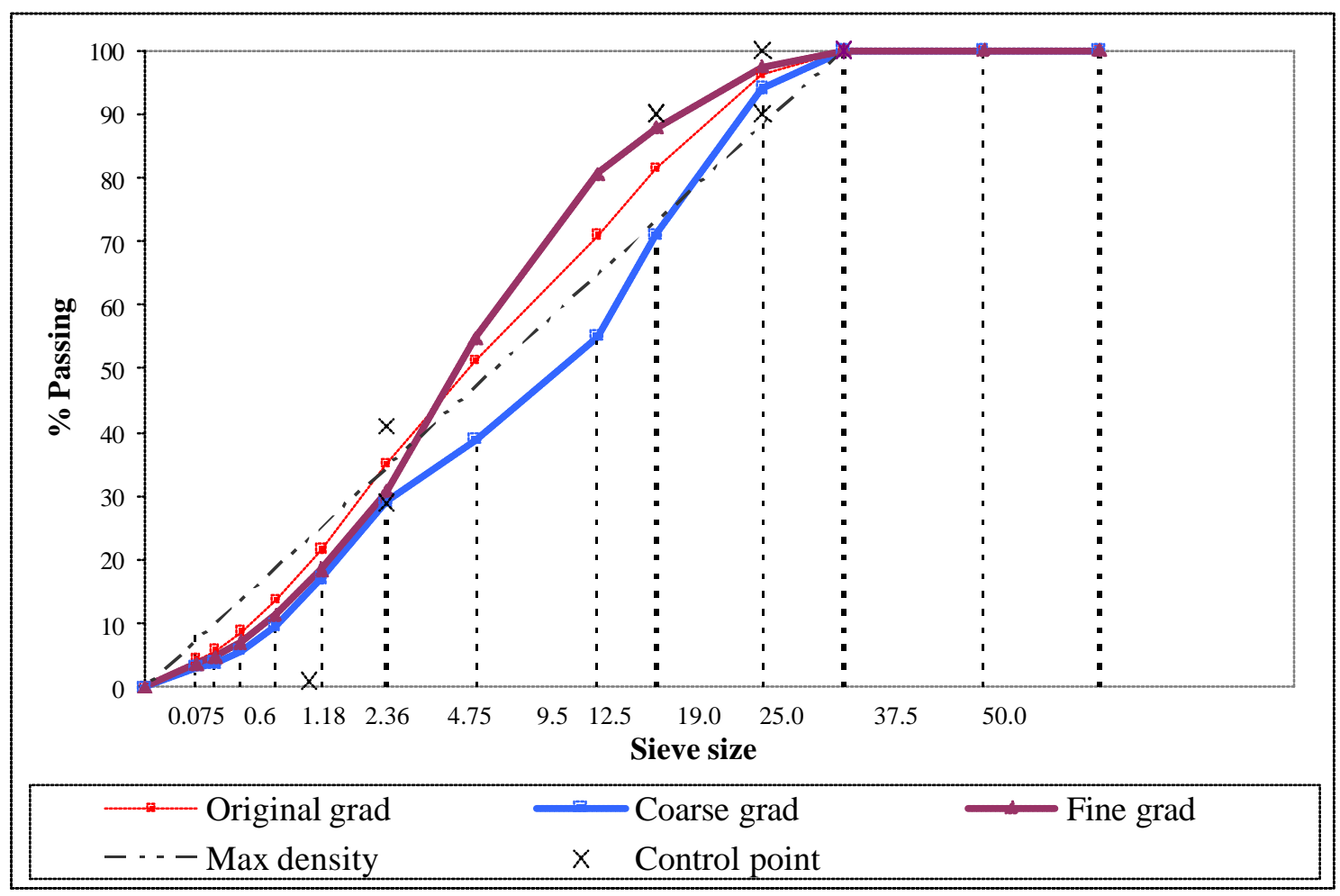

Figure 3.2 Gradation Curve for 19 mm NMAS 


\subsubsection{Aggregate Specific Gravity}

Specific Gravity and water absorption were measured for Limestone Coarse, fine and Natural sand (AASHTO T 84 for coarse aggregate and AASHTO T 85 for fine aggregate). The blending equation was then used to determine the specific gravity of the aggregate blend.

$$
G=\frac{100}{\left(\left(P_{1} / G_{1}\right)+\left(P_{2} / G_{2}\right)+\ldots+\left(P_{n} / G_{n}\right)\right)}
$$

where,

$\mathrm{G}=$ Specific gravity of the blend

$\mathrm{G}_{1}, \mathrm{G}_{2}, \mathrm{G}_{3} \ldots \mathrm{G}_{\mathrm{n}}=$ specific gravity values for fractions $1,2,3 \ldots \mathrm{n}$

$\mathrm{P}_{1}, \mathrm{P}_{2}, \mathrm{P}_{3} \ldots \mathrm{P}_{\mathrm{n}}=$ weight percentages of fraction $1,2,3 \ldots \mathrm{n}$

The bulk and apparent specific gravity of each blend is given in Table 3.3.

Table 3.3 Specific Gravity of the Blend

\begin{tabular}{|c|c|c|c|c|}
\hline \multicolumn{2}{|l|}{ Specific Gravity } & $\mathrm{G}_{\mathrm{sa}}$ & $\mathrm{G}_{\mathrm{sb}}$ \\
\hline \multirow{3}{*}{$9.5 \mathrm{~mm}$} & \multirow{3}{*}{ Coarse } & $0 \%$ sand & 2.759 & 2.615 \\
\cline { 3 - 5 } & & $40 \%$ sand & 2.752 & 2.619 \\
\cline { 3 - 5 } & \multirow{3}{*}{ Fine } & $0 \%$ sand & 2.747 & 2.583 \\
\cline { 3 - 5 } & & $40 \%$ sand & 2.736 & 2.589 \\
\hline \multirow{3}{*}{$19 \mathrm{~mm}$} & \multirow{3}{*}{ Coarse } & $0 \%$ sand & 2.763 & 2.628 \\
\cline { 3 - 5 } & & $40 \%$ sand & 2.735 & 2.631 \\
\cline { 3 - 5 } & \multirow{2}{*}{ Fine } & $0 \%$ sand & 2.728 & 2.607 \\
\cline { 3 - 5 } & & $40 \%$ sand & 2.690 & 2.611 \\
\hline
\end{tabular}




\subsection{PREPARATION}

Once the blend gradation was decided and the specific gravity of aggregates was determined, weigh-out tables were prepared for a trial binder content. The optimum asphalt content, as obtained by the contractor, was used as the starting binder content. The required amount of aggregates weighed close to $0.1 \mathrm{~g}$ was heated to the mixing temperature in the oven. Asphalt cement was also heated to the same temperature. A mechanical bucket mixer was used to make the mix. Prior to mixing, the bucket and the paddle were sufficiently heated. The heated aggregates were added into the bucket, required amount of binder was also weighed in, and the material was mixed until the aggregates were uniformly coated with asphalt. Care was taken to see that not more than $5 \mathrm{~g}$ of the material was lost in the bucket or the paddle.

With a view of reducing the variability in the way the mix was prepared, the material for both volumetric pills and that for finding the theoretical maximum specific gravity was batched and mixed at one time. The mixed material was then quartered and $4800 \mathrm{~g}$ was weighed in to pre-heated pans, for volumetric pills and minimum of $1800 \mathrm{~g}$ for the Rice test. These pans were then placed in the oven for two hours, which was maintained at the maximum compacting temperature. The mix was stirred after one hour. The mixing and compacting temperatures varies with the binder grade and is as specified in Table 3.4 .

\section{Table 3.4 Mixing and Compaction Temperatures}

\begin{tabular}{|c|c|c|c|c|}
\hline \multirow{2}{*}{ Binder Grade } & \multicolumn{2}{|c|}{ Mixing Temp, $\left({ }^{\circ} \mathrm{C}\right)$} & \multicolumn{2}{c|}{ Compaction Temp, $\left({ }^{\circ} \mathrm{C}\right)$} \\
\cline { 2 - 5 } & Min & Max & Min & Max \\
\hline PG70 - 22 & 159 & 165 & 148 & 153 \\
\hline PG76-22 & 156 & 167 & 147 & 158 \\
\hline
\end{tabular}

After curing in the oven for 2 hours, the mix was transferred to a preheated gyratory mold. The mold was then placed in a gyratory compactor and appropriate amount of compaction was applied i.e., the machine was set to 100 gyrations for the pills used for volumetric analysis, while for APA and IDT strength test samples, the mix was compacted until a height of $75 \mathrm{~mm}$ was attained. During the compaction of volumetric 
pills, the height of the specimen at the $8^{\text {th }}\left(\mathrm{N}_{\text {initial }}\right)$ and the $100^{\text {th }}\left(\mathrm{N}_{\text {design }}\right)$ gyration was noted for computing the compaction slope. When the APA and IDT strength pills were made, the number of gyrations required in attaining a height of $75 \mathrm{~mm}$ was noted.

\subsection{VOLUMETRIC ANAL YSIS}

The pills compacted to 100 gyrations were used for further volumetric analysis. They were allowed to cool. Weight in air, weight in water and saturated surface dry weight were taken to compute the bulk specific gravity of the mix (AASHTO T166). Using the following set of equations, the maximum theoretical specific gravity and the bulk specific gravity of the mix, the volumetric properties of the asphalt mix were evaluated.

$\% G_{m m, N d e s}=\frac{G_{m b}}{G_{m m}}$
$G_{s e}=\frac{1-P_{b}}{\frac{1}{G_{m m}}-\frac{P_{b}}{G_{b}}}$

$P_{b a}=100\left(\frac{G_{s e}-G_{s b}}{G_{s b}\left(G_{s e}\right)} G_{b}\right)$

$P_{b e}=P_{b}-P_{b a}\left(1-P_{b}\right)$

$\frac{d}{B}=\frac{\left(\frac{\% P_{\# 200}}{100}\right)}{P_{b e}}$

$V T M=1-\frac{G_{m b}}{G_{m m}}$

$V M A=100\left(1-\frac{G_{m b}\left(1-P_{b}\right)}{G_{s b}}\right)$

$V F A=100\left(\frac{V M A-V T M}{V M A}\right)$ 
where,

$\% \mathrm{G}_{\mathrm{mm}, \mathrm{Ndes}}=$ Percent of maximum specific gravity at design number of revolutions;

$\mathrm{G}_{\mathrm{mb}}=$ Bulk specific gravity;

$\mathrm{G}_{\mathrm{mm}}=$ Maximum specific gravity;

$\mathrm{G}_{\mathrm{se}}=$ Effective specific gravity of aggregate;

$\mathrm{P}_{\mathrm{b}}=$ Percent binder;

$\mathrm{G}_{\mathrm{b}}=$ Specific gravity of the binder;

$\mathrm{P}_{\mathrm{ba}}=$ Percent binder absorbed;

$\mathrm{G}_{\mathrm{sb}}=$ Bulk specific gravity of aggregate;

$\mathrm{P}_{\mathrm{be}}=$ Effective percent binder;

$\% \mathrm{P}_{\# 200}=$ Percent of the aggregate blend passing the \#200 sieve;

$\% \mathrm{G}_{\mathrm{mm} \text {,Nini }}=$ Percent of maximum specific gravity at initial number of revolutions;

$\mathrm{h}_{\mathrm{des}}=$ Height at the design number of revolutions;

$\mathrm{h}_{\text {ini }}=$ Height at the initial number of revolutions;

$\mathrm{VTM}=$ Air voids in compacted mixture;

$\mathrm{VMA}=$ Volume of voids in mineral aggregates; and

$\mathrm{VFA}=$ Voids filled with asphalt.

\subsection{COMPACTION SLOPE}

Compaction slope was computed after the volumetric pills were compacted in the SGC. During compaction, the height of the specimen at $\mathrm{N}_{\text {ini }}$ and $\mathrm{N}_{\text {des }}$ was noted and compaction slope, $\mathrm{k}$, was computed using the Equation 2.5 through 2.7.

\subsection{EVALUATION OF RUTTING POTENTIAL USING APA}

Asphalt Pavement Analyzer (Pavement Technology, INC) was used to evaluate the rutting potential of asphalt mixtures. The weight of material for making the specimens for the APA machine was obtained from the theoretical maximum specific gravity, $\mathrm{G}_{\mathrm{mm}}$, of the mix. The weight for the sample was estimated taking into consideration the volume of the specimen to be compacted. The following equations were used to estimate the weight required:

$V_{m m}=0.93 * V_{c}$

$V_{c}=\pi * R^{2} * H$ 
$W_{m}=V_{m m} / G_{m m}$

where,

$\mathrm{V}_{\mathrm{mm}}=$ Volume of the mix;

$\mathrm{V}_{\mathrm{c}}=$ Gross volume of the sample;

$\mathrm{R}=$ Radius of the mold;

$\mathrm{H}=$ Height of the sample;

$\mathrm{W}_{\mathrm{m}}=$ Weight of the mix;

$\mathrm{G}_{\mathrm{mm}}=$ Theoretical maximum specific gravity of the mix;

Since the target air voids for the APA sample is $7 \pm 0.5 \%$, those specimens out of this air void range were discarded and more specimens were made to replace them. About $30 \%$ of the samples made were discarded due to unacceptable void content.

This research involved 32 mixes. After applying half fractional factorial, 16 of the 32 mixes were tested. Six specimens of $150 \mathrm{~mm}$ diameter and $75 \mathrm{~mm}$ tall were made for each of these 16 combinations. During each run of the machine the six specimens tested were for one experimental combination as defined in Section 3.2. The order in which these combinations were tested was randomized and is shown in Table 3.5.

Table 3.5 Randomization for APA Testing

\begin{tabular}{|c|c|c|c|c|c|c|c|c|c|}
\hline \multirow{3}{*}{\multicolumn{2}{|c|}{\begin{tabular}{|c|} 
Gradation \\
NMAS \\
Sand \%
\end{tabular}}} & \multicolumn{4}{|c|}{ Coarse } & \multicolumn{4}{|c|}{ Fine } \\
\hline & & \multicolumn{2}{|c|}{$9.5 \mathrm{~mm}$} & \multicolumn{2}{|c|}{$19 \mathrm{~mm}$} & \multicolumn{2}{|c|}{$9.5 \mathrm{~mm}$} & \multicolumn{2}{|c|}{$19 \mathrm{~mm}$} \\
\hline & & 0 & 40 & 0 & 40 & 0 & 40 & 0 & 40 \\
\hline \multicolumn{10}{|c|}{ Binder Grade } \\
\hline \multirow{2}{*}{$76-22$} & Opti & 2 & & & 3 & & 8 & 5 & \\
\hline & $\mathrm{Opti}^{+}$ & & 12 & 9 & & 14 & & & 15 \\
\hline \multirow{2}{*}{$70-22$} & Opti & & 4 & 1 & & 6 & & & 7 \\
\hline & Opti ${ }^{+}$ & 10 & & & 11 & & 16 & 13 & \\
\hline
\end{tabular}

All samples were tested at $60^{\circ} \mathrm{C}$ with a hose pressure of $100 \mathrm{psi}$ and a wheel load of 100 lbs. After 8000 load applications, rut depths were measured with a rut depth 
measurement template and a Digimatic depth gauge, at the front and back of each specimen. The Digimatic depth gauge can measure a maximum rut depth of $13.66 \mathrm{~mm}$. In cases where the rut depth was greater than $13.66 \mathrm{~mm}$, a simple bridge, fabricated in the West Virginia Asphalt Technology laboratory was used. The rut depth of six specimens belonging to one type of mix was averaged to the nearest $0.1 \mathrm{~mm}$ and reported as the rut depth for that mix. Figure 3.3 shows typical rut depths.
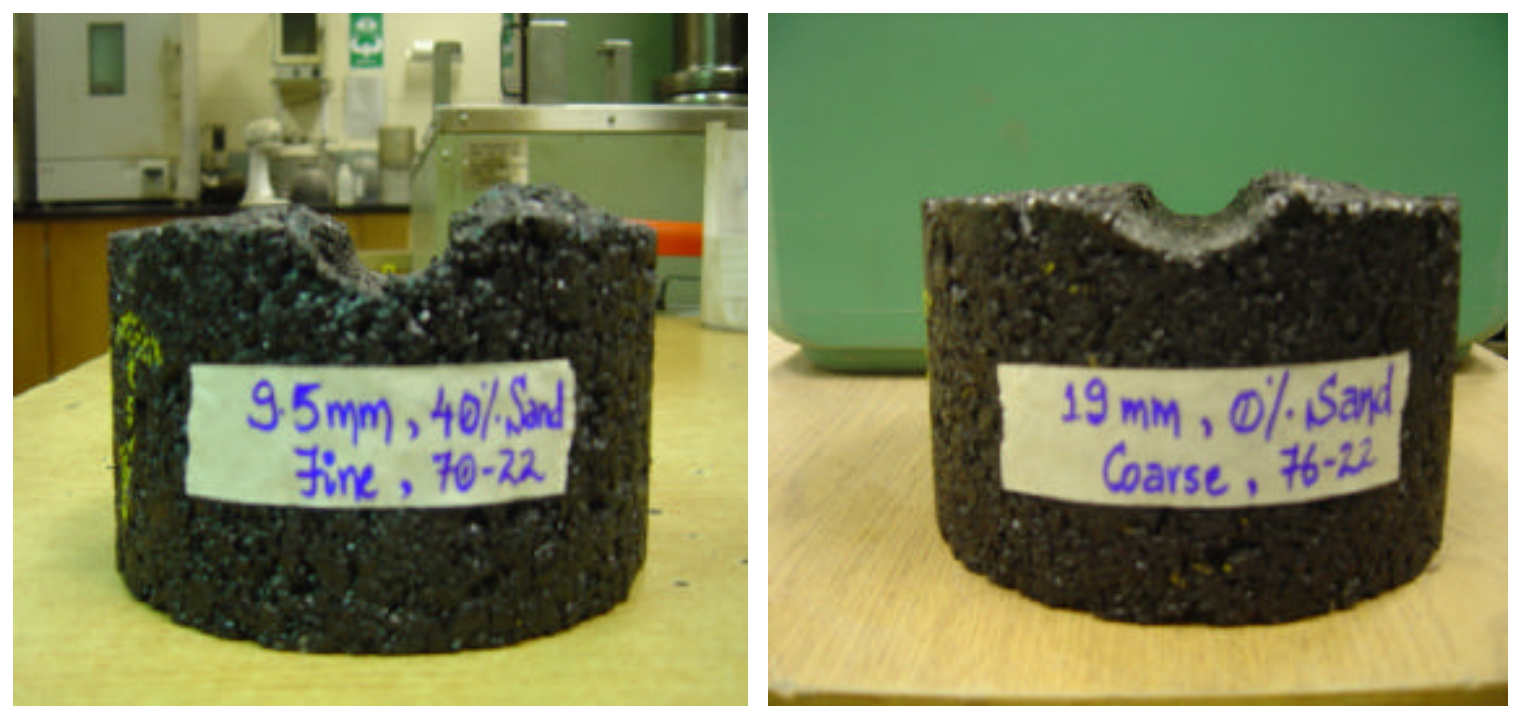

\section{Figure 3.3 Typical Rut Depths}

\subsection{INDIRECT TENSILE STRENGTH TEST}

With a view of maintaining consistency in making the samples, dimensions of the pills for IDT strength test were kept similar to the APA pills, i.e. 2 specimens of $150 \mathrm{~mm}$ diameter and $75 \mathrm{~mm}$ tall were made for each of the 16 mixes using a Superpave Gyratory Compactor. Based on the theoretical maximum specific gravity of the mix, $\mathrm{G}_{\mathrm{mm}}$, and the target air voids of $7 \pm 0.5 \%$, the weight of material was estimated.

Prior to testing, the samples were heated in a constant temperature water bath at $60^{\circ} \mathrm{C}$ for one hour and 15 minutes. This time was selected based on the ratio of the volume of the IDT strength sample to the volume of a Marshall sample multiplied by the standard conditioning time of one half hour used for Marshall stability testing.

A test temperature of $60^{\circ} \mathrm{C}$ was selected based on:

Anderson et al [2002] tested samples at $34^{\circ} \mathrm{C}$ with a load rate of 3.75 $\mathrm{mm} / \mathrm{min}$. Since the Marshall stability tests at $50 \mathrm{~mm} / \mathrm{min}$, the test 
temperature should be greater than that used by Anderson. Time temperature shift factors could be used to estimate a test temperature for the stabilometer load rate, but this was not estimated.

$60^{\circ} \mathrm{C}$ is the standard temperature for Marshall stability testing.

Proof testing demonstrated that the Marshall stabilometer could reliably measure the split tensile strength of the samples at this temperature.

The specimen was taken out of the water bath, and tested immediately in the Marshall Stabilometer with a modified loading head and at a deformation rate of $50 \mathrm{~mm} / \mathrm{min}$. The load was applied parallel to and along the vertical diametral plane.
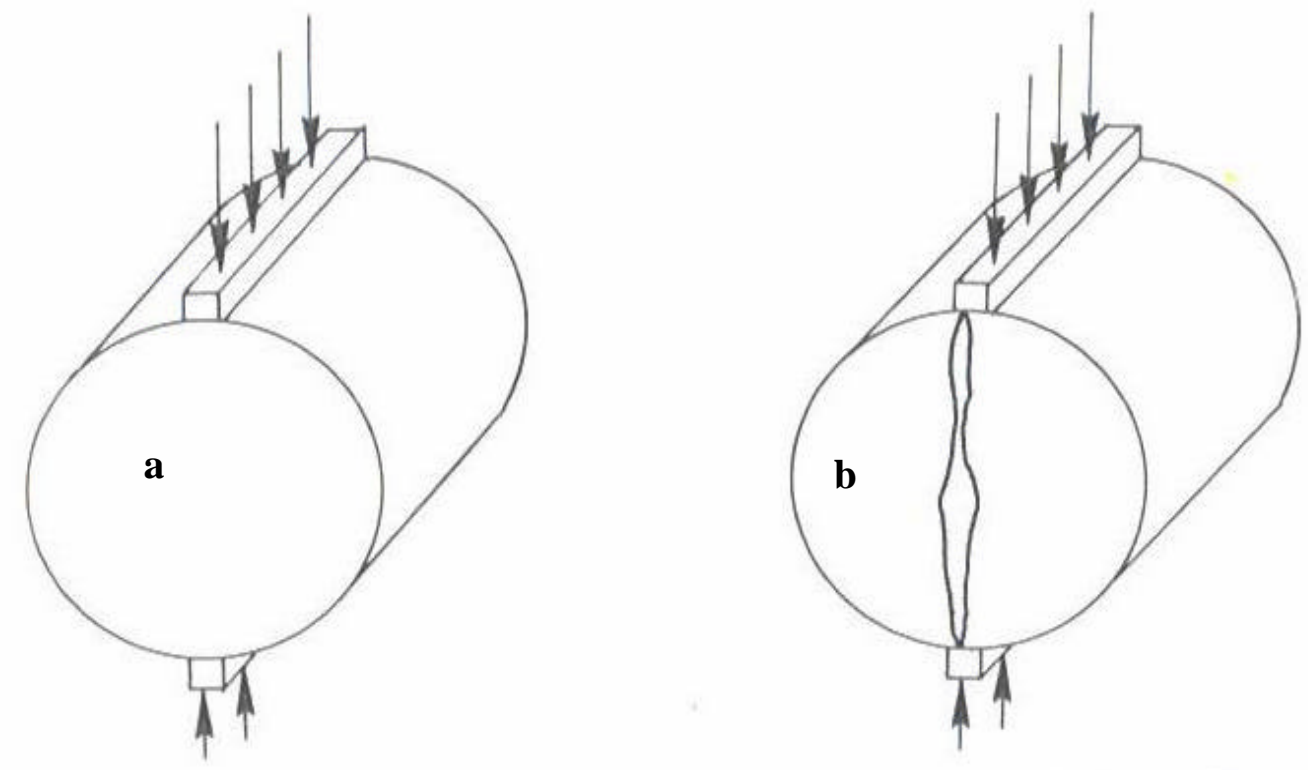

Figure 3.4 Indirect Tensile Strength Test a) loading mode, b) failure plane

This loading configuration developed a relatively uniform tensile stress perpendicular to the direction of the applied load and along the vertical diametral plane. Thus, the specimen failed by splitting along the vertical diameter as shown in Figure 3.4b. Figure 3.5 shows the laboratory test setup for the IDT strength test.

From the plot of load versus deformation, maximum load carried by the specimen was found, and Equation 3.13 was used to determine the indirect tensile stress at failure. IDT stress for the two specimens was averaged and reported as the IDT strength of the mix. A typical plot of load versus deformation is shown in Figure A1 in Appendix A. 
$\sigma_{x}=\frac{2 P}{\pi d t}$

where,

$\mathrm{S}_{\mathrm{x}}=$ Horizontal tensile stress at center of specimen, psi;

$\mathrm{P}=$ Applied load, lbs;

$\mathrm{d}=$ Diameter of the specimen, inches;

$\mathrm{t}=$ Thickness of the specimen, inches;
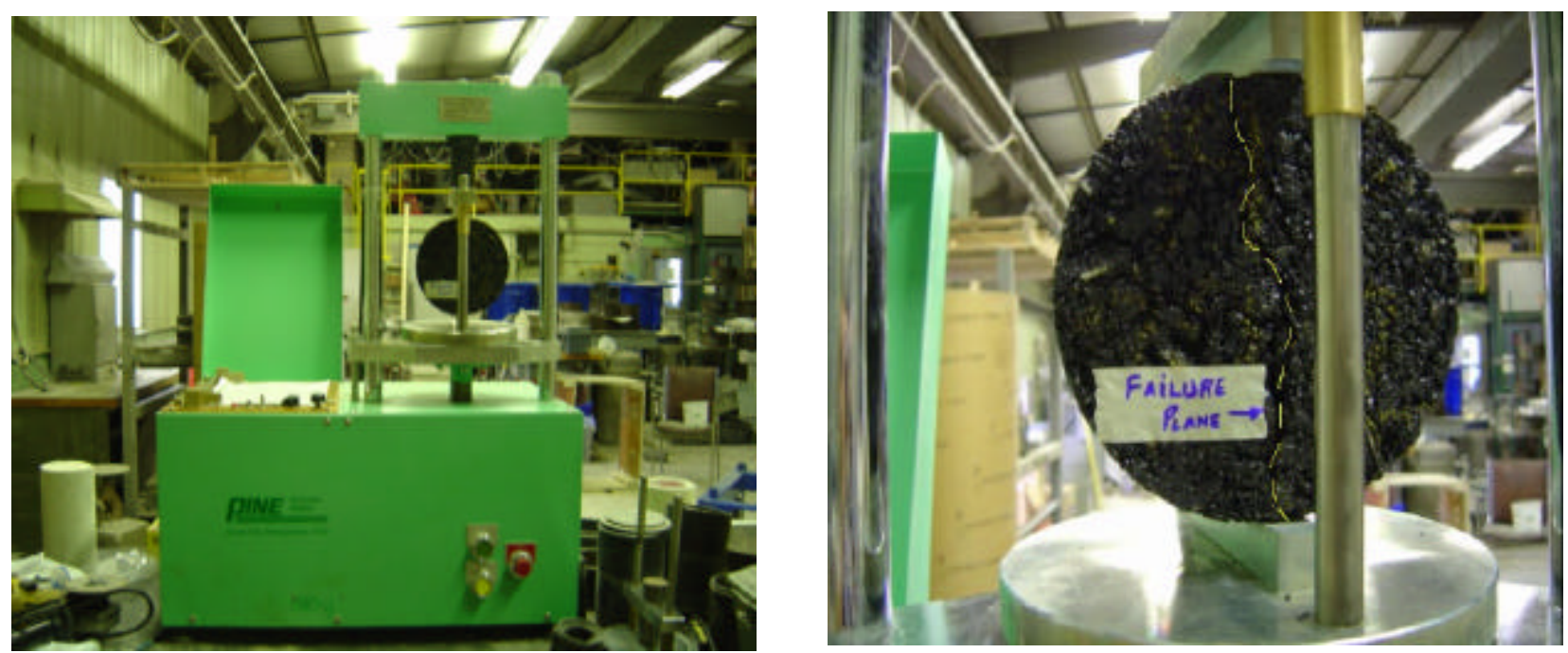

Figure 3.5 IDT Strength Test Setup and Failure Plane

\subsection{COMPACTED AGGREGATE RESISTANCE TEST}

The samples for the CAR test were prepared to the gradations used for the mix designs using only the material passing the $2.36 \mathrm{~mm}$ sieve. Eleven hundred grams of the material passing $2.36 \mathrm{~mm}$ were weighed to the nearest $0.1 \mathrm{~g}$. This was uniformly mixed with 3.5 percent water by dry weight of the sample. After 15 to 19 hours of soaking, these samples were compacted using the Pine Automatic Marshall compactor, giving 50 blows on just one side of the sample. The CAR values were measured using a Pine Stabilometer. Since none of these mixes demonstrated a peak force, the force at 0.25 inches of penetration was reported as the CAR force. A typical plot of load versus deformation is shown in Figure A2 in Appendix A 


\section{CHAPTER 4: RESULTS AND ANALYSIS}

The data reported in Chapter 3 was used for analysis. To start with, 16 mixes involved in the experimental design were evaluated for their volumetric properties. Once the optimum asphalt content was determined, APA and IDT strength pills were made at these asphalt contents. Design Expert 6.0 was used to perform the fractional factorial design and to determine the significant factors that affect rutting and IDT strength of asphalt mixtures. An attempt was also made to understand if there exists any relationship between the rutting potential and the indirect tensile strength of asphalt mixtures.

\subsection{VOLUMETRIC PROPERTIES}

Samples were made for $19 \mathrm{~mm}$ and $9.5 \mathrm{~mm}$ NMAS, with the original gradation and contractor specified optimum asphalt content. The results obtained on checking the volumetrics for this asphalt content are compared with the results reported by the contractor for the same asphalt content in Table 4.1. The volumetric properties for the specimens compacted to $\mathrm{N}_{\text {design }}, 100$ gyrations, did not meet the specifications. The air voids was found to be 70 percent below the required 4 percent for $9.5 \mathrm{~mm}$ mixes while close to 38 percent below the criteria for $19 \mathrm{~mm}$ mixes. While the VMA was well below the required minimum value, VFA was on the higher side of the range of 65-75 percent for both gradations.

\section{Table 4.1 Comparison of Volumetric Properties}

\begin{tabular}{|l|c|c|c|c|c|c|}
\hline NMAS & \multicolumn{3}{|c|}{$9.5 \mathrm{~mm}$} & \multicolumn{3}{c|}{$19.0 \mathrm{~mm}$} \\
\hline & Criteria & Contractor & WVU lab & Criteria & Contractor & WVU Lab \\
\hline Pb, \% & - & 5.7 & 5.7 & - & 4.8 & 4.8 \\
\hline VTM, \% & 4.0 & 4.0 & 1.2 & 4.0 & 4.0 & 2.5 \\
\hline VMA, \% & 15 min & 15.5 & 13.7 & 13 min & 14.0 & 12.5 \\
\hline VFA, \% & $65-75$ & 74.0 & 91.2 & $65-75$ & 71.0 & 80.0 \\
\hline
\end{tabular}

Samples were made for various asphalt contents to determine the optimum asphalt content. However, it was not possible to increase the VMA above the minimum required 
value. Based on earlier research, an attempt was made to increase VMA, by reducing the dust content. For mixes with 40 percent natural sand, dust from the sand source was reduced to increase the VMA. For instance, for $19 \mathrm{~mm}$ mix with fine gradation and 0 percent sand, reducing the original dust content from 4.5 to 3.6 percent increased the VMA from 11.4 to 14.0 percent. For the same mix with 40 percent sand, reducing dust from the sand source from 1.4 to 0.96 percent increased VMA from 13 to 14.6 percent. The weight of dust that was removed was compensated for by increasing the amount of sand on the other sieves. Table A5 through A8 in Appendix A gives a summary of the various trials made to arrive at the right volumetric properties for $9.5 \mathrm{~mm}$ and $19 \mathrm{~mm}$ NMAS.

\subsection{RESULTS}

\subsubsection{APA Rut Results}

The rutting potential of asphalt mixtures was determined by testing six specimens for each of the 16 mixes in the APA. Table 4.2 shows rut depths and percentage air voids, averaged over six specimens for each of the 16 mixes tested.

\subsubsection{IDT Strength Test Results}

The IDT strength was determined by testing two specimens for each mix as explained in Section 3.7. The average of the two specimens was reported as the IDT strength for that mix. Table 4.2 shows average IDT strength and percentage air voids for the 16 mixtures tested.

\subsubsection{Compaction Slope Computations}

Knowing the height of the pill and $\% \mathrm{G}_{\mathrm{mm}}$ at $\mathrm{N}_{\mathrm{ini}}$, (8 gyrations) and $\mathrm{N}_{\mathrm{des}}(100$ gyrations) compaction slope, $\mathrm{k}$, was computed for the 16 mixtures as discussed in Section 3.6. The test results are summarized in Table 4.2. Compaction slope computations are shown in Table A9 in Appendix A. 
Table 4.2 Average Rut Depths and Percent Air Voids

\begin{tabular}{|c|c|c|c|c|c|}
\hline Mix $^{+}$ & $\begin{array}{c}\text { Air voids, } \\
\%^{*}\end{array}$ & $\begin{array}{c}\text { Rut depth, } \\
\mathrm{mm}\end{array}$ & $\begin{array}{c}\text { Air voids, } \\
\%^{* *}\end{array}$ & $\begin{array}{c}\text { IDT strength, } \\
\mathrm{psi}\end{array}$ & $\begin{array}{c}\text { Compaction } \\
\text { Slope, } \mathrm{k}\end{array}$ \\
\hline 1 & 6.9 & 5.7 & 6.5 & 14.8 & 9.88 \\
\hline 4 & 6.9 & 5.4 & 6.6 & 12.6 & 8.47 \\
\hline 6 & 7.1 & 8.1 & 7.5 & 10.96 & 8.88 \\
\hline 7 & 6.7 & 5.5 & 6.8 & 13.88 & 9.57 \\
\hline 10 & 6.8 & 8.8 & 6.9 & 10.69 & 8.94 \\
\hline 11 & 6.9 & 5.5 & 7.0 & 15.07 & 10.19 \\
\hline 13 & 7.3 & 7.7 & 7.4 & 12.97 & 9.99 \\
\hline 16 & 6.8 & 10.6 & 6.9 & 10.5 & 8.9 \\
\hline 18 & 7.0 & 12.9 & 7.4 & 9.96 & 8.95 \\
\hline 19 & 7.2 & 10.4 & 7.3 & 11.78 & 9.55 \\
\hline 21 & 7.5 & 12.5 & 7.2 & 12.06 & 10.27 \\
\hline 24 & 6.7 & 18.1 & 6.9 & 8.22 & 8.88 \\
\hline 25 & 6.8 & 11.9 & 6.7 & 9.96 & 10.07 \\
\hline 28 & 6.7 & 12.2 & 6.5 & 9.68 & 9.18 \\
\hline 30 & 7.0 & 23.2 & 7.3 & 6.85 & 8.92 \\
\hline 31 & 7.0 & 12.4 & 6.9 & 8.86 & 9.89 \\
\hline
\end{tabular}

${ }^{+}$Mixture combinations given in Table 3.2

* Percent air voids for the APA pills

**Percent air voids for IDT strength pills

\subsubsection{CAR Test Results}

For each blend of fine aggregates, three specimens were prepared and tested as discussed in Section 3.8. The average of these three results was reported as the CAR value for the mix and is summarized in Table 4.3.

A Plot of CAR force and measured rutting potential is shown in Figure 4.1. There is a general trend for the rutting potential to decrease as CAR force increases, as would be expected. However, the quality of the correlation is too poor to permit the development of predictive equations from this data set. 
Table 4.3 CAR Test Results

\begin{tabular}{|l|c|}
\hline Mix & CAR Force, lbs \\
\hline $9.5 \mathrm{~mm}$, Coarse, 0 \% sand & 3143 \\
\hline $9.5 \mathrm{~mm}$, Coarse, $40 \%$ sand & 2195 \\
\hline $9.5 \mathrm{~mm}$, Fine, 0 \% sand & 3437 \\
\hline $9.5 \mathrm{~mm}$, Fine, 40 \% sand & 2920 \\
\hline $19 \mathrm{~mm}$, Coarse, 0 \% sand & 3842 \\
\hline $19 \mathrm{~mm}$, Coarse, $40 \%$ sand & 2685 \\
\hline $19 \mathrm{~mm}$, Fine, 0 \% sand & 3450 \\
\hline $19 \mathrm{~mm}$, Fine, $40 \%$ sand & 3138 \\
\hline
\end{tabular}

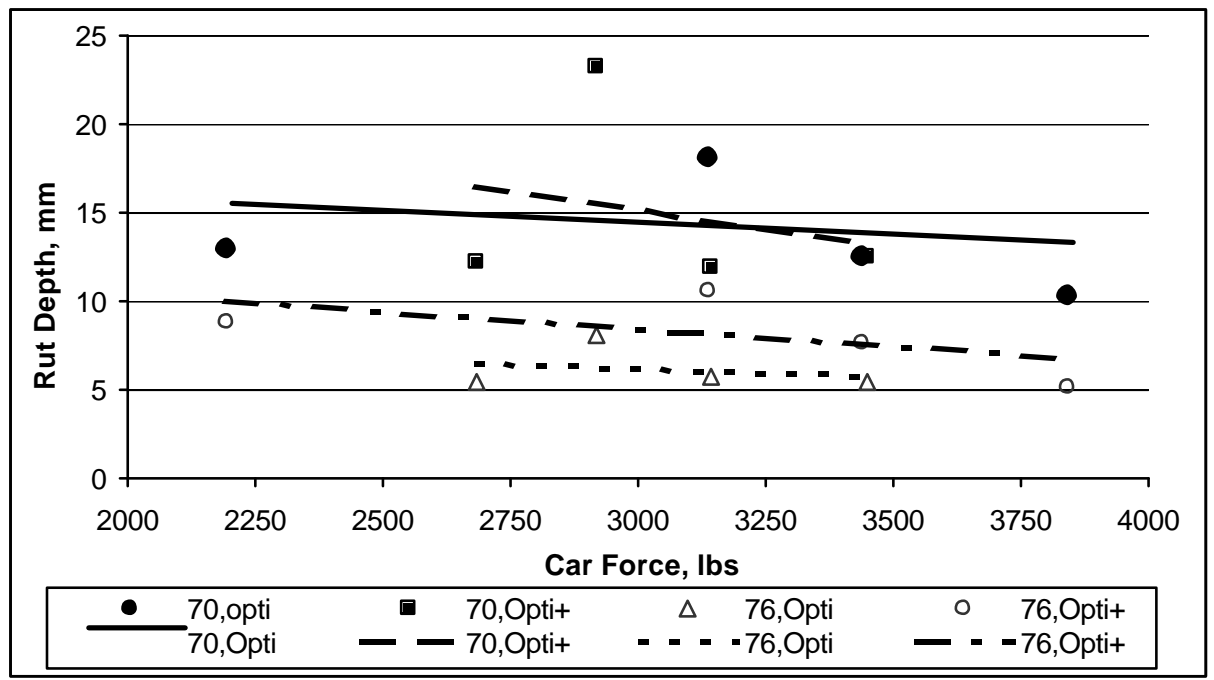

Figure 4.1 Relationship between CAR Force and Rutting Potential

\subsection{ANALYSIS}

\subsubsection{ANOVA of APA Results}

Statistical analysis was conducted using the Design Expert software, to identify the factors that have a significant effect on rutting potential of asphalt mixtures. Value of "probability > F" less than 0.0500 was used as an indication for the existence of a significant effect. The ANOVA results are presented in Table B1 in Appendix B. All five main factors, gradation, NMAS, sand content, binder content and binder grade were 
found to have a significant effect on rutting potential. Interaction of gradation with sand content, gradation with binder grade, NMAS with binder content and sand content with binder grade were the most significant among the two factor interactions.

Among the main effects, binder grade had a significant effect on rutting potential with a "probability $>$ F" value being less than 0.0001 . The average rut depth of mixtures made with PG70-22 asphalt binders was twice as high (14.2 $\mathrm{mm})$ as the average rut depth of mixtures made with PG76-22 asphalt binder $(7.17 \mathrm{~mm})$. The values of "Probability $>F$ " for the factors that have significant effect on estimated rutting potential of asphalt mixtures is shown in Table 4.4.

For the estimated rut depth, two factor interactions can be explained as follows:

* Gradation interaction with sand content: For mixtures with 0 percent sand, the estimated rut depth increased by $2.7 \mathrm{~mm}$, when gradation was changed from coarse to fine. For mixtures with 40 percent sand, the rut depth increased by $6.7 \mathrm{~mm}$, on using fine gradation instead of a coarse gradation. Hence, the effect of gradation was much greater when sand was used.

* Gradation interaction with Binder grade : Changing gradation from coarse to fine increased rut depth by $1.6 \mathrm{~mm}$, when PG76-22 binder was used. But on using the PG70-22 binder, rut depth increased by $4.7 \mathrm{~mm}$. Hence, the effect of gradation was greater when PG70-22 was used.

* NMAS interaction with binder content: For mixtures with $9.5 \mathrm{~mm}$ NMAS, increasing the binder content from optimum to optimum +0.5 percent, increased the rut depth by $3.1 \mathrm{~mm}$. But, for mixes with $19 \mathrm{~mm}$ NMAS, increasing the binder content by 0.5 percent, did not have a significant effect on rut depth $(0.37 \mathrm{~mm})$. Hence, the effect of NMAS is more significant when optimum+ binder content was used.

* Binder grade interaction with sand content: For mixtures with 0 percent sand, the estimated rut depth increased by $7.2 \mathrm{~mm}$ when a PG70-22 asphalt binder was used instead of a PG76-22. Whereas, for mixtures with 40 percent sand, there was a $9.9 \mathrm{~mm}$ increase in rut depth, when a PG70-22 binder grade was used instead of PG76-22. 


\subsubsection{ANOVA of IDT Strength Test Results}

Design Expert was run to identify the factors that have a significant effect on the estimated IDT strength test and the values of "Probability > F" for the factors are shown in Table 4.4. The ANOVA results are summarized in Table B2 in Appendix B.

\section{Table 4.4 Effect of Factors on Rut Depth and IDT Strength}

\begin{tabular}{|l|l|l|}
\hline \multirow{2}{*}{ Factors } & \multicolumn{2}{c|}{ Prob > F } \\
\cline { 2 - 3 } & Rut depth & $\begin{array}{l}\text { IDT } \\
\text { strength }\end{array}$ \\
\hline A-Gradation & 0.001 & 0.0087 \\
\hline B-NMAS & 0.0453 & $0.3842^{*}$ \\
\hline C-Sand Content & 0.0006 & 0.0005 \\
\hline D-Binder Content & 0.016 & 0.0109 \\
\hline E-Binder Grade & $<0.0001$ & 0.0002 \\
\hline AC-Gradation \& Sand content interaction & 0.0089 & $0.5471^{*}$ \\
\hline AE- Gradation \& Binder grade interaction & 0.0255 & $0.8346^{*}$ \\
\hline BD-NMAS \& Binder content interaction & 0.0393 & $0.1003^{*}$ \\
\hline CE- Sand content \& Binder grade interaction & 0.0436 & $0.1624^{*}$ \\
\hline
\end{tabular}

* Non-significant at $95 \%$ confidence interval

The following conclusions were made after carrying out the statistical analysis

* Except for NMAS, the other four main factors had a significant effect on the estimated IDT strength of asphalt mixtures.

* None of the two factor interactions had a significant effect on IDT strength.

* Reducing the sand content from 40 percent to 0 percent, increased the IDT strength by $2.5 \mathrm{psi}$

* IDT strength is significantly affected by asphalt binder grade, where the use of PG76-22 binder instead of PG70-22 increased the IDT strength by 3.01 psi. This confirms the findings of Anderson et al [2003]

* Binder grade having the most significant effect on IDT strength confirms the fact that IDT strength test provides information on mixture cohesion, 
which is a binder property, and not much information on angle of internal friction, which is an aggregate property.

\subsubsection{Regression Analysis}

Following the ANOVA, least-square regression analysis was performed using Microsoft Excel to further explore trends in the data. Figure 4.2 shows the relationship between rutting potential and indirect tensile strength. The resulting equation, as shown

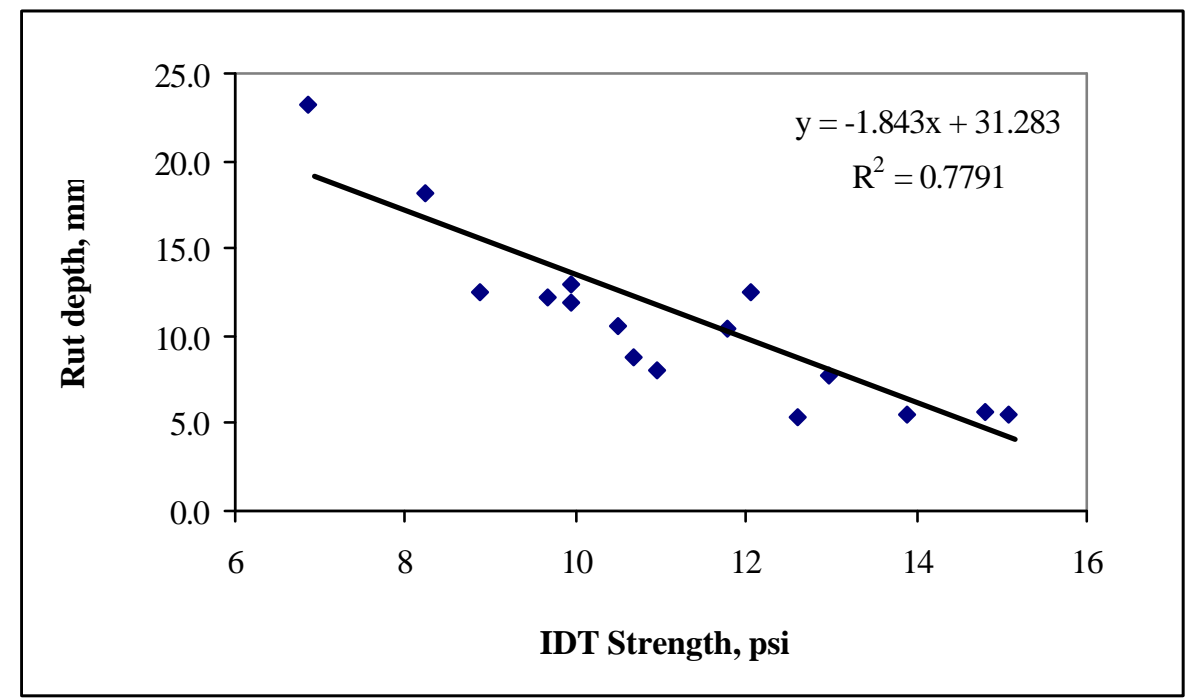

\section{Figure 4.2 Relationship between IDT Strength and Rutting Potential}

in the Figure shows a significant trend between rutting potential and IDT strength. The standard error for this equation was 2.36 and the $\mathrm{R}^{2}$ was 0.78 . Since the ANOVA showed that all the main effect factors had a significant effect on rut depth, a regression model was developed with all of the experiment factors and the indirect tensile strength as the independent variables. The results of this analysis are shown in Table 4.5.

Figure 4.3 shows the relationship between rutting potential and IDT strength with the influence of binder type highlighted. It can be observed that the slope for the trend line for the samples with the PG70-22 binder is similar to the slope for all the data, while the slope of the samples with the PG76-22 binder is much flatter. In other words, the use of modified binder minimized the influence of the other factors on rutting potential. It can also be noted that most of the samples with the modified binder had lower rutting potential than the samples made with the unmodified binder. 
Next the influence of binder content was evaluated. As shown on Figure 4.4, there is no discernable difference between the slope of all the data and the slopes for the samples with optimum binder content and optimum plus 0.5 percent binder content.

Table 4.5 Regression Analysis of Rutting Potential with IDT Strength and Main Experimental Factors.

\begin{tabular}{|c|c|c|c|c|c|}
\hline \multicolumn{2}{|c|}{ Regression Statistics } & & & & \\
\hline Multiple R & 0.93 & & & & \\
\hline R Square & 0.87 & & & & \\
\hline Adjusted R Square & 0.78 & & & & \\
\hline Standard Error & 2.25 & & & & \\
\hline Observations & 16 & & & & \\
\hline \multicolumn{6}{|l|}{ ANOVA } \\
\hline & $\overline{d f}$ & SS & $\overline{\mathrm{MS}}$ & $\bar{F}$ & Significance F \\
\hline Regression & 6 & 306.56 & 51.09 & 10.11 & 0.001 \\
\hline Residual & 9 & 45.50 & 5.06 & & \\
\hline \multirow[t]{2}{*}{ Total } & 15 & 352.06 & & & \\
\hline & Coefficients & Standard Error & t Stat & & \\
\hline Intercept & 16.09 & 9.59 & 1.68 & & \\
\hline IDT & -0.48 & 0.86 & -0.57 & & \\
\hline Gradation & -1.27 & 0.78 & -1.61 & & \\
\hline NMAS & -0.59 & 0.58 & -1.03 & & \\
\hline Sand & 1.14 & 1.20 & 0.95 & & \\
\hline Binder Content & 0.58 & 0.76 & 0.76 & & \\
\hline Binder Grade & -2.79 & 1.41 & -1.98 & & \\
\hline
\end{tabular}

Based on this graph, it was decided to perform a Student $t$ test on the means of the optimum and the optimum plus samples. The computed $t$ statistic is 0.71 ; the critical $t$ value for an alpha level of 95 percent and 14 degrees of freedom is 2.14 . Hence, there is not sufficient evidence to reject the null hypothesis that the means of the two sample sets are equal.

The influence of aggregate characteristics on rutting potential is evaluated in Figure 4.5. The slope of the trend lines for each combination of NMAS, $9.5 \mathrm{~mm}$ and $19 \mathrm{~mm}$ and gradation, coarse versus fine is similar to the slope of the trend line for all data. 


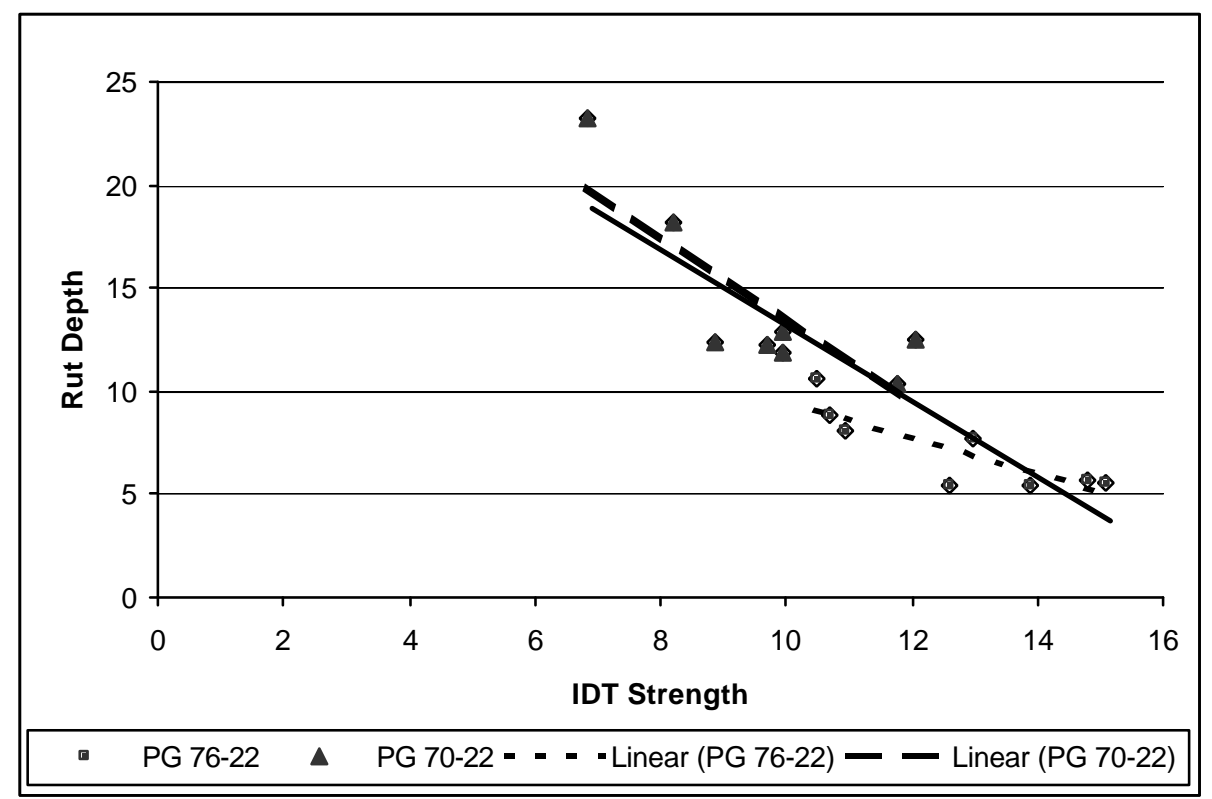

Figure 4.3 Relationship between Rutting Potential and IDT Strength, with Influence of Binder Type

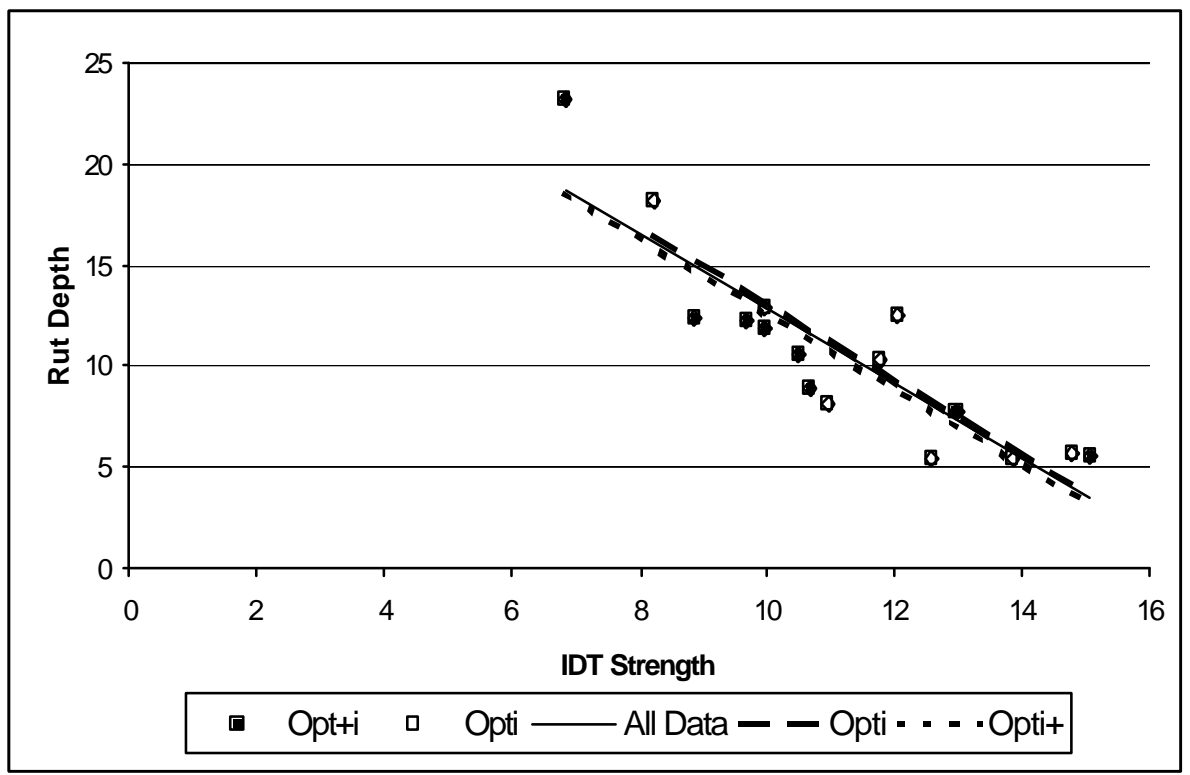

Figure 4.4 Influence of Binder Content on Rutting Potential 


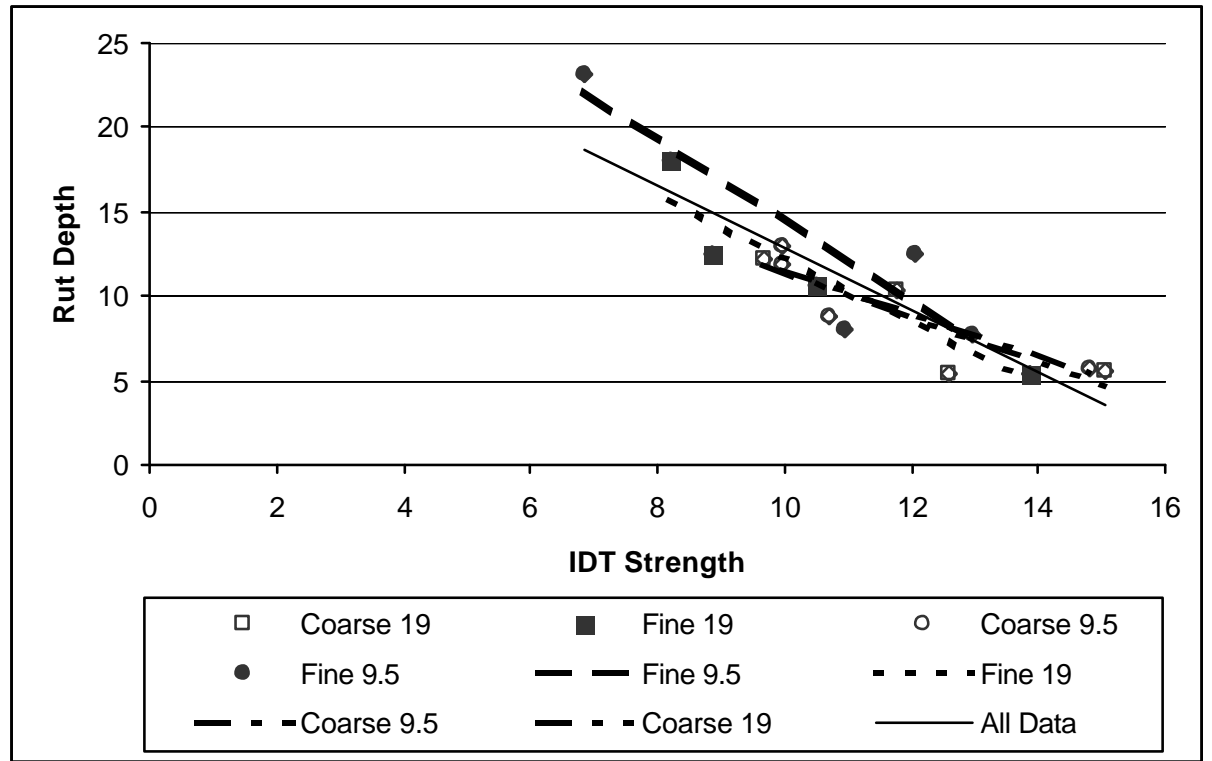

\section{Figure 4.5 Influence of Aggregate Characteristics on Rutting Potential}

The influence of gradation and sand content is shown on Figure 4.6. The slope of the trend lines for the combinations of aggregate and sand content appear different from the trend line for all the data. Since the sand content is known to influence rutting performance, $\mathrm{t}$ tests were preformed to investigate the influence of these parameters. The results of the $t$ tests were:

\begin{tabular}{lccc} 
& $\mathrm{t}$ value & $\mathrm{df}$ & $\mathrm{t}$ crit \\
\hline With sand -No sand & 1.50 & 14 & 2.14 \\
With sand -Binder type & -3.02 & 6 & 2.45 \\
No sand -Binder type & -7.76 & 6 & 2.45
\end{tabular}

The comparison of samples with and without sand indicates there is not sufficient information to reject the null hypothesis of equal means. However, when the data are separated by binder type, analysis indicates the null hypothesis can be rejected. In other words, the main factor of sand content was not significant, but the interaction of sand content and binder type is significant. The ANOVA found both the main factor and interaction terms were significant. The difference in conclusions that can be drawn from the ANOVA and the t test is attributed to the differences in the statistical analysis methods. 


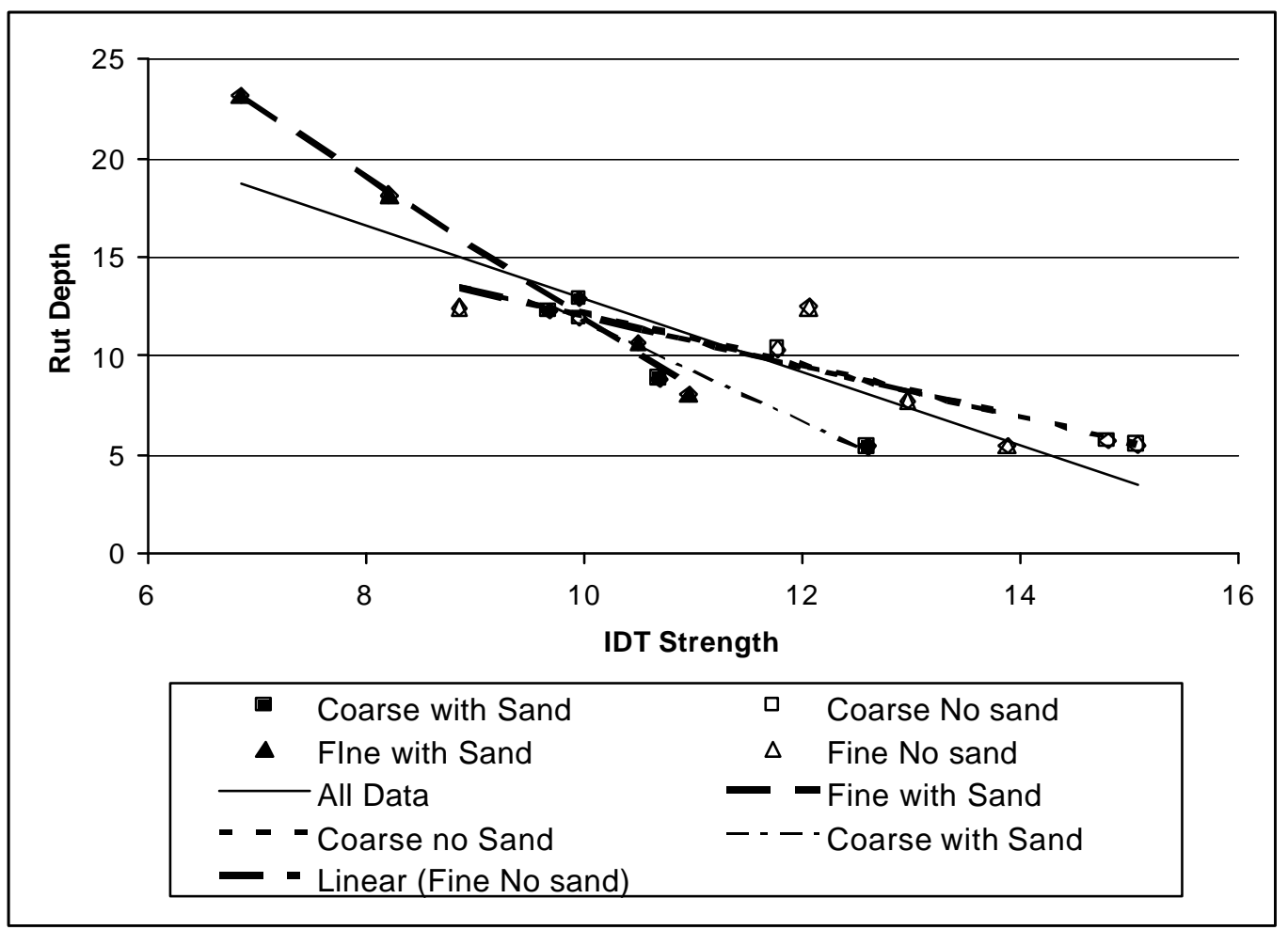

Figure 4.6 Influence of Sand and Gradation on Rutting Potential

\subsection{EVALUATION OF COVARIANT TERMS}

As reviewed in Chapter 2, Anderson et al [2003] found that rutting potential could be estimated from IDT strength, VMA and k. Since these factors were not directly controlled in the experimental design, an ANOVA could not be performed. Therefore, a least-squares regression analysis was performed to evaluate the relationship between these variables and rutting performance. The results of the regression analysis are presented in Table 4.6. The $\mathrm{t}$ test for the coefficients indicates IDT strength and $\mathrm{k}$ were significant and VMA was not significant at the 95 percent confidence level. Therefore, the regression was repeated with only IDT and compaction slope, producing the results in Table 4.7. Figure 4.7 is a plot of the measured and predicted values of rut depths. The line of equality demonstrates the equation does a reasonable job of prediction. The $\mathrm{R}^{2}$ for the equation in Table 4.7 is 0.848 , which compares favorably with Anderson et al [2003]. The sign of the coefficients, positive for $\mathrm{k}$ value and negative for IDT strength 
are the same as found by Anderson et al [2003]. It is not possible to compare the magnitude of the coefficients since the testing methods are different between this research and the previous literature.

Table 4.6 Regression Analysis of Rutting Potential versus IDT Strength, VMA and k

\begin{tabular}{|c|c|c|c|c|c|}
\hline \multicolumn{2}{|c|}{ Regression Statistics } & & & & \\
\hline Multiple R & 0.92 & & & & \\
\hline R Square & 0.85 & & & & \\
\hline Adjusted R Square & 0.81 & & & & \\
\hline Standard Error & 2.11 & & & & \\
\hline Observations & 16 & & & & \\
\hline \multicolumn{2}{|c|}{ ANOVA } & & & & \\
\hline & $d f$ & $S S$ & $M S$ & $F$ & Significance $F$ \\
\hline Regression & 3 & 298.6 & 99.54 & 22.36 & $3.34 \mathrm{E}-05$ \\
\hline Residual & 12 & 53.4 & 4.45 & & \\
\hline \multirow[t]{2}{*}{ Total } & 15 & 352.1 & & & \\
\hline & Coefficients & \begin{tabular}{|c|} 
Standard \\
Error
\end{tabular} & t Stat & & \\
\hline Intercept & 10.4 & 12.63 & 0.82 & & \\
\hline $\mathrm{k}$ & 2.454 & 1.047 & 2.34 & & \\
\hline VMA & -0.0030 & 0.522 & $<0.10$ & & \\
\hline IDT & -2.038 & 0.274 & -7.44 & & \\
\hline
\end{tabular}

Table 4.7 Regression Analysis of Rutting Potential versus IDT Strength, and k

\begin{tabular}{|c|c|c|c|c|c|}
\hline \multicolumn{2}{|c|}{ Regression Statistics } & & & & \\
\hline Multiple R & 0.921 & & & & \\
\hline R Square & 0.848 & & & & \\
\hline $\begin{array}{l}\text { Adjusted R } \\
\text { Square }\end{array}$ & 0.825 & & & & \\
\hline $\begin{array}{l}\text { Standard } \\
\text { Error }\end{array}$ & 2.027 & & & & \\
\hline Observations & 16 & & & & \\
\hline $\mathbf{A N}$ & $\mathbf{V A}$ & & & & \\
\hline & $d f$ & $S S$ & $M S$ & $F$ & Significance $F$ \\
\hline Regression & 2 & 298.630 & 149.315 & 36.329 & $<0.001$ \\
\hline Residual & 13 & 53.431 & 4.110 & & \\
\hline Total & 15 & 352.062 & & & \\
\hline & Coefficients & $\begin{array}{c}\text { Standard } \\
\text { Error }\end{array}$ & t Stat & & \\
\hline Intercept & 10.36 & 8.97 & 1.15 & & \\
\hline$\overline{\mathrm{k}}$ & 2.45 & 1.01 & 2.43 & & \\
\hline IDT & -2.04 & 0.24 & -8.51 & & \\
\hline
\end{tabular}




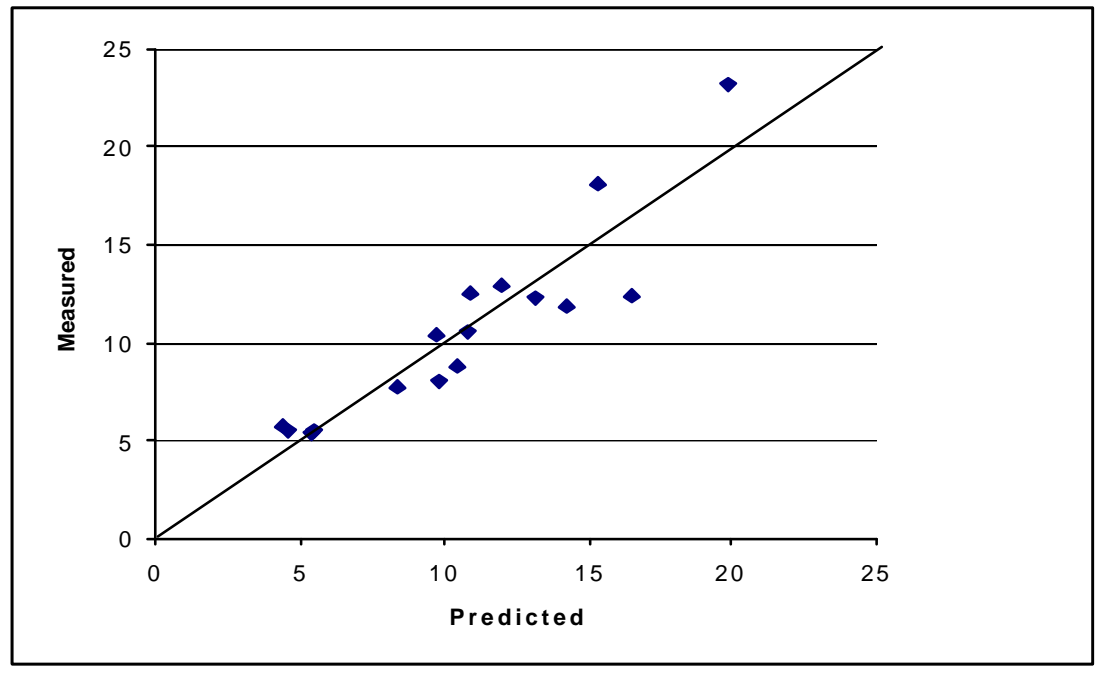

Figure 4.7 Predicted versus Measured Rutting Potential

\subsection{SUMMARY OF RESULTS}

All the five factors considered in the research had a significant effect on rutting potential. Binder grade had the most significant effect based on the Prob $>F$ value of the ANOVA. In addition, the five of the ten two-way interaction effects were significant. The ANOVA for the IDT strength demonstrated all main effects except for NMAS as significant. Since binder grade had the most significant effect on IDT strength, this result agrees with the research presented by Christensen et al [2000] who found that cohesion is linearly related to IDT strength, Figure 2.6, and that cohesion is largely dependent on binder properties and is insensitive to aggregate characteristics. However, the significance of gradation on IDT strength cannot be explained by Christensen's concept of using Mohr's theory.

Rutting potential of asphalt mixtures, as evaluated with the APA, has a strong correlation with its IDT strength as estimated using the Marshall Stabilometer. Anderson et al [2003] found a strong correlation between rutting potential and IDT strength, VMA, and k. But in this research, VMA was not a significant contributor to rutting potential. IDT and compaction slope provided a regression equation with good predictive capability. CAR force indicated a negative slope with rutting potential. 


\section{CHAPTER 5:CONCLUSIONS AND RECOMMENDATIONS}

\subsection{CONCLUSIONS}

This research was based on the hypothesis that the rutting potential of asphalt mixtures evaluated from APA is governed by three main parameters-compaction slope, VMA and IDT strength. As per Anderson et al [2003], IDT strength provides valuable information about the rutting potential of asphalt mixtures. Anderson used RSCH to estimate the rutting potential, which is sophisticated and expensive. APA is widely available in the industry for evaluating the rutting potential of asphalt mixtures. Anderson evaluated the IDT strength at a deformation rate of $3.75 \mathrm{~mm} / \mathrm{min}$, and not many state highway agencies have IDT strength measuring equipment that operates at this deformation rate. For the IDT strength testing procedure to be readily implemented by state highway agencies, there was a need to extend Anderson's work to use equipment readily available to state highway agencies.

The Marshall Stabilometer, with a modified loading head, has a fixed deformation rate of $50 \mathrm{~mm} / \mathrm{min}$ and is widely used to measure the IDT strength for evaluating the stripping behavior of asphalt concrete. The objective of this research was to see if the IDT strength obtained from a Marshall Stabilometer could be used as a simple proof test. Since the loading rate $(50 \mathrm{~mm} / \mathrm{min})$ used in this research was higher than that used by Anderson $(3.75 \mathrm{~mm} / \mathrm{min})$, testing was done at a temperature $\left(60^{\circ} \mathrm{C}\right)$ higher than that adopted by Anderson $\left(34^{?} \mathrm{C}\right)$.

In addition to IDT strength, VMA and compaction slope obtained from SGC were also evaluated to see if rutting potential could be correlated with these parameters of asphalt concrete.

Half fractional factorial was applied and factors that have a significant effect on rut depth and IDT strength were evaluated using Design Expert 6.0. It was found that all main factors were significant in the analysis of rut depth. NMAS was not a significant factor in the analysis of IDT strength. Binder grade had "Probability $>$ F" $<0.0001$ for both rut depth and IDT strength, indicating that it is the most significant factor. Binder

grade having a significant effect on IDT strength, while NMAS being insignificant, is in 
argument with Anderson et al's [2003] assertion that IDT strength is actually an indicator of mixture cohesion and not internal friction.

Statistical models were developed to evaluate the relationship of rut depth with IDT strength, VMA, and compaction slope. The best model statistically was the one that correlated rut depth with IDT strength and compaction slope. In this model, the negative coefficient for IDT strength indicated that as the IDT strength increases, there is a decrease in rut depth. The compaction slope had a positive coefficient, indicating that mixes with more resistance to compaction offer better rutting resistance. Contrary to Anderson's results, VMA was not selected as an independent variable for the final equation. Least squares regression with VMA included demonstrated the coefficient was not statistically significant. This is an apparent contradiction with Anderson's work, however, it should be noted that the range of VMA for the materials studied in this research was very limited and in all cases close to the minimum allowable values. Hence, the failure to find VMA as a significant regression variable could be an artifact of the mixes studied in this research.

\subsection{RECOMMENDATIONS FOR FUTURE STUDY}

This preliminary investigation ind icates that the IDT strength of asphalt concrete, as measured with the Marshall stabilometer at $50 \mathrm{~mm} / \mathrm{min}$ and $60^{\circ} \mathrm{C}$, provides valuable information about the rutting potential of asphalt concrete. However, a considerable amount of further research is needed before the results of this research should be implemented.

Sample dimensions and testing protocol were selected based on convenience rather than scientific principles. In keeping with the requirements that the methodology is restricted to readily available equipment, the parameters of sample diameter $(150 \mathrm{~mm})$ and loading rate $(50 \mathrm{~mm} / \mathrm{min})$ should remain fixed. However, research could be performed to evaluate the selection of other testing parameters, including sample thickness, air voids, and test temperature. The principle of time-temperature superposition could be developed to allow interpretation of results across different testing parameters and there by aid in the selection of loading rate and test temperature.

The inference space of this experiment could be extended by including a wider range of aggregate types, gradations, and sizes. Based on the work of Jahn [2003], it may 
be possible to use the CAR test to evaluate the potential internal friction of an aggregate blend in an asphalt mix as part of the fine aggregate specification. An attempt can be made to see how well the rutting potential of asphalt mixtures correlate with IDT strength, and CAR force. By doing this, in a relatively simple way, it might be possible to evaluate the effect of both cohesion and internal friction on rut resistance.

It has been intrinsically assumed throughout this research that the asphalt pavement analyzer provides reliable information about the rutting potential of asphalt concrete mixes. This assumption is not universally embraced by the paving community. Before the results of this research, or any similar studies of mixture performance, are used for the developments of standards or specifications, there should be field studies of mixture performance to validate the laboratory results. 


\section{REFERENCES}

Anani, A. B., "Laboratory and Field Study of Pavement Rutting in Saudi Arabia", Transportation Research Record, 1259, National Research Council, Washington D.C, 1990, pp 79-90.

Anderson, R.M., Turner, A. P., Peterson, L R., and Mallick, B. R., "Relationship of Superpave Gyratory Compaction Properties to HMA Rutting Behavior", NCHRP Report 478, Transportation Research Board, Washington D.C, 2002a, pp 1-16.

Anderson, R.M., "Relationship between Superpave Gyratory Compaction Properties and the Rutting Potential of Asphalt Mixtures", Asphalt Paving Technology, Association of Asphalt Paving Technologists-Proceedings of the Technical Sessions, Vol - 71, 2002b, pp 207-247.

Anderson, R.M., "Using Superpave Gyratory Compaction Properties to Estimate the Rutting Potential of Asphalt Mixtures", Asphalt Paving Technology, Association of Asphalt Paving Technologists-Proceedings of the Technical Sessions, Vol - 71, 2002c, pp 725-738.

Anderson, R.M., Christensen, W. D., and Bonaquist, R. "Estimating the Rutting Potential of Asphalt Mixtures Using Superpave Gyratory Compaction Properties and Indirect Tensile Strength", Association of Asphalt Paving Technologists-Proceedings of the Technical Sessions, Vol - 72, 2003.

Christensen, W. D., Bonaquist, R., and Jack, D.P., "Evaluation of Triaxial Strength as a Simple Test for Asphalt Concrete Rut Resistance", Final Report, Pennsylvania Department of Transportation, 2000.

Christensen, W. D., and Bonaquist, R., "Use of Strength Tests for Evaluating the Rut Resistance of Asphalt Concrete", Asphalt Paving Technology, Association of Asphalt Paving Technologists-Proceedings of the Technical Sessions, Vol - 71, 2002, pp 692711.

Jahn D. W., “Compacted Aggregate Resistance Test”, Presentation at ICAR, May 2003. http://www.seaupg.org/Media/Agg_Issues_DJahn_02.pdf

McGennis, R. B., Anderson, R. M., Perdomo, D., and Turner, A.P., 'Issues Pertaining to Use of Superpave Gyratory Compactor", Transportation Research Record 1543, Transportation Research Board, National Research Council, Washington D.C, 1996, pp 139-144.

Roque, R., and Buttlar, G. W., "The Development of a Measurement and Analysis System to Accurately Determine Asphalt Concrete Properties Using the Indirect Tensile Mode", Association of Asphalt Paving Technologists-Proceedings of the Technical Sessions, Vol61, 1992, pp 304 - 328.

Sontowski, P., "Better Roads", Proceedings of the ICSM, n - 12, Dec 1995, pp 35-36. 


\section{Specifications and Test Methods}

1. Sieve Analysis, ASTM C136, 1984 Specification for Superpave Volumetric Mix Design, AASHTO MP2, 2001.

2. Specific Gravity and Absorption of Fine Aggregate, AASHTO T84, 2000

3. Specific Gravity and Absorption of Coarse Aggregate, AASHTO T85, 2000

4. Bulk Specific Gravity of Compacted Bituminous Mixtures Using Saturated Surface-Dry Specimens, AASHTO T166, 2000.

5. Theoretical Maximum Specific Gravity and Density of Bituminous Paving Mixtures, AASHTO T209, 1999.

6. West Virginia Division of Highways, Standard Specifications, Charleston, West Virginia, 2000. 


\section{APPENDIX A - TEST RESULTS}

Table A1 Blend Gradation - 9.5mm NMAS - Coarse

\begin{tabular}{|c|c|c|c|c|c|}
\hline Material & $\# 9$ & $\# 1$ & $\# 2$ & Skid(2002) & Blend \\
\hline Sieve size & $0 \%$ & $0 \%$ & $47 \%$ & $53 \%$ & $100 \%$ \\
\hline 9.5 & 100 & 100 & 100 & 94 & 96.8 \\
\hline 4.75 & 75 & 99.8 & 100 & 2.8 & 48.5 \\
\hline 2.36 & 2.5 & 80.9 & 75.5 & 1.6 & 36.3 \\
\hline 1.18 & 1.5 & 50.9 & 43 & 1.5 & 21.0 \\
\hline 0.6 & 1.4 & 32.9 & 23.6 & 1.4 & 11.8 \\
\hline 0.3 & 1.3 & 21.2 & 12.7 & 1.3 & 6.7 \\
\hline 0.15 & 1.3 & 13.6 & 7.6 & 1.3 & 4.3 \\
\hline 0.075 & 1.2 & 9.5 & 6 & 1.1 & 3.4 \\
\hline
\end{tabular}

Table A2 Blend Gradation - 9.5mm NMAS - Fine

\begin{tabular}{|c|c|c|c|c|c|}
\hline Material & $\# 9$ & $\# 1$ & $\# 2$ & Skid(2002) & Blend \\
\hline & $32 \%$ & $25 \%$ & $23 \%$ & $20 \%$ & $100 \%$ \\
\hline 12.5 & 100 & 100 & 100 & 100 & 100.0 \\
\hline 9.5 & 100 & 100 & 100 & 94 & 98.8 \\
\hline 4.75 & 75 & 99.8 & 100 & 2.8 & 72.5 \\
\hline 2.36 & 2.5 & 80.9 & 75.5 & 1.6 & 38.7 \\
\hline 1.18 & 1.5 & 50.9 & 43 & 1.5 & 23.4 \\
\hline 0.6 & 1.4 & 32.9 & 23.6 & 1.4 & 14.4 \\
\hline 0.3 & 1.3 & 21.2 & 12.7 & 1.3 & 8.9 \\
\hline 0.15 & 1.3 & 13.6 & 7.6 & 1.3 & 5.8 \\
\hline 0.075 & 1.2 & 9.5 & 6 & 1.1 & 4.4 \\
\hline
\end{tabular}


Table A3 Blend Gradation - 19mm NMAS - Coarse

\begin{tabular}{|c|c|c|c|c|c|c|}
\hline Material & $\# 1$ & $\# 2$ & $\# 3$ & $\# 4$ & $\# 5$ & Blend \\
\hline Sieve size & $50 \%$ & $13 \%$ & $0 \%$ & $0 \%$ & $37 \%$ & $100 \%$ \\
\hline 25 & 100 & 100 & 100 & 100 & 100 & 100.0 \\
\hline 19 & 88 & 100 & 100 & 100 & 100 & 94.0 \\
\hline 12.5 & 42 & 100 & 100 & 100 & 100 & 71.0 \\
\hline 9.5 & 11 & 96.6 & 100 & 100 & 100 & 55.1 \\
\hline 4.75 & 2 & 6.9 & 75 & 99.8 & 100 & 38.9 \\
\hline 2.36 & 1.9 & 1.6 & 2.5 & 80.9 & 75.5 & 29.1 \\
\hline 1.18 & 1.8 & 1.3 & 1.5 & 50.9 & 43 & 17.0 \\
\hline 0.6 & 1.7 & 1.2 & 1.4 & 32.9 & 23.6 & 9.7 \\
\hline 0.3 & 1.7 & 1.2 & 1.3 & 21.2 & 12.7 & 5.7 \\
\hline 0.15 & 1.6 & 1.2 & 1.3 & 13.6 & 7.6 & 3.8 \\
\hline 0.075 & 1.5 & 1 & 1.2 & 9.5 & 6 & 3.1 \\
\hline
\end{tabular}

Table A4 Blend Gradation - 19mm NMAS - Fine

\begin{tabular}{|c|c|c|c|c|c|c|}
\hline Material & $\# 1$ & $\# 2$ & $\# 3$ & $\# 4$ & $\# 5$ & Blend \\
\hline Sieve size & $21 \%$ & $21 \%$ & $20 \%$ & $16 \%$ & $22 \%$ & $100 \%$ \\
\hline 25 & 100 & 100 & 100 & 100 & 100 & 100.0 \\
\hline 19 & 88 & 100 & 100 & 100 & 100 & 97.5 \\
\hline 12.5 & 42 & 100 & 100 & 100 & 100 & 87.8 \\
\hline 9.5 & 11 & 96.6 & 100 & 100 & 100 & 80.6 \\
\hline 4.75 & 2 & 6.9 & 75 & 99.8 & 100 & 54.8 \\
\hline 2.36 & 1.9 & 1.6 & 2.5 & 80.9 & 75.5 & 30.8 \\
\hline 1.18 & 1.8 & 1.3 & 1.5 & 50.9 & 43 & 18.6 \\
\hline 0.6 & 1.7 & 1.2 & 1.4 & 32.9 & 23.6 & 11.3 \\
\hline 0.3 & 1.7 & 1.2 & 1.3 & 21.2 & 12.7 & 7.1 \\
\hline 0.15 & 1.6 & 1.2 & 1.3 & 13.6 & 7.6 & 4.7 \\
\hline 0.075 & 1.5 & 1 & 1.2 & 9.5 & 6 & 3.6 \\
\hline
\end{tabular}


Table A5 9.5 mm NMAS - 0\% Natural Sand

\begin{tabular}{|c|c|c|c|c|c|c|c|c|c|c|}
\hline \multicolumn{4}{|c|}{} & \multicolumn{3}{c|}{ COARSE } & \multicolumn{5}{c|}{ FINE } \\
\hline & & \multicolumn{2}{|c|}{ Original } & \multicolumn{2}{|c|}{ Lime Stone dust reduced } & \multicolumn{3}{c|}{ Original LS dust reduced } \\
\hline Trial \# & Contractor & Orig 1 & Orig 2 & \multicolumn{2}{|c|}{ Trial 1 } & \multicolumn{2}{|c|}{ Trial 2 } & \multicolumn{2}{|c|}{ Trial 1 } & \multicolumn{2}{c|}{ Trial 2 } & Trial 3 \\
\hline Binder & 70 & 70 & 76 & 70 & 76 & 70 & 70 & 76 & 70 & 70 \\
\hline $\mathrm{P}_{\mathrm{b}}$ & 5.7 & 5.7 & 5.4 & 5.1 & 5.1 & 5.8 & 5.4 & 5.4 & 6.0 & 6.6 \\
\hline VTM & 4.0 & 1.2 & 3.0 & 5.4 & 5.2 & 4.2 & 4.4 & 5.0 & 5.5 & 3.7 \\
\hline VMA & 15.5 & 13.7 & 14.4 & 14.2 & 14.0 & 14.7 & 13.2 & 13.6 & 15.3 & 14.6 \\
\hline VFA & 74.0 & 91.2 & 79.2 & 62.0 & 62.9 & 71.4 & 66.7 & 63.2 & 64.1 & 74.6 \\
\hline Dust \% & 5.2 & 5.2 & 5.2 & 3.6 & 3.6 & 3.4 & 4.4 & 4.4 & 3.8 & 3.8 \\
\hline D/P & - & - & - & 0.92 & 0.92 & 0.74 & 1.16 & 1.16 & 0.88 & 0.81 \\
\hline
\end{tabular}

* with the original gradation and contractor specified optimum asphalt content

Table A6 9.5 mm NMAS - 40\% Natural Sand

\begin{tabular}{|c|c|c|c|c|c|c|c|c|c|c|c|c|c|c|c|c|c|c|c|c|}
\hline & & & \multicolumn{8}{|c|}{ FINE } & \multicolumn{10}{|c|}{ COARSE } \\
\hline & \multirow{2}{*}{\multicolumn{2}{|c|}{$\begin{array}{l}\text { Original } \\
\text { LS dust }\end{array}$}} & \multicolumn{8}{|c|}{ Lime stone dust reduced } & \multirow{2}{*}{\multicolumn{2}{|c|}{$\begin{array}{l}\text { Original } \\
\text { LS dust }\end{array}$}} & \multicolumn{8}{|c|}{ LS dust reduced } \\
\hline & & & \multirow{2}{*}{\multicolumn{2}{|c|}{$\begin{array}{c}\text { LS dust } \\
\text { Trial } 1\end{array}$}} & \multirow{2}{*}{\multicolumn{2}{|c|}{$\frac{\text { NS dust }}{\text { Trial } 1}$}} & \multicolumn{4}{|c|}{ NS dust reduced further } & & & \multicolumn{4}{|c|}{ Original NS dust } & \multicolumn{4}{|c|}{ NS dust reduced } \\
\hline Trial \# & \multicolumn{2}{|c|}{ Trial 1} & & & & & Trial 2 & Trial 2 & Trial 3 & Trial 4 & \multicolumn{2}{|c|}{ Trial 1} & \multicolumn{2}{|c|}{ Trial 1} & \multicolumn{2}{|c|}{ Trial 2} & \multicolumn{2}{|c|}{ Trial 1} & \multicolumn{2}{|c|}{ Trial 2} \\
\hline Binder & 70 & 76 & 70 & 76 & 70 & 76 & 70 & 70 & 70 & 76 & 70 & 76 & 70 & 76 & 70 & 76 & 70 & 76 & 70 & 70 \\
\hline $\mathrm{P}_{\mathrm{b}}$ & 5.0 & 5.0 & 5.5 & 5.5 & 5.8 & 5.4 & 5.7 & 6.2 & 6.4 & 6.6 & 5.0 & 5.0 & 5.0 & 5.0 & 5.9 & 5.9 & 5.7 & 5.3 & 5.7 & 6.2 \\
\hline VTM & 5.5 & 5.1 & 5.8 & 5.2 & 4.8 & 4.9 & 5.7 & 5.0 & 5.2 & 3.8 & 4.1 & 4.3 & 6.2 & 6.2 & 3.4 & 2.5 & 4.9 & 5.3 & 5.5 & 4.0 \\
\hline VMA & 13.7 & 13.4 & 15.0 & 14.4 & 14.9 & 14.5 & 15.3 & 15.8 & 17.1 & 14.7 & 13.7 & 13. & 15.4 & 15.4 & 14.8 & 14.3 & 15.7 & 15.2 & 16.3 & 15.7 \\
\hline VFA & 59.9 & 61.9 & 61.3 & 63.9 & 67.8 & 66.2 & 62.7 & 68.4 & 69.6 & 74.1 & 70.1 & 67. & 59.7 & 59.7 & 77.0 & 82.5 & 68.8 & 65.1 & 66.3 & 74.5 \\
\hline Dust \% & 5.2 & 5.2 & 4.4 & 4.4 & 3.6 & 3.6 & 3.2 & 3.2 & 2.8 & 3.2 & 4.1 & 4.1 & 3.6 & 3.6 & 3.6 & 3.6 & 3.2 & 3.2 & 2.7 & 2.7 \\
\hline $\mathrm{D} / \mathrm{P}_{\mathrm{be}}$ & 1.44 & 1.41 & 1.07 & 1.07 & 0.98 & 1.02 & 0.74 & 0.67 & 0.52 & 0.68 & 1.00 & 1.0 & 0.88 & 0.88 & 0.72 & 0.71 & 0.75 & 0.84 & 0.55 & 0.52 \\
\hline
\end{tabular}


Table A7 19 mm NMAS - 0\% Sand

\begin{tabular}{|c|c|c|c|c|c|c|c|c|c|c|c|c|}
\hline & & & \multicolumn{5}{|c|}{ COARSE } & \multicolumn{5}{c|}{ FINE } \\
\hline & & Original & \multicolumn{3}{|c|}{ Lime Stone dust reduced } & \multicolumn{3}{c|}{ Original dust } & \multicolumn{2}{c|}{ LS dust reduced } \\
\hline Trial \# & Contractor & Orig 1 & \multicolumn{2}{|c|}{ Trial 2 } & \multicolumn{2}{|c|}{ Trial 3 } & Trial 4 & Trial 1 & \multicolumn{2}{|c|}{ Trial 2 } & Trial 1 & Trial 2 \\
\hline Binder & 70 & 76 & 70 & 76 & 70 & 76 & 70 & 70 & 70 & 76 & 70 & 70 \\
\hline P & 4.8 & 4.8 & 5.3 & 5.3 & 4.6 & 4.2 & 4.8 & 5.5 & 4.4 & 4.3 & 5.1 & 5.9 \\
\hline VTM & 4.0 & 2.5 & 2.2 & 1.3 & 3.7 & 4.0 & 3.8 & 1.3 & 4.2 & 4.2 & 5.4 & 3.7 \\
\hline VMA & 14.0 & 12.5 & 12.2 & 11.5 & 11.6 & 11.0 & 12.5 & 11.3 & 11.4 & 11.0 & 14.1 & 14.0 \\
\hline VFA & 71.0 & 80.0 & 82.0 & 88.7 & 68.1 & 63.6 & 69.6 & 88.5 & 63.2 & 61.8 & 61.7 & 73.6 \\
\hline Dust $\%$ & 4.3 & 4.3 & 3.5 & 3.5 & 3.5 & 3.5 & 3.1 & 4.5 & 4.5 & 4.5 & 3.6 & 3.6 \\
\hline D/P & - & - & 0.92 & 0.92 & 1.13 & 1.30 & 0.82 & 1.10 & 1.5 & 1.55 & 0.95 & 0.80 \\
\hline
\end{tabular}

* with the original gradation and contractor specified optimum asphalt content

Table A8 19 mm NMAS - 40\% Sand

\begin{tabular}{|c|c|c|c|c|c|c|c|c|c|c|}
\hline & \multicolumn{4}{|c|}{ COARSE } & \multicolumn{5}{c|}{ FINE } \\
\hline & \multicolumn{2}{|c|}{ Original dust } & \multicolumn{2}{|c|}{ NS dust reduced } & \multicolumn{2}{|c|}{ Original dust } & \multicolumn{3}{c|}{ NS dust reduced } \\
\hline & \multicolumn{2}{|c|}{ Trial 1 } & \multicolumn{2}{|c|}{ Trial 1 } & \multicolumn{2}{|c|}{ Trial 1 } & \multicolumn{2}{|c|}{ Trial 1 } & Trial 2 & Trial 3 \\
\hline Binder & 70 & 76 & 70 & 76 & 70 & 76 & 70 & 76 & 70 & 70 \\
\hline $\mathrm{P}_{\mathrm{b}}$ & 4.6 & 4.2 & 4.8 & 4.8 & 4.4 & 4.3 & 4.8 & 4.8 & 5.4 & 5.9 \\
\hline VTM & 1.7 & 3.0 & 3.8 & 3.6 & 4.6 & 3.4 & 6.9 & 6.1 & 4.5 & 4.1 \\
\hline VMA & 11.5 & 11.5 & 12.7 & 12.3 & 12.0 & 11.4 & 14.4 & 13.6 & 14.6 & 15.2 \\
\hline VFA & 85.2 & 73.9 & 70.1 & 70.7 & 61.7 & 70.2 & 52.1 & 55.1 & 69.2 & 73.0 \\
\hline Dust $\%$ & 3.5 & 3.5 & 2.7 & 2.7 & 4.5 & 4.5 & 3.1 & 3.1 & 3.1 & 3.1 \\
\hline D/P & 0.85 & 0.97 & 0.71 & 0.71 & 1.36 & 1.32 & 0.91 & 0.94 & 0.69 & 0.63 \\
\hline
\end{tabular}

*NS: Natural Sand 
Table A9 Description of Mixes

\begin{tabular}{|l|l|}
\hline Mix & Description \\
\hline 1 & $9.5 \mathrm{~mm}$, Coarse, 0\% Sand, PG 76-22, Optimum \\
\hline 4 & $19 \mathrm{~mm}$, Coarse, 40\% Sand, PG 76-22, Optimum \\
\hline 6 & $9.5 \mathrm{~mm}$, Fine, 40\% Sand, PG 76-22, Optimum \\
\hline 7 & $19 \mathrm{~mm}$, Fine, 0\% Sand, PG 76-22, Optimum \\
\hline 10 & $9.5 \mathrm{~mm}$, Coarse, 40\% Sand, PG 76-22, Optimum $+0.5 \%$ \\
\hline 11 & $19 \mathrm{~mm}$, Coarse, 0\% Sand, PG 76-22, Optimum $+0.5 \%$ \\
\hline 13 & $9.5 \mathrm{~mm}$, Fine, 0\% Sand, PG 76-22, Optimum $+0.5 \%$ \\
\hline 16 & $19 \mathrm{~mm}$, Fine, $40 \%$ Sand, PG 76-22, Optimum $+0.5 \%$ \\
\hline 18 & $9.5 \mathrm{~mm}$, Coarse, 40\% Sand, PG 70-22, Optimum \\
\hline 19 & $19 \mathrm{~mm}$, Coarse, 0\% Sand, PG 70-22, Optimum \\
\hline 21 & $9.5 \mathrm{~mm}$, Fine, 0\% Sand, PG 70-22, Optimum \\
\hline 24 & $19 \mathrm{~mm}$, Fine, 40\% Sand, PG 70-22, Optimum \\
\hline 25 & $9.5 \mathrm{~mm}$, Coarse, 0\% Sand, PG 70-22, Optimum $+0.5 \%$ \\
\hline 28 & $19 \mathrm{~mm}$, Coarse, 40\% Sand, PG 70-22, Optimum $+0.5 \%$ \\
\hline 30 & $9.5 \mathrm{~mm}$, Fine, 40\% Sand, PG 70-22, Optimum $+0.5 \%$ \\
\hline 31 & $19 \mathrm{~mm}$, Fine, 0\% Sand, PG 70-22, Optimum $+0.5 \%$ \\
\hline
\end{tabular}


Table A10 Computations for Compaction Slope

\begin{tabular}{|c|c|c|c|c|c|c|c|c|c|}
\hline Mix & $\mathrm{G}_{\mathrm{mb}}$ & $\mathrm{G}_{\mathrm{mm}}$ & $\mathrm{h}_{\mathrm{ini}}$ & $\mathrm{h}_{\text {des }}$ & $\mathrm{N}_{\text {ini }}$ & $\mathrm{N}_{\text {des }}$ & $\% \mathrm{G}_{\mathrm{mm}, \text { des }}$ & $\%_{\mathrm{mm}, \text { ini }}$ & $\mathrm{k}$ \\
\hline 1 & 2.379 & 2.483 & 130.9 & 116.1 & 8 & 100 & 95.81 & 84.98 & 9.88 \\
\hline 4 & 2.412 & 2.502 & 127.7 & 115.4 & 8 & 100 & 96.40 & 87.12 & 8.47 \\
\hline 6 & 2.345 & 2.450 & 131.6 & 118.2 & 8 & 100 & 95.71 & 85.97 & 8.88 \\
\hline 7 & 2.393 & 2.473 & 130.9 & 116.7 & 8 & 100 & 96.77 & 86.27 & 9.57 \\
\hline 10 & 2.377 & 2.427 & 128.8 & 115.9 & 8 & 100 & 97.94 & 88.13 & 8.94 \\
\hline 11 & 2.628 & 2.489 & 128.5 & 114.9 & 8 & 100 & 105.58 & 94.41 & 10.19 \\
\hline 13 & 2.369 & 2.423 & 131.1 & 116.4 & 8 & 100 & 97.77 & 86.81 & 9.99 \\
\hline 16 & 2.386 & 2.443 & 129 & 116.1 & 8 & 100 & 97.67 & 87.90 & 8.90 \\
\hline 18 & 2.354 & 2.452 & 129.1 & 115.9 & 8 & 100 & 96.00 & 86.19 & 8.95 \\
\hline 19 & 2.415 & 2.510 & 130.4 & 116.2 & 8 & 100 & 96.22 & 85.74 & 9.55 \\
\hline 21 & 2.363 & 2.453 & 132.6 & 117.1 & 8 & 100 & 96.33 & 85.07 & 10.27 \\
\hline 24 & 2.353 & 2.454 & 129.9 & 116.7 & 8 & 100 & 95.88 & 86.14 & 8.88 \\
\hline 25 & 2.379 & 2.471 & 131.9 & 117.1 & 8 & 100 & 96.28 & 85.47 & 10.07 \\
\hline 28 & 2.402 & 2.496 & 129.0 & 115.5 & 8 & 100 & 96.23 & 86.16 & 9.18 \\
\hline 30 & 2.246 & 2.433 & 132.5 & 117.4 & 8 & 100 & 92.31 & 81.79 & 8.92 \\
\hline 31 & 2.382 & 2.473 & 130.5 & 115.8 & 8 & 100 & 96.32 & 85.47 & 9.89 \\
\hline
\end{tabular}




\section{Figure A1 Plot of Load versus Deformation - IDT Strength}

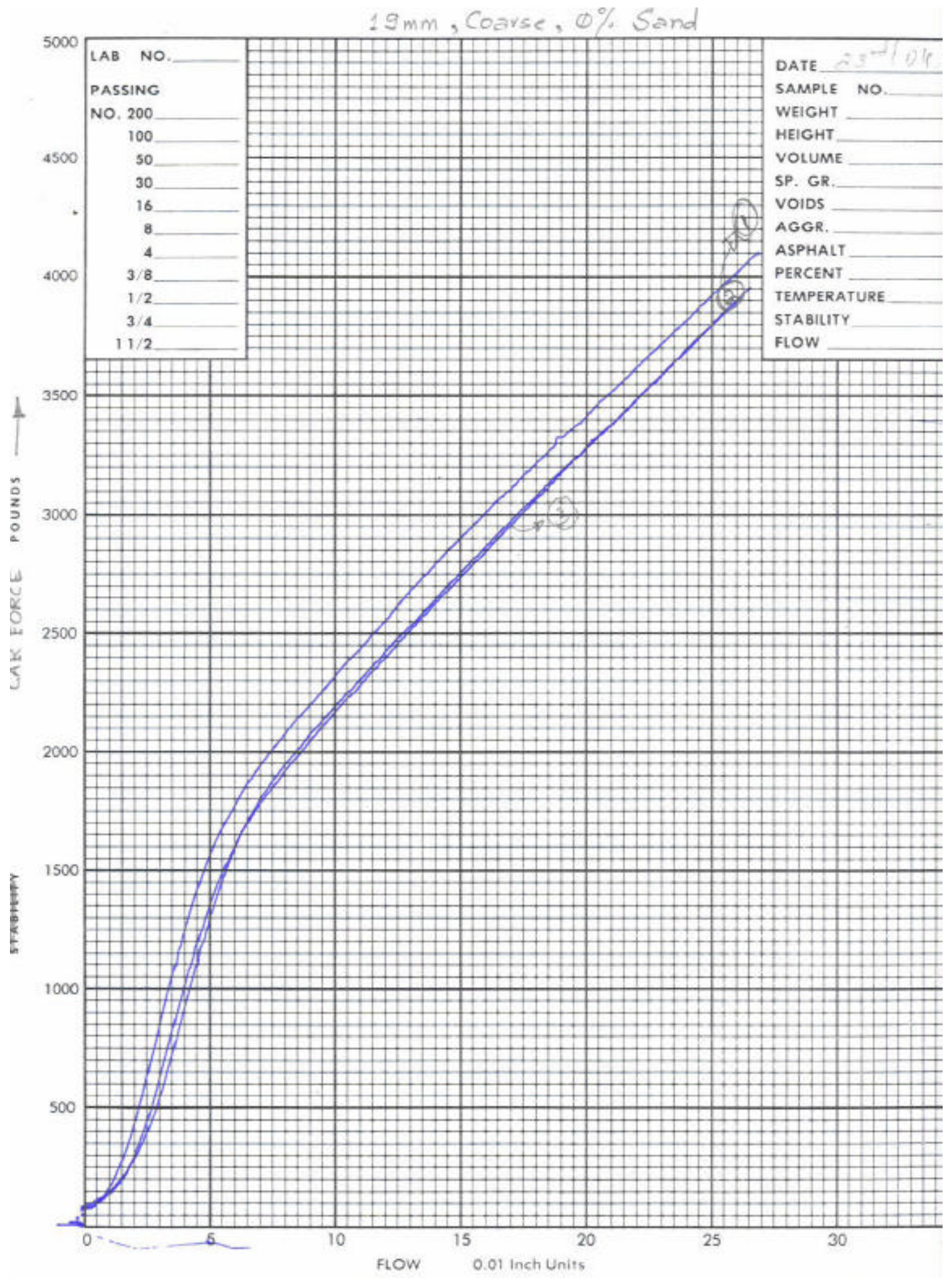


Figure A2 Plot of CAR Force versus Deformation

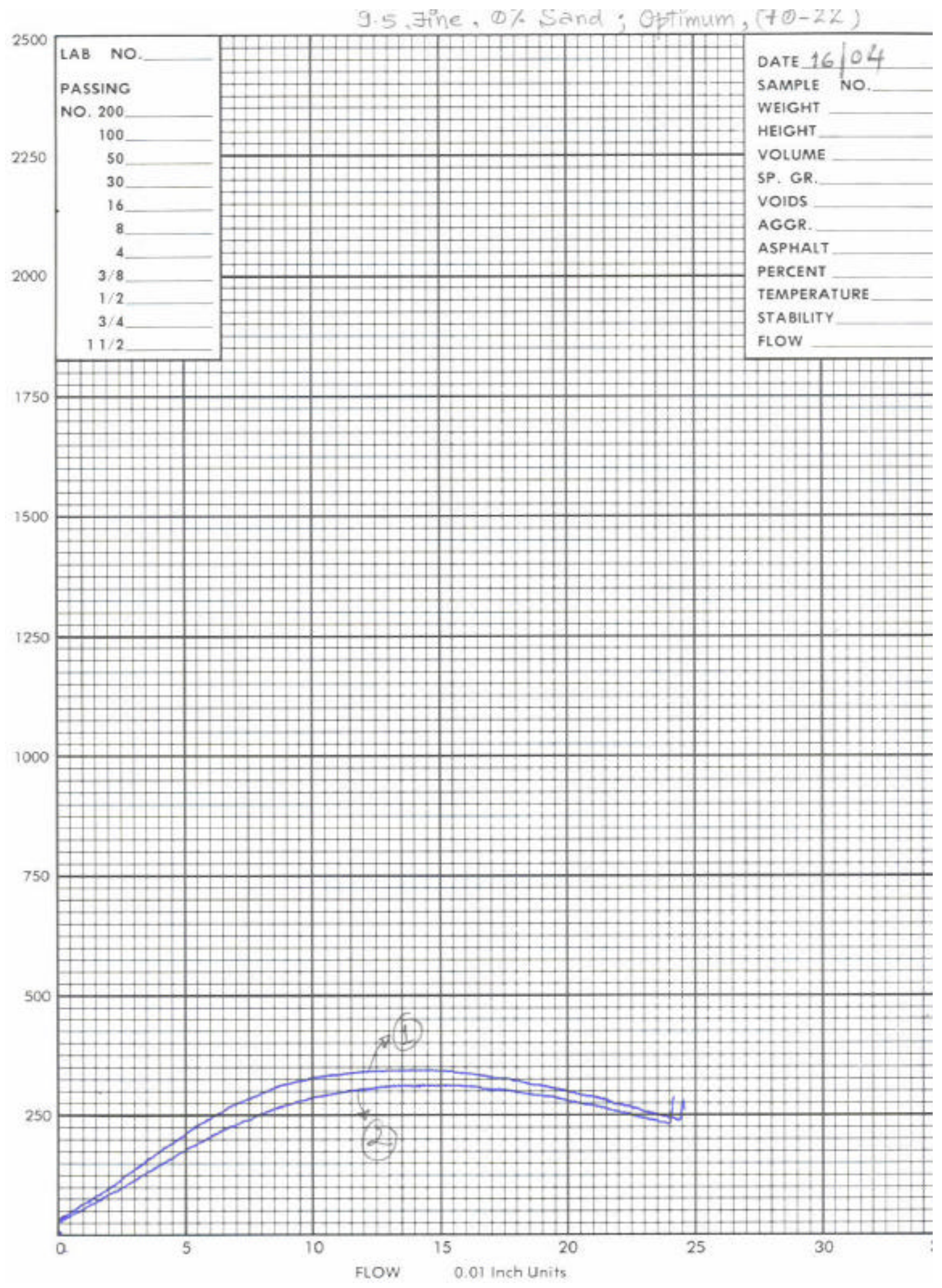




\section{APPENDIX B - ANOVA}

Table B1 ANOVA for Rut Depth

\section{Response: $\quad$ Rut depth}

ANOVA for Selected Factorial Model

Analysis of variance table [Partial sum of squares]

\begin{tabular}{|l|c|c|c|c|c|c|}
\hline Source & $\begin{array}{c}\text { Sum of } \\
\text { Squares }\end{array}$ & DF & $\begin{array}{c}\text { Mean } \\
\text { Square }\end{array}$ & $\begin{array}{c}\text { F } \\
\text { Value }\end{array}$ & Prob > F & Model \\
\hline Model & 345.43 & 9 & 38.38 & 34.71 & 0.0002 & significant \\
\hline A & 39.69 & 1 & 39.69 & 35.9 & 0.001 & \\
\hline B & 7.02 & 1 & 7.02 & 6.35 & 0.0453 & \\
\hline C & 48.51 & 1 & 48.51 & 43.88 & 0.0006 & \\
\hline D & 12.18 & 1 & 12.18 & 11.02 & 0.016 & \\
\hline E & 197.54 & 1 & 197.54 & 178.67 & $<0.0001$ & \\
\hline AC & 16.04 & 1 & 16.04 & 14.51 & 0.0089 & \\
\hline AE & 9.64 & 1 & 9.64 & 8.72 & 0.0255 & \\
\hline BD & 7.62 & 1 & 7.62 & 6.89 & 0.0393 & \\
\hline CE & 7.18 & 1 & 7.18 & 6.5 & 0.0436 & \\
\hline Residual & 6.63 & 6 & 1.11 & & & \\
\hline Cor Total & 352.06 & 15 & & & & \\
\hline
\end{tabular}

The Model F-value of 34.71 implies the model is significant. There is only a $0.02 \%$ chance that a "Model F-Value" this large could occur due to noise.

Values of "Prob > F" less than 0.0500 indicate model terms are significant. In this case A, B, C, D, E, AC, AE, BD, CE are significant model terms. Values greater than 0.1000 indicate the model terms are not significant. If there are many insignificant model terms (not counting those required to support hierarchy), model reduction may improve your model.

\begin{tabular}{|l|c|l|c|}
\hline Std. Dev. & 1.05 & R-Squared & 0.9812 \\
\hline Mean & 10.68 & Adj R-Squared & 0.9529 \\
\hline C.V. & 9.84 & Pred R-Squared & 0.866 \\
\hline PRESS & 47.17 & Adeq Precision & 20.613 \\
\hline
\end{tabular}

The "Pred R-Squared" of 0.8660 is in reasonable agreement with the "Adj R-Squared" of 0.9529.

Adeq Precision measures the signal to noise ratio. A ratio greater than 4 is desirable. Your ratio of 20.613 indicates an adequate signal. This model can be used to navigate the design space. 


\begin{tabular}{|l|c|c|c|c|c|c|}
\hline \multicolumn{1}{|c|}{ Factor } & $\begin{array}{c}\text { Coefficient } \\
\text { Estimate }\end{array}$ & DF & $\begin{array}{c}\text { Standard } \\
\text { Error }\end{array}$ & $\begin{array}{c}\text { 95\% CI } \\
\text { Low }\end{array}$ & $\begin{array}{c}\text { 95\% CI } \\
\text { High }\end{array}$ & VIF \\
\hline Intercept & 10.68 & 1 & 0.26 & 10.04 & 11.33 & \\
\hline A-Gradation & -1.57 & 1 & 0.26 & -2.22 & -0.93 & 1 \\
\hline B-NMAS & -0.66 & 1 & 0.26 & -1.31 & -0.019 & 1 \\
\hline C-Sand content & 1.74 & 1 & 0.26 & 1.1 & 2.38 & 1 \\
\hline D-Binder Content & -0.87 & 1 & 0.26 & -1.52 & -0.23 & 1 \\
\hline E-Binder Grade & -3.51 & 1 & 0.26 & -4.16 & -2.87 & 1 \\
\hline AC & -1 & 1 & 0.26 & -1.64 & -0.36 & 1 \\
\hline AE & 0.78 & 1 & 0.26 & 0.13 & 1.42 & 1 \\
\hline BD & 0.69 & 1 & 0.26 & 0.047 & 1.33 & 1 \\
\hline CE & -0.67 & 1 & 0.26 & -1.31 & -0.027 & 1 \\
\hline
\end{tabular}

Final Equation in Terms of Coded Factors:

$\begin{array}{rl}\text { Rut depth } & = \\ 10.68 & \\ -1.57 & * \mathrm{~A} \\ -0.66 & * \mathrm{~B} \\ 1.74 & * \mathrm{C} \\ -0.87 & * \mathrm{D} \\ -3.51 & * \mathrm{E} \\ -1 & * \mathrm{~A} * \mathrm{C} \\ 0.78 & * \mathrm{~A} * \mathrm{E} \\ 0.69 & * \mathrm{~B} * \mathrm{D} \\ -0.67 & * \mathrm{C} * \mathrm{E}\end{array}$

Final Equation in Terms of Actual Factors:

Not available, because this model contains more than 4 categorical equations.

Diagnostic s Case Statistics

\begin{tabular}{|c|c|c|c|c|c|c|c|c|}
\hline $\begin{array}{c}\text { Standard } \\
\text { Order }\end{array}$ & $\begin{array}{c}\text { Actual } \\
\text { Value }\end{array}$ & $\begin{array}{c}\text { Predicted } \\
\text { Value }\end{array}$ & Residual & Leverage & $\begin{array}{c}\text { Student } \\
\text { Residual }\end{array}$ & $\begin{array}{c}\text { Cook's } \\
\text { Distance }\end{array}$ & $\begin{array}{c}\text { Outlier } \\
\mathrm{t}\end{array}$ & $\begin{array}{c}\text { Run } \\
\text { Order }\end{array}$ \\
\hline 1 & 7.71 & 8.12 & -0.41 & 0.625 & -0.637 & 0.068 & -0.602 & 7 \\
\hline 2 & 11.9 & 12.66 & -0.76 & 0.625 & -1.18 & 0.232 & -1.23 & 6 \\
\hline 3 & 12.43 & 12.65 & -0.22 & 0.625 & -0.349 & 0.02 & -0.322 & 15 \\
\hline 4 & 5.52 & 5.82 & -0.3 & 0.625 & -0.466 & 0.036 & -0.433 & 8 \\
\hline 5 & 23.18 & 22.18 & 1 & 0.625 & 1.545 & 0.398 & 1.818 & 16 \\
\hline 6 & 8.84 & 8.66 & 0.18 & 0.625 & 0.272 & 0.012 & 0.25 & 4 \\
\hline 7 & 10.62 & 9.56 & 1.06 & 0.625 & 1.646 & 0.452 & 2.029 & 5 \\
\hline 8 & 12.24 & 12.77 & -0.53 & 0.625 & -0.831 & 0.115 & -0.806 & 14 \\
\hline 9 & 12.46 & 12.23 & 0.23 & 0.625 & 0.349 & 0.02 & 0.322 & 11 \\
\hline 10 & 5.7 & 5.4 & 0.3 & 0.625 & 0.466 & 0.036 & 0.433 & 9 \\
\hline 11 & 5.46 & 5.05 & 0.41 & 0.625 & 0.637 & 0.068 & 0.602 & 1 \\
\hline 12 & 10.35 & 9.59 & 0.76 & 0.625 & 1.18 & 0.232 & 1.23 & 10 \\
\hline 13 & 8.08 & 9.14 & -1.06 & 0.625 & -1.646 & 0.452 & -2.029 & 13 \\
\hline 14 & 12.89 & 12.35 & 0.54 & 0.625 & 0.831 & 0.115 & 0.806 & 12 \\
\hline 15 & 18.12 & 19.11 & -0.99 & 0.625 & -1.545 & 0.398 & -1.818 & 3 \\
\hline 16 & 5.42 & 5.59 & -0.17 & 0.625 & -0.272 & 0.012 & -0.25 & 2 \\
\hline
\end{tabular}


Table B2 ANOVA for IDT Strength

Response: IDT Strength

ANOVA for Selected Factorial Model

Analysis of variance table [Partial sum of squares]

\begin{tabular}{|c|c|c|c|c|c|c|}
\hline Source & $\begin{array}{c}\text { Sum of } \\
\text { Squares }\end{array}$ & DF & $\begin{array}{c}\text { Mean } \\
\text { Square }\end{array}$ & $\begin{array}{c}\text { F } \\
\text { Value }\end{array}$ & Prob > F & Model \\
\hline Model & 73.85 & 5 & 14.77 & 21.41 & $<0.0001$ & significant \\
\hline A & 6.55 & 1 & 6.55 & 9.5 & 0.0116 & \\
\hline B & 0.34 & 1 & 0.34 & 0.5 & 0.4973 & \\
\hline C & 24.8 & 1 & 24.8 & 35.95 & 0.0001 & \\
\hline D & 5.86 & 1 & 5.86 & 8.49 & 0.0155 & \\
\hline E & 36.3 & 1 & 36.3 & 52.62 & $<0.0001$ & \\
\hline Residual & 6.9 & 10 & 0.69 & & & \\
\hline Cor Total & 80.75 & 15 & & & & \\
\hline
\end{tabular}

The Model F-value of 21.41 implies the model is significant. There is only a $0.01 \%$ chance that a "Model F-Value" this large could occur due to noise.

Values of "Prob > F" less than 0.0500 indicate model terms are significant. In this case A, C, D, E are significant model terms.

Values greater than 0.1000 indicate the model terms are not significant.

If there are many insignificant model terms (not counting those required to support hierarchy), model reduction may improve your model.

\begin{tabular}{|c|c|c|c|}
\hline Std. Dev. & 0.83 & R-Squared & 0.9146 \\
\hline Mean & 11.18 & Adj R-Squared & 0.8719 \\
\hline C.V. & 7.43 & Pred R-Squared & 0.7813 \\
\hline PRESS & 17.66 & Adeq Precision & 15.714 \\
\hline
\end{tabular}

The "Pred R-Squared" of 0.7813 is in reasonable agreement with the "Adj R-Squared" of 0.8719.

Adeq Precision measures the signal to noise ratio. A ratio greater than 4 is desirable. Your ratio of 15.714 indicates an adequate signal. This model can be used to navigate the design space.

\begin{tabular}{|c|c|c|c|c|c|c|}
\hline Factor & $\begin{array}{c}\text { Coefficient } \\
\text { Estimate }\end{array}$ & DF & $\begin{array}{c}\text { Standard } \\
\text { Error }\end{array}$ & $\begin{array}{c}\text { 95\% CI } \\
\text { Low }\end{array}$ & $\begin{array}{c}95 \% \text { CI } \\
\text { High }\end{array}$ & VIF \\
\hline Intercept & 11.18 & 1 & 0.21 & 10.71 & 11.64 & \\
\hline A-Gradation & 0.64 & 1 & 0.21 & 0.18 & 1.1 & 1 \\
\hline B-NMAS & 0.15 & 1 & 0.21 & -0.32 & 0.61 & 1 \\
\hline C-Sand content & -1.25 & 1 & 0.21 & -1.71 & -0.78 & 1 \\
\hline D-Binder Content & 0.6 & 1 & 0.21 & 0.14 & 1.07 & 1 \\
\hline E-Binder Grade & 1.51 & 1 & 0.21 & 1.04 & 1.97 & 1 \\
\hline
\end{tabular}


Final Equation in Terms of Coded Factors:

$\begin{array}{rl}\text { IDT Strength } & = \\ 11.18 & \\ 0.64 & * \mathrm{~A} \\ 0.15 & * \mathrm{~B} \\ -1.25 & * \mathrm{C} \\ 0.6 & * \mathrm{D} \\ 1.51 & * \mathrm{E}\end{array}$

Final Equation in Terms of Actual Factors:

Not available, because this model contains more than 4 categorical equations.

Diagnostics Case Statistics

\begin{tabular}{|c|c|c|c|c|c|c|c|c|}
\hline $\begin{array}{c}\text { Standard } \\
\text { Order }\end{array}$ & $\begin{array}{c}\text { Actual } \\
\text { Value }\end{array}$ & $\begin{array}{c}\text { Predicted } \\
\text { Value }\end{array}$ & Residual & Leverage & $\begin{array}{c}\text { Student } \\
\text { Residual }\end{array}$ & $\begin{array}{c}\text { Cook's } \\
\text { Distance }\end{array}$ & $\begin{array}{c}\text { Outlier } \\
\text { t }\end{array}$ & $\begin{array}{c}\text { Run } \\
\text { Order }\end{array}$ \\
\hline 1 & 12.97 & 12.54 & 0.43 & 0.375 & 0.659 & 0.043 & 0.639 & 7 \\
\hline 2 & 9.96 & 10.81 & -0.85 & 0.375 & -1.287 & 0.166 & -1.337 & 6 \\
\hline 3 & 8.86 & 9.82 & -0.96 & 0.375 & -1.458 & 0.213 & -1.559 & 15 \\
\hline 4 & 15.07 & 14.11 & 0.96 & 0.375 & 1.462 & 0.214 & 1.564 & 8 \\
\hline 5 & 6.85 & 7.03 & -0.18 & 0.375 & -0.282 & 0.008 & -0.268 & 16 \\
\hline 6 & 10.69 & 11.33 & -0.64 & 0.375 & -0.971 & 0.094 & -0.968 & 4 \\
\hline 7 & 10.5 & 10.34 & 0.16 & 0.375 & 0.244 & 0.006 & 0.232 & 5 \\
\hline 8 & 9.68 & 8.61 & 1.07 & 0.375 & 1.633 & 0.267 & 1.81 & 14 \\
\hline 9 & 12.06 & 10.74 & 1.32 & 0.375 & 2.018 & 0.407 & 2.486 & 11 \\
\hline 10 & 14.8 & 15.03 & -0.23 & 0.375 & -0.346 & 0.012 & -0.331 & 9 \\
\hline 11 & 13.88 & 14.04 & -0.16 & 0.375 & -0.244 & 0.006 & -0.232 & 1 \\
\hline 12 & 11.78 & 12.31 & -0.53 & 0.375 & -0.803 & 0.065 & -0.788 & 10 \\
\hline 13 & 10.96 & 11.26 & -0.3 & 0.375 & -0.453 & 0.021 & -0.434 & 13 \\
\hline 14 & 9.96 & 9.53 & 0.43 & 0.375 & 0.662 & 0.044 & 0.643 & 12 \\
\hline 15 & 8.22 & 8.54 & -0.32 & 0.375 & -0.484 & 0.023 & -0.464 & 3 \\
\hline 16 & 12.6 & 12.83 & -0.23 & 0.375 & -0.35 & 0.012 & -0.334 & 2 \\
\hline
\end{tabular}

Proceed to Diagnostic Plots (the next icon in progression). Be sure to look at the:

1) Normal probability plot of the studentized residuals to check for normality of residuals.

2) Studentized residuals versus predicted values to check for constant error.

3) Outlier $t$ versus run order to look for outliers, i.e., influential values.

4) Box-Cox plot for power transformations.

If all the model statistics and diagnostic plots are OK, finish up with the Model Graphs icon. 